\title{
TRANSCRIPTIONAL REGULATION IN THE HIBERNATING THIRTEEN-LINED GROUND SQUIRREL, SPERMOPHILUS TRIDECEMLINEATUS
}

\author{
Pier Jr Morin \\ B.Sc. Concordia University, 2002

\begin{abstract}
A Thesis Submitted to the Faculty of Graduate Studies and Research in partial fulfillment of the requirements for the degree of
\end{abstract}

\author{
Doctor of Philosophy \\ Department of Chemistry
}

Carleton University

Ottawa, Ontario, Canada

(C) copyright 2006

Pier Jr Morin 


$\begin{array}{ll}\begin{array}{l}\text { Library and } \\ \text { Archives Canada }\end{array} & \begin{array}{l}\text { Bibliothèque et } \\ \text { Archives Canada }\end{array} \\ \begin{array}{l}\text { Published Heritage } \\ \text { Branch }\end{array} & \begin{array}{l}\text { Direction du } \\ \text { Patrimoine de l'édition }\end{array} \\ \begin{array}{l}\text { 395 Wellington Street } \\ \text { Ottawa ON K1A ON4 }\end{array} & \begin{array}{l}\text { 395, rue Wellington } \\ \text { Ottawa ON K1A ON4 } \\ \text { Canada }\end{array}\end{array}$

Your file Votre référence ISBN: 978-0-494-16670-3 Our file Notre référence ISBN: 978-0-494-16670-3

NOTICE:

The author has granted a nonexclusive license allowing Library and Archives Canada to reproduce, publish, archive, preserve, conserve, communicate to the public by telecommunication or on the Internet, loan, distribute and sell theses worldwide, for commercial or noncommercial purposes, in microform, paper, electronic and/or any other formats.

The author retains copyright ownership and moral rights in this thesis. Neither the thesis nor substantial extracts from it may be printed or otherwise reproduced without the author's permission.
AVIS:

L'auteur a accordé une licence non exclusive permettant à la Bibliothèque et Archives Canada de reproduire, publier, archiver, sauvegarder, conserver, transmettre au public par télécommunication ou par l'Internet, prêter, distribuer et vendre des thèses partout dans le monde, à des fins commerciales ou autres, sur support microforme, papier, électronique et/ou autres formats.

L'auteur conserve la propriété du droit d'auteur et des droits moraux qui protège cette thèse. $\mathrm{Ni}$ la thèse ni des extraits substantiels de celle-ci ne doivent être imprimés ou autrement reproduits sans son autorisation.
In compliance with the Canadian

Privacy Act some supporting forms may have been removed from this thesis.

While these forms may be included in the document page count, their removal does not represent any loss of content from the thesis.
Conformément à la loi canadienne sur la protection de la vie privée, quelques formulaires secondaires ont été enlevés de cette thèse.

Bien que ces formulaires aient inclus dans la pagination, il n'y aura aucun contenu manquant.

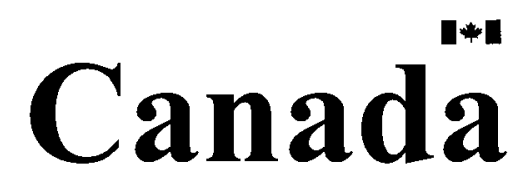




\begin{abstract}
Many small mammals enter hibernation to survive the winter. Metabolic rate during torpor can drop to just $1-5 \%$ of the euthermic rate providing energy savings of $\sim 90 \%$ compared to the costs of remaining euthermic. Hibernation consists of cycles of torpor bouts interspersed by short arousal periods. Regulation of torpor-arousal requires tight overall control of energy-consuming metabolic processes as well as selective expression of genes to accomplish these transitions and readjust metabolism for long term viability in a hypometabolic, hypothermic state. Hence, despite overall metabolic rate depression in hibernation, certain processes must be activated to ensure survival. The present studies examined transcriptional control in the hibernating thirteen-lined ground squirrel, Spermophilus tridecemlineatus. Regulation of gene expression by the hypoxiainducible transcription factor (HIF-1) pathway was shown to be important in hibernation; HIF-1 $\alpha$ subunit levels rose by $60-70 \%$ in skeletal muscle and brown adipose tissue (BAT) during hibernation and HIF-1 DNA-binding activity increased 6-fold in hibernating BAT. By contrast, the overall transcriptional state in muscle was strongly suppressed during torpor. Both activity and protein levels of histone deacetylases, enzymes involved in transcriptional repression, were elevated during torpor whereas the activity of RNA Polymerase II, a key enzyme of gene transcription, was strongly reduced by $43 \%$. To evaluate the involvement of oxidative stress and antioxidant defenses in hibernation, the responses of the Nrf2 transcription factor, involved in the oxidative stress response pathway, were evaluated as well as antioxidant genes/proteins under Nrf2 control. Nrf2 protein levels were elevated (by 1.4-fold) in all heterothermic parts of the hibernation cycle whereas the protein contents of three downstream gene targets of $\mathrm{Nrf} 2$
\end{abstract}


were only elevated during entrance into hibernation. This suggests a Nrf2-mediated anticipatory enhancement of antioxidant defenses to deal with oxidative stress during torpor and/or arousal. Other antioxidant enzymes, the 2-Cys peroxiredoxins, also showed enhanced protein levels in torpor and increased enzyme activity (1.5-fold in heart and 3.4-fold in BAT) indicating a potential role in ROS detoxification during hibernation. The data reported in this thesis provides new insights on the roles of selected transcription factors and on the importance of their tight regulation during all stages of hibernation. 


\section{Acknowledgements}

I would first like to thank my thesis supervisor Dr. Kenneth B. Storey for giving me a chance to develop my skills inside and outside of his laboratory. Whether at the lab, at the Storey home or on our numerous road trips, Ken always had some great advice for me. I have become a much more confidant scientist working under his supervision and for that I am extremely grateful. Thanks to Janet Storey for her excellent editing of my work and for her encouragement with my writing.

I would also like to thank my parents, Pierre and Sylvie, for their constant support. They always supported me in undertaking this important project knowing that, in the end, moving to Ottawa and working on my $\mathrm{PhD}$ would be what's best for me. For your encouragement and help, I say thanks. A special thanks also goes to Ashley for her constant support and for helping me to keep things in perspective. Without her, I would not have enjoyed this experience as much.

Finally, many thanks to the original "Storey boys"; Am, Sean and Dave, for taking me under their wing from the minute I started in this laboratory, and to the current lab members for numerous coffee breaks and science talks. 


\section{Page}

Title Page

Acceptance Sheet $\quad$ ii

$\begin{array}{lll}\text { Abstract } & \text { iii }\end{array}$

Acknowledgements $\quad$ v

Table of Contents vi

List of Abbreviations vii

List of Figures $\quad \mathrm{x}$

Chapter 1 General Introduction 1

Chapter 2 Role of the hypoxia-inducible factor $1 \alpha$ in hibernation of $\quad 16$ 13-lined ground squirrels.

$\begin{array}{lll}\text { Chapter } 3 & \text { Evidence for a reduced transcriptional state during } & 43\end{array}$ hibernation in ground squirrel muscle.

Chapter 4 Expression of Nrf2 and downstream targets in ground squirrel heart.

Chapter 5 Peroxiredoxins and antioxidant defense in mammalian 82 hibernation.

$\begin{array}{ll}\text { Chapter } 6 \quad \text { General Discussion } & 99\end{array}$

$\begin{array}{ll}\text { Publication List } & 114\end{array}$

$\begin{array}{ll}\text { References } & 118\end{array}$ 


\section{List of Abbreviations}

\begin{tabular}{|c|c|}
\hline $\mathrm{AA}$ & amino acid \\
\hline AFAR & aflatoxin aldehyde reductase \\
\hline APS & ammonium persulphate \\
\hline ARE & antioxidant response element \\
\hline ATP & adenosine triphosphate \\
\hline BAT & brown adipose tissue \\
\hline bHLH & basic helix-loop-helix \\
\hline CBP & CREB binding protein \\
\hline cDNA & complementary DNA \\
\hline CREB & cAMP response element binding protein \\
\hline DEPC & diethylpyrocarbonate \\
\hline DNA & deoxyribonucleic acid \\
\hline DTT & dithiothreitol \\
\hline EDTA & ethylenediamine tetra-acetic acid \\
\hline egr & early growth response \\
\hline EGTA & ethylene glycol bis(ß-aminoethyl ether) tetra-acetic acid \\
\hline $\mathrm{eIF} 2 \alpha$ & eukaryotic initiation factor $2 \alpha$ subunit \\
\hline EMSA & electrophoretic mobility shift assay \\
\hline $\mathrm{EPO}$ & erythropoietin \\
\hline ERK2 & extracellular signal-regulated protein kinase 2 \\
\hline $\mathrm{EtBr}$ & ethidium bromide \\
\hline FABP & fatty acid binding protein \\
\hline
\end{tabular}




$\begin{array}{ll}\text { HDAC } & \text { histone deacetylase } \\ \text { HIF-1 } & \text { hypoxia inducible factor-1 } \\ \text { HO-1 } & \text { heme oxygenase-1 } \\ \text { HRE } & \text { hypoxia response element } \\ \text { HSP } & \text { heat shock protein } \\ \text { kb } & \text { kilobase } \\ \text { kDa } & \text { kilodalton } \\ \text { MAPK } & \text { mitogen activated protein kinase } \\ \text { mRNA } & \text { messenger RNA } \\ \text { NFKB } & \text { nuclear factor-kappaB } \\ \text { Nrf2 } & \text { nuclear factor (erythroid-derived 2)-like 2 } \\ \text { ODD } & \text { oxygen-dependent degradation domain } \\ \text { ORF } & \text { open reading frame } \\ \text { Pag } & \text { proliferative associated gene } \\ \text { PAGE } & \text { polyacrylamide gel electrophoresis } \\ \text { PAS } & \text { Per/Arnt/Sim } \\ \text { PCR } & \text { polymerase chain reaction } \\ \text { PDK4 } & \text { pyruvate dehydrogenase kinase isozyme 4 } \\ \text { PMSF } & \text { phenylmethylsulfonyl fluoride } \\ \text { Prdx } & \text { polyunsaturated fatty acid } \\ \text { PUFA } & \text { ros }\end{array}$

viii 
reverse transcription

SDS

sodium dodecyl sulfate

SEM

standard error of the mean

SOD

superoxide dismutase

$\mathrm{SSC}$

saline sodium citrate

$T_{b}$

body temperature

Tris

tris(hydroxymethyl)aminomethane

UCP

uncoupling protein

VEGF

vascular endothelial growth factor

WAT

white adipose tissue 


\section{LIST OF FIGURES}

Figure

Page

1.1 Body temperature as a function of time in goldenmantled ground squirrel hibernation cycles.

1.2 Effect of ambient temperature $\left(\mathrm{T}_{\mathrm{a}}\right)$ on the length of the torpor bouts in the hibernating Arctic ground squirrels, Spermophilus parryii.

2.1 Molecular mechanisms that regulate HIF-1 $\alpha$ stability under normoxic and hypoxic conditions.

2.2 Complete nucleotide and deduced amino acid sequence of HIF-1 $\alpha$ from $S$. tridecemlineatus.

sequence with other known mammalian sequences.

$2.4 \quad$ Homology trees of mammalian HIF-1 $\alpha$ (A) protein and mammalian HIF-1 $\alpha$ with $X$. laevis and zebrafish HIF-1 $\alpha$ (B).

2.5 mRNA expression levels of hif- $1 \alpha$ in euthermic and hibernating tissues of $S$. tridecemlineatus.

2.6 HIF-1 $\alpha$ protein expression in four tissues of hibernating versus euthermic $S$. tridecemlineatus.

2.7 HIF-1 DNA binding activity in hibernating and euthermic brown adipose tissue samples of $S$. tridecemlineatus.

3.1 Representative Western blots of HDAC1 and HDAC4 from

S. tridecemlineatus muscle tissue.

3.2 Representative blots showing total histone H3, phosphorylated histone H3 (Ser 10), and acetylated histone H3 (Lys 23) protein expression in skeletal muscle of euthermic and hibernating $S$. tridecemlineatus.

Results of Western blotting for total RNA polymerase II and phosphorylated RNA polymerase II protein levels in euthermic and hibernating muscle.

3.4 EGFP amplification by RNA polymerase II in euthermic and hibernating muscle samples after 1,5 and 10 minutes of 
incubation.

4.1 Amplified partial cDNA sequence from S. tridecemlineatus $n r f 2 \quad 73$ with deduced amino acid sequence.

4.2 Multiple alignment of S. tridecemlineatus Nrf2 partial protein sequence with other known mammalian sequences.

4.3 S. tridecemlineatus Nrf2 partial amino acid sequence homology 76 analysis.

4.4 mRNA expression levels of $n r f 2$ in euthermic and hibernating tissues of $S$. tridecemlineatus.

4.5 Nrf2 protein expression in heart tissue of $S$. tridecemlineatus.

4.6 $\mathrm{Cu} / \mathrm{Zn}$ SOD protein expression in heart tissue of

S. tridecemlineatus.

AFAR1 protein expression in heart tissue of S. tridecemlineatus.

5.1 Amplified partial cDNA sequence from $S$. tridecemlineatus $\operatorname{prd} x 2$ with deduced amino acid sequence. protein sequence with other known mammalian sequences.

5.3 S. tridecemlineatus $\operatorname{Prdx} 2$ partial amino acid sequence homology analysis.

5.4 The effects of hibernation on S. tridecemlineatus prdxl, prdx 2 and $p r d x 3$ mRNA levels in heart and brown adipose tissue.

5.5 Prdx1, Prdx2 and Prdx 3 protein expression in euthermic and hibernating heart and brown adipose tissue of $S$. tridecemlineatus.

6.1 Changes in HIF-1 $\alpha$ protein levels in hibernating brown adipose tissue of the little brown bat, Myotis lucifugus.

Profile of seasonal changes in HIF-1 $\alpha$ protein expression in E. solidaginis larvae. 


\section{Chapter 1}

\section{General Introduction}


Hibernation is used by a variety of small mammals to survive the low ambient temperatures and food restriction typically associated with the winter months. This strategy involves a controlled and coordinated regulation of all metabolic and physiological processes such that a strong suppression of overall metabolic rate occurs (typically to $<5 \%$ of the euthermic rate) (Wang and Lee, 1996), body temperature (Tb) falls to ambient and/or is regulated at about $0-5^{\circ} \mathrm{C}$, physiological functions such as heart rate (Frerichs et al., 1994), breathing and kidney function are strongly reduced, and multiple cell functions are inhibited. The decrease in heart rate produces a corresponding strong reduction in organ perfusion rate, a condition that would impose severe ischemia on a non-hibernator, but that does not harm hibernators. Similarly, hibernators survive for weeks at $\mathrm{Tb}$ values that are near $0^{\circ} \mathrm{C}$ but with none of the metabolic injuries that are caused by hypothermia in non-hibernating mammals. Humans, for example, show severe damage if core $\mathrm{Tb}$ drops below $27^{\circ} \mathrm{C}$. It has been calculated that by using hibernation small mammals can save as much as $90 \%$ of the energy that would otherwise be required to remain euthermic $\left(\mathrm{Tb}=37-38^{\circ} \mathrm{C}\right)$ over the winter months (Wang and Lee, 1996).

\section{A typical hibernation cycle}

A wide variety of mammalian species possess the ability to hibernate. It is currently believed that hibernation and daily torpor are plesiomorphic (ie. ancestral, primitive), that heterothermy is common among endotherms, and that homeothermic endothermy in mammals evolved via heterothermy (Grigg et al., 2004). Hence, in a sense, hibernation represents an abandonment of euthermy and a return to an ancestral facultative endothermic state where body temperature is allowed to fluctuate with 
ambient temperature except for regulation in some situations; for the hibernator, there are two such situations: (a) to prevent $\mathrm{Tb}$ from falling below $0^{\circ} \mathrm{C}$, and (b) to intermittently return the animal to the euthermic state.

The hibernating season consists of prolonged torpor bouts that are interspersed with short periods of arousal when animals rewarm themselves to $37-38^{\circ} \mathrm{C}$ and maintain euthermia for several hours (Figure 1.1). Four physiological phases of hibernation can be distinguished: entry into torpor, torpor, arousal from torpor, and interbout arousal. Typically, there is a progressive increase in the length of torpor bouts during the autumn and early winter with maximum lengths in midwinter followed by shortening again in the spring (Figure 1.1). The maximum length of torpor bouts varies from species to species and also with ambient temperature during hibernation (Figure 1.2) (Buck and Barnes, 2000). Since smaller mammals have a higher metabolic rate in the euthermic state than larger mammals, the extent of the metabolic inhibition can be considerable; indeed, $\mathrm{Q}_{10}$ values, ratio of the rate of a reaction at one temperature divided by the rate of the same reaction at a temperature $10 \mathrm{C}^{\circ}$ less, can be 3-4 for the difference between euthermic and hibernating metabolic rates for some species with small body masses (Geiser, 2004). This translates to important energy savings for smaller hibernating mammals. Torpor is not continuous over the hibernation season but instead is interspersed with arousals during which the animal returns to euthermic Tb for a short time: Arousal is initially and primarily fueled by non-shivering thermogenesis in brown adipose tissue (BAT) but after $\mathrm{Tb}$ rises above about $15^{\circ} \mathrm{C}$ skeletal muscle shivering also contributes to rewarming. The whole process is quite drastic as it involves raising $\mathrm{Tb}$ by more than $30^{\circ} \mathrm{C}$, increasing heartbeat from $5-10$ beats per minute to the euthermic rate of $350-400$ beats per minute, 
and increasing the breaths taken per minute from 4-6 to more than 100 breaths per minute (Zatzman, 1984; McArthur and Milsom, 1991). All of these feats are accomplished within minutes to hours without harming the animal. Arousal usually occurs only every 3-4 weeks during the midwinter months and lasts for a few hours. Multiple reasons have been postulated for these periodic arousals from torpor including a need to eliminate metabolic wastes, to readjust neural circuits, or for species that eat during arousal to stock up on fuel reserves (Heller and Ruby, 2004).

\section{Transcriptional control in hibernation}

Energetically expensive biochemical processes in hibernation must be tightly coordinated and regulated so that energy is not wasted and stored metabolic fuels are conserved to last over the full winter hibernation season (and often well into spring before eating resumes). In general, just as physiological functions are suppressed during torpor (see above), all cellular metabolic processes that have been examined are also strongly suppressed during torpor. These include rates of fuel catabolism, transmembrane ion pumping, gene transcription, and protein translation (Frerichs et al., 1998; MacDonald and Storey, 1999; van Breukelen and Martin, 2002; Storey and Storey, 2004). However, the hibernator must still retain the ability to selectively activate specific pathways and processes when needed at all stages of the hibernation cycle. For example, selected genes may need to be transcribed during entry into torpor even though overall rates of gene transcription are being strongly suppressed during this time. Multiple mechanisms can be involved in metabolic regulation but one of the prominent ones that provides tight control of biological processes during major changes in metabolic state is 
reversible protein phosphorylation. For example, when hibernating mammals descend into torpor, carbohydrate catabolism is inhibited and animals switch to a primary dependence on lipid fuels. Inhibition of carbohydrate catabolism comes from reversible phosphorylation control of several glycolytic enzymes as well as pyruvate dehydrogenase, the entry point of carbohydrate fuel into the tricarboxylic acid cycle (Storey, 1987; Brooks and Storey, 1992). Suppression of protein translation during torpor also comes from phosphorylation-mediated inactivation of selected ribosomal initiation and elongation factors (Frerichs et al., 1998; Chen et al., 2001). Indeed, down-regulation of translation in torpor has been confirmed by studies that monitored ${ }^{14} \mathrm{C}$ leucine or ${ }^{3} \mathrm{H}$ leucine incorporation into proteins; incorporation of both radiolabels was strongly reduced in tissues of hibernating 13-lined ground squirrels when measured both in vivo and in vitro (Frerichs et al., 1998; Hittel and Storey, 2002). The same thing can be said about gene transcription, although studies on the subject are more sparse. It was previously estimated that out of the total energy budget of cells, $1-10 \%$ is allocated to transcription (Rolfe and Brown, 1997). In hibernating golden-mantled ground squirrels (Spermophilus lateralis) transcription initiation was reduced two-fold in torpid versus aroused animals (van Breukelen and Martin, 2002) whereas results from a study that monitored the incorporation of $\left[{ }^{3} \mathrm{H}\right]$-uridine into RNA of hibernating hamsters also showed reduced RNA synthesis in torpid animals (Osborne et al., 2004).

Despite this decrease in the overall rate of transcription, certain genes and their protein products are still upregulated during torpor in ground squirrels. Of particular interest to the research reported in this thesis are the genes that are up-regulated during entry into or exit from torpor; these potentially represent genes that are key to the 
hibernation phenotype and that are expressed to achieve specific goals for survival during torpor. Arousal from hibernation also includes activation of selected genes that could deal with potential problems that arise when oxygen consumption and metabolic functions increase rapidly. The switches that govern transcription are transcription factors; these bind to response elements present in the promoter region of genes under the transcription factor's control.

One of the metabolic concerns during hibernation is antioxidant defense. For hibernators, it has been shown that the repeated cycles of torpor and arousal lead to variations in the perfusion rate that might lead to ischemic events. The arousal period is particularly susceptible to ROS generation as it has been shown that the rate of oxygen consumption can raise by many-fold over a short period of time (Boyer and Barnes, 1999). Furthermore, hibernators maintain high levels of polyunsaturated fatty acids (PUFAs) (e.g. linoleic acid) in their lipid depots in order to maintain lipid fluidity at cold body temperatures but these PUFAs increase the risk for oxidative stress because they are susceptible to ROS attack and can autoxidize very easily (Carey et al., 2000). All of these factors can explain the need for hibernators to upregulate their antioxidant defenses to deal with the potential high levels of oxidative stress throughout hibernation. It has previously been shown that activities of antioxidant enzymes increase in tissues of hibernating animals (Buzadzic et al., 1990; Carey et al., 2000). Furthermore, data from our lab using DNA microarrays to search for hibernation-responsive genes also showed putative up-regulation of several genes associated with antioxidant defense during hibernation (Storey, 2003). Based on these pieces of information, transcription factors 
responsible for stimulating the expression of genes associated with antioxidant defense should have important roles in hibernation.

Another pathway that could come into play in regulating hibernation is the hypoxia response pathway. Some researchers have argued that hibernators could be good models for studying ischemia, but this argument has been contested because the decrease in metabolic rate and oxygen demand of tissues during torpor goes hand in hand with the reduction in oxygen delivery to tissues. Still, the fact that hibernating animals show an increase in multiple hypoxia related genes suggest that hypoxic conditions and hibernation are connected somehow. Overall, this thesis will look at transcription and its control by transcription factors in selected tissues of a hibernating mammal.

\section{Model Animal}

The model animal used in our laboratory to explore the metabolic responses in hibernation is the thirteen-lined ground squirrel, Spermophilus tridecemlineatus. It is one of several ground squirrel species that can hibernate. Ground squirrels typically initiate torpor bouts in late September or early October and the hibernation season can last through until late March to early May. Ground squirrels primarily feed on seeds, insects and flowers (Wang and Lee, 1996). During the late summer animals enter a period of hyperphagia and raise their body mass by about $50 \%$ (adult mass typically increases from $130-180 \mathrm{~g}$ in the summer to $220-240 \mathrm{~g}$ before hibernation begins) with a massive accumulation of lipid reserves. Diet selection is also used to elevate the proportion of PUFAs in lipid depots so that these remain fluid, and therefore can be metabolized, when $\mathrm{Tb}$ sinks to near $0^{\circ} \mathrm{C}$ during torpor (Frank and Storey, 1995). 
This thesis focuses on the changes at the gene and protein levels of selected transcription factors and antioxidant-related proteins in hibernator tissues and an overview of how each tissue deals with hibernation is necessary at this point.

\section{Heart}

The hibernating heart is able to function efficiently despite the low body temperatures and the drastic reduction in heart rate of about 100-fold when compared to euthermic levels (Zatzman, 1984). Evidently, an emphasis on the transcription of selected genes and gene products that allows the heart to cope with these fluctuations is necessary. Such is the case for the gene coding for the enzyme pyruvate dehydrogenase kinase isozyme 4 (PDK4) that shows a marked increase in hibernating heart (Buck et al., 2002). PDK4 inhibits pyruvate dehydrogenase, a key enzyme of carbohydrate catabolism, and the up-regulation of this gene correlates with the known switch from a carbohydrate-based metabolism to a lipid-fueled metabolism during torpor (Andrews et al., 1998). Other hibernation-responsive genes in heart include some that enhance lipid catabolism including the heart and adipose isoforms of fatty acid binding protein (Hittel and Storey, 2001) and pancreatic triacylglycerol lipase (Andrews et al., 1998) and, hence, further highlight the importance of lipid-fueled metabolism in hibernators. Other genes that are up-regulated in ground squirrel heart include the ventricular isoform of myosin light chain 1 (MLC1v), indicative of myosin restructuring for function at low $\mathrm{Tb}$ (Fahlman et al., 2000), and four genes on the mitochondrial genome: NADH ubiquinoneoxidoreductase subunit 2 (ND2), cytochrome c oxidase subunit 1 (COX1) and ATPase subunits 6 and 8 (Fahlman et al., 2000; Hittel and Storey, 2002a). 


\section{Brown adipose tissue}

The primary purpose of this tissue is to generate heat through a process called non-shivering thermogenesis (NST) (Foster, 1984). NST is key to the arousal process but is also employed to generate low level heating while the animal is in deep torpor so that the animal does not freeze if ambient temperature drops below $0^{\circ} \mathrm{C}$. NST is fueled through the oxidization of lipids by the high numbers of mitochondria in BAT. The electron transport system in BAT can be uncoupled from oxidative phosphorylation so that the energy produced from substrate oxidation is released as heat instead of being used to synthesize ATP. This is accomplished by the action of a BAT-specific uncoupling protein, UCP1 (Kuroshima, 1993). UCP1 is seasonally up-regulated in hibernator BAT and can also be further elevated when the demand for heat production by BAT is high (ie. during hibernation at subzero ambient temperatures) (Boyer et al., 1998).

\section{Skeletal muscle}

During the hibernating season, animals are largely inactive; skeletal muscle is inactive during torpor and even during the periods of interbout arousal, the animals spend most of their time asleep. However, shivering by skeletal muscle does contribute to reheating the animal during interbout arousals. A prolonged period of skeletal muscle inactivity such as occurs during weeks of torpor would result in serious muscle atrophy in non-hibernating mammalian species. However, it has been shown that hibernators experience less muscle atrophy during torpor than would be expected from about eight months of inactivity (Wickler et al., 1991). Certain physiological changes have been identified that might help the skeletal muscle of hibernators to cope with the long 
sedentary months of winter. For example, capillarity is increased in the hibernating skeletal muscle to maximize blood delivery and an increase in myoglobin content has also been reported (Postnikova et al., 1999). At the gene level, hibernation-responsive genes in skeletal muscle are very similar to those identified in heart. An increase of HFABP gene expression has been reported and this is an indicator that skeletal muscle also relies on lipid metabolism in hibernation (Hittel and Storey, 2001). Similarly, PDK4 expression was also increased under hibernating conditions (Buck et al., 2002). MLC1v and selected mitochondrially-encoded genes are also up-regulated (Fahlman et al., 2000).

\section{Objectives and Hypotheses}

\section{Objective 1: Hibernation and the hypoxia-inducible transcription factor}

During hibernation, blood flow and oxygen delivery are strongly reduced. This reduction in organ perfusion would lead to levels that would usually be considered ischemic for other mammals. Hibernating species also tend to breathe irregularly, leading to fluctuations in tissue oxygen levels. Finally, an ancient link involving hypoxia and hypothermia could be part of the mechanism by which core body temperature is reduced during entry into torpor. Hypoxia exposure can lead to a drop in $\mathrm{Tb}$ for certain mammals. Lower amounts of oxygen could reduce ATP supply and the animal would reduce its ATP demand by lowering its Tb. All of these factors, along with the fact that various genes associated with the hypoxic response are up-regulated in hibernating animals, suggest that low oxygen signals and the intracellular signaling mechanisms that are stimulated by low oxygen are involved in regulating hibernation-responsive changes in gene expression. 
Hypothesis: Regulatory proteins involved in the hypoxic response, such as the hypoxia inducible factor-1 (HIF-1), are activated during hibernation and show enhanced transcriptional activity.

Chapter 2 tests this hypothesis by examining the gene and protein expression of the inducible subunit of this transcription factor. RT-PCR and Western blotting were used to show that whereas HIF-1 $\alpha$ mRNA levels remained stable, HIF-1 $\alpha$ protein levels were significantly increased in BAT and skeletal muscle of 13-lined ground squirrels during hibernation. This suggests either an increase in HIF-1 $\alpha$ translation or a decrease in HIF- $1 \alpha$ degradation via interaction with the von Hippel-Lindau protein (pVHL); a protein forming an ubiquitin ligase complex with other proteins that can lead to HIF-1 $\alpha$ ubiquitinylation and degradation. Furthermore, an increase in HIF-1 DNA binding activity correlated with the increase in HIF- $1 \alpha$ protein levels in hibernating BAT. The complete sequence of ground squirrel HIF- $1 \alpha$, the first HIF-1 $\alpha$ cloned from a hibernating species, was also deduced and a sequence comparison with non-hibernating mammals was used to look for specific amino acid substitutions that could aid HIF-1 $\alpha$ function at the low $\mathrm{Tb}$ values during torpor.

\section{Objective 2: Hibernation and transcriptional suppression}

For hibernating animals, reducing the rates of energetically costly processes is necessary to survive the long winter months. Previous studies have shown that protein translation is one such process that is reduced in torpid animals. On the other hand, not much is known about transcriptional status in hibernating animals.

Hypothesis: Since gene transcription can consume $1-10 \%$ of the energy available in cells, I hypothesize that this process would be strongly 
suppressed during hibernation.

Chapter 3 uses a three-step approach to analyze this problem. The first two steps rely on the post-transcriptional modifications of histones and the resulting implications for gene silencing or activation. Histone acetylation is linked with transcriptional activation (Brownell et al., 1996) whereas histone deacetylation leads to hypomethylation and repression of gene transcription (Wade, 2001). Deacetylation is performed through the activity of histone deacetylases (HDACs) which are divided into three different classes; the classical HDAC family (class I and II) and the NAD ${ }^{+}$-dependent HDAC (class III) (Thiagalingam et al., 2003). Protein levels and enzyme activity of class I and II HDACs were measured. Results presented in this chapter highlight the increase in HDAC activity, the up-regulation of HDAC protein levels during hibernation and the reduction of modified histone $\mathrm{H} 3$. All these changes are associated with a reduced transcriptional state. The third step uses a non-radioactive assay to measure RNA Polymerase II activity in muscle of hibernating ground squirrels. The RNA Polymerase II assay also demonstrates a significant reduction in the activity of this enzyme in hibernating muscle.

\section{Objective 3: Hibernation and the Nrf2 transcription factor}

Genes and proteins involved in the oxidative stress response are specifically upregulated during hibernation. Enzymes with antioxidant properties are also activated to deal with potentially harmful ROS.

Hypothesis: A transcription factor involved in the detoxification of ROS such as the Nrf2 transcription factor and its associated downstream gene products are over-expressed during hibernation. 
Chapter 4 analyzes Nrf2 gene and protein expression in ground squirrel heart to test this hypothesis using methods of RT-PCR and Western blotting. Changes in Nrf2 protein levels are measured at multiple time points over a hibernating cycle to identify the time at which the Nrf2 pathway is solicited. To further analyze the importance of this pathway, Nrf2 downstream gene targets were measured. Using Western blotting, protein levels of $\mathrm{Cu} / \mathrm{Zn}$ SOD, HO-1 and AFAR1 were measured in hibernating heart.

\section{Objective 4: Hibernation and the 2-Cys Peroxiredoxins}

Brown adipose tissue is the main site for fatty acid degradation during hibernation and this has been associated with generation of hydrogen peroxide. Meanwhile, heart tissue subjected to ischemia and reperfusion also shows an increase in hydrogen peroxide. Hydrogen peroxide is a stable, uncharged and freely diffusible ROS that can attack proteins, lipids and DNA. A means to deal with this particular ROS must be used by the hibernators to prevent harmful actions.

Hypothesis: To deal with oxidative stress during hibernation, animals will up-regulate a principal set of enzymes responsible for hydrogen peroxide detoxification, the 2-Cys peroxiredoxins, increasing both their expression and activity.

This hypothesis is tested in Chapter 5 where RT-PCR and Western blotting are used to look at changes in the levels of peroxiredoxin family members brown adipose tissue and heart during hibernation. Activity of the 2-Cys peroxiredoxin family is also assayed to see if it correlates with measured protein levels. 
Figure 1.1

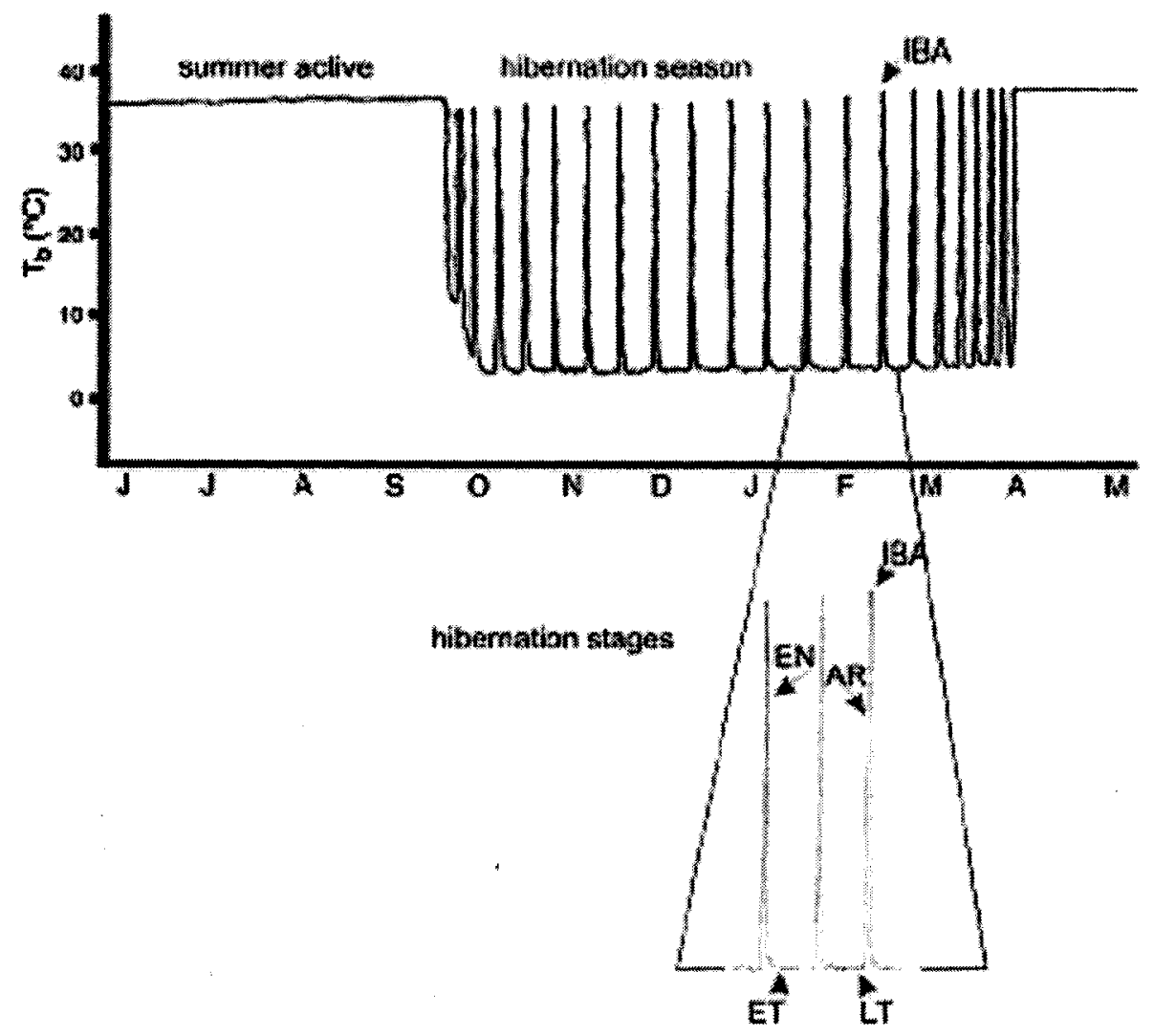


Figure 1.2

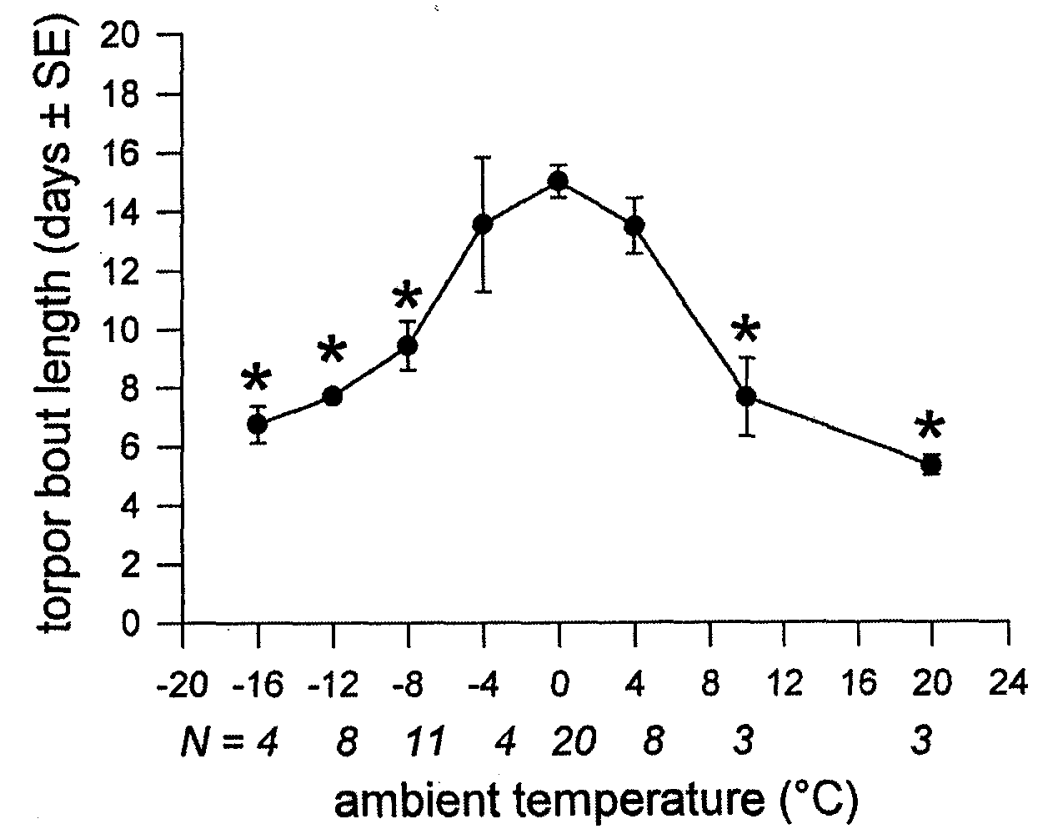




\section{Chapter 2}

\section{Role of the hypoxia-inducible factor $1 \alpha$ in hibernation of 13-lined ground squirrels}




\section{INTRODUCTION}

As discussed in Chapter 1, mammalian hibernation involves extended periods of deep torpor characterized by a profound metabolic rate depression. Metabolic rate often falls to just $1-5 \%$ of the normal euthermic rate and body temperature decreases to near ambient (often falling to $0-5^{\circ} \mathrm{C}$ ). Transitions to and from torpor are closely regulated in part by the enhanced expression of selected genes whose protein products address specific needs of the animal in the hypometabolic, hypothermic state of torpor. While hibernating both heartbeat and breathing rate are profoundly depressed and organ perfusion rates can drop to $\sim 10 \%$ of normal (Frerichs et al., 1994), a level that would be considered severely ischemic under normal circumstances. Furthermore, many hibernating species breath irregularly while in torpor and show long periods of apnea so that tissues could experience a wide range of oxygen levels, potentially even hypoxic values. An ancient link between hypoxia and hypothermia occurs in mammals - core temperature falls when oxygen is limiting and hibernating species show a more pronounced drop in body temperature under hypoxia than do nonhibernators (Barros $e t$ al., 2001). Indeed, this hypoxia-hypothermia connection is one of the mechanisms that has been proposed to help initiate and manage the fall in body temperature that occurs during entry into hibernation (Barros et al., 2001; Storey, 2003).

This potential link led me to wonder about the regulation of gene expression during entry into hibernation and the role that might be played by the hypoxia-inducible factor 1 (HIF-1), a transcription factor that responds to low oxygen. HIF-1 is known to upregulate the transcription of a variety of genes that enhance hypoxia tolerance including those that improve the delivery of oxygen to tissues (e.g. vascular endothelial 
growth factor, erythropoietin) and those that enhance ATP generation by anaerobic glycolysis (e.g. several glycolytic enzymes, glucose transporter isoform 1) in order to enhance/replace the ATP output from oxidative phosphorylation (Ratcliffe et al., 1998; Semenza, 2000; Hopfl et al., 2003). Intermediate metabolites of the glycolytic pathway are also precursors of purine, pyrimidine and phospholipids and these have been linked to cell growth and maintenance of cells under stress (Vander Heiden et al., 2001) which highlights the importance of activating such a pathway under potentially harmful conditions. HIF-1 has also been linked to the cell proliferation/survival pathway. Genes such as the insulin-like growth factor-2 (IGF2) and the transforming growth factor- $\alpha$ (TGF- $\alpha$ ) are hypoxia-induced growth factors and are HIF-1 target genes (Feldser et al., 1999; Krishnamachary et al., 2003).

HIF-1 is composed of $\alpha$ and $\beta$ subunits, both of which are members of the bHLHPAS (Per/Arnt/Sim) family of transcription factors. The bHLH and PAS domains are both important for the subunits to bind to each other and for DNA binding (Jiang et al., 1996). Levels of the $\alpha$ subunit are the limiting factor in net HIF-1 amount and activity since the $\beta$ subunit is constitutively expressed and its activity is regulated in an oxygenindependent manner (Wang and Semenza, 1993). When oxygen levels are high, HIF-1 $\alpha$ is susceptible to the oxygen-dependent hydroxylation of two proline residues within its oxygen dependent degradation domain (ODD), Pro 402 and Pro 564, via the enzyme prolyl-4-hydroxylase. Proline hydroxylation leads to HIF-1 $\alpha$ interaction with the von Hippel-Lindau (pVHL) protein, a protein that has E3 ubiquitin ligase activity (Iwai et al., 1999). This 213-amino acid protein is known to be part of an ubiquitin ligase complex capable of interacting with HIF-1 $\alpha$ ODD. pVHL is associated with elongins B and C, 
and cullin-2 (Cul-2), forming the VHL-BC-Cul-2 complex (Kaelin and Maher, 1998). Elongins $\mathrm{B}$ and $\mathrm{C}$ and $\mathrm{Cul}-2$ are homologous to the SCF (Skp1-Cul-1-F-box protein) multiprotein complex, which targets cell cycle regulatory proteins for ubiquitin-mediated proteolysis (Ciechanover, 1998). Hence, modification of the two proline residues in the ODD targets HIF-1 $\alpha$ for rapid ubiquitinylation and degradation (Huang et al., 1998; Maxwell et al., 1999; Jewell et al., 2001) (Figure 2.1a). Hydroxylation of an asparagine residue on the C-terminal of HIF-1 $\alpha$, Asn 803, also plays a role in the HIF-1 $\alpha$ degradation pathway. The factor inhibiting HIF-1 (FIH-1) hydroxylates this asparagine residue under normoxic conditions and this prevents HIF-1 association with transcriptional coactivators such as p300/CBP (Hewitson et al., 2002; Lando et al., 2002).

Under low oxygen conditions, the rate of proline hydroxylation is reduced and, therefore, HIF-1 $\alpha$ is stabilized and can move into the nucleus to form the HIF-1 heterodimer and then stimulate the transcription of genes. Whereas HIF-1 $\alpha$ via the proline hydroxylation mechanism has received by far the most experimental attention, HIF- $1 \alpha$ can also be controlled by another mechanism - this is activation by protein phosphorylation. HIF-1 transcriptional activity can be increased through direct phosphorylation of the HIF-1 $\alpha$ subunit by the $\mathrm{p} 42 / \mathrm{p} 44-$ mitogen-activated protein kinases (p42/p44-MAPK) (Richard et al., 1999). Phosphorylated HIF-1 $\alpha$ then moves to the nucleus where it can bind to the HRE of genes under its control. More recent discoveries have shown that HIF-1 $\alpha$ can also be induced and activated under non-hypoxic conditions through the PI3 kinase (PI3K) pathway (left panel, Figure 2.1b) (Dery et al., 2005). In this case, the rate at which HIF-1 $\alpha$ is degraded does not change, but the rate of HIF-1 $\alpha$ 
mRNA translation rises. Cytokines and hormones have also been shown to induce HIF-1 under non-hypoxic conditions (Hellwig-Burgel et al., 1999; Gorlach et al., 2001).

The goal of research described in this chapter was to investigate the potential relationship between HIF-1 $\alpha$ mediated gene regulation and hibernation in tissues of thirteen-lined ground squirrels, Spermophilus tridecemlineatus. I hypothesized that the physiological conditions of hibernation would elevate HIF-1 $\alpha$ transcript and/or protein levels in hibernator organs, thereby leading to increased HIF-1 DNA binding activity to the hypoxia response element (HRE) to increase expression of selected HIF-1 regulated genes. HIF-1 $\alpha$ mRNA and protein levels were quantified in four organs of ground squirrels and HIF-1 DNA binding activity was assessed in brown adipose tissue (BAT). The full length HIF-1 $\alpha$ sequence from ground squirrels, the first HIF-1 $\alpha$ sequenced from a hibernating species, was also retrieved and probed for key amino acid differences that could aid the function of the transcription factor under the low body temperature conditions of the hibernating state.

\section{MATERIALS AND METHODS}

Animals.

Thirteen lined ground squirrels, Spermophilus tridecemlineatus (130-180 g) were captured by a licensed trapper (TLS Research, Michigan) and transported to the Animal Hibernation Facility (NIH, Bethesda, MD). Hibernation experiments were conducted by the laboratory of Dr. J.M. Hallenbeck (National Institute of Neurological Disorders and Stroke). Animals were kept on a fall day/night light cycle in shoebox cages maintained at $21^{\circ} \mathrm{C}$ and fed ad libitum until they entered and finished the pre-hibernation phase of 
hyperphagia that maximizes lipid stores. A sensor chip was introduced under the squirrel skin and the body temperature of each animal was monitored electronically. When squirrels had reached a plateau weight gain of $220-240 \mathrm{~g}$, they were randomly divided into two groups. One group (euthermic controls) was maintained under the same conditions as previously and body temperatures of the animals were confirmed as being $36-38^{\circ} \mathrm{C}$ at the time of tissue sampling. The other group was placed in a dark chamber at $5-6^{\circ} \mathrm{C}$ (food was withdrawn) to induce hibernation. Individuals settled into hibernation after different lengths of time but all were sampled on the same day after each individual had been hibernating for 2-5 days (as indicated by continuous body temperature readings of $\sim 6^{\circ} \mathrm{C}$ ). Euthermic control animals were sampled on the same day. All animals were sacrificed by decapitation and tissues were excised, frozen immediately in liquid nitrogen and then transported to Ottawa on dry ice where they were then placed at $-80^{\circ} \mathrm{C}$ until use.

Total RNA isolation and quality assessment.

Total RNA was isolated from tissue samples using Trizol reagent (Gibco BRL), according to manufacturer's instructions, and resuspended in diethylpyrocarbonate (DEPC) treated water. RNA concentration was determined by absorbance at $260 \mathrm{~nm}$ and the ratio of absorbance at $260 / 280 \mathrm{~nm}$ was used as an indicator of RNA purity. RNA quality was also assessed by running samples on a $1.2 \%$ agarose denaturing gel and staining with ethidium bromide to reveal two sharp bands in every sample.

cDNA synthesis and PCR amplification of HIF-1a.

An aliquot containing $30 \mu \mathrm{g}$ of total RNA from BAT of hibernating $S$. tridecemlineatus was used for first strand cDNA synthesis using Superscript II reverse transcriptase (Invitrogen) and following the manufacturer's protocol. Serial dilutions of 
the cDNA in water were prepared $\left(10^{-1}-10^{-4}\right)$ and were used to amplify both HIF-1 $\alpha$ and $\alpha$-tubulin. The primers used for amplification of HIF-1 $\alpha$ were designed using the Primer Designer program, version 3.0 (Scientific and Educational Software) based on the consensus sequences of mammalian HIF-1 $\alpha$. The forward primer sequence was 5'TGCTCATCAGTTGCCACTTC - 3' and the reverse primer sequence was 5'GTACTGTCCTGTGGTGACTT - 3'. For a control gene, $\alpha$-tubulin was amplified with forward (5' - AAGGAAGATGCTGCCAATAA - 3') and reverse (5' GGTCACATTTCACCATCTG - 3') primers. The PCR reaction was performed by mixing $5 \mu \mathrm{L}$ of each cDNA dilution with $1.25 \mu \mathrm{L}$ of primer mixture $(0.5 \mu \mathrm{M}$ forward and $0.5 \mu \mathrm{M}$ reverse), $15 \mu \mathrm{L}$ of sterile water, $2.5 \mu \mathrm{L}$ of 10X PCR buffer (Invitrogen), $1.25 \mu \mathrm{L}$ of $50 \mathrm{mM} \mathrm{MgCl} 2,0.5 \mu \mathrm{L}$ of $10 \mathrm{mM}$ dNTPs and $0.125 \mu \mathrm{L}$ of Taq Polymerase (Invitrogen) for a total volume of $25 \mu \mathrm{L}$. The cycles performed for amplification consisted of an initial step of $2 \mathrm{~min}$ at $94^{\circ} \mathrm{C}$, followed by $94^{\circ} \mathrm{C}$ for $1 \mathrm{~min}, 63^{\circ} \mathrm{C}$ for $1 \mathrm{~min}$, and $72^{\circ} \mathrm{C}$ for $1 \mathrm{~min}$ repeated 37 times; the final step was at $72^{\circ} \mathrm{C}$ for $2 \mathrm{~min}$. PCR products were separated on a $1.0 \%$ agarose gel. The gel was prepared by adding $3 \mathrm{~g}$ of agarose to $300 \mathrm{~mL}$ of $1 \mathrm{X}$ TAE bufier prepared by mixing $6 \mathrm{~mL}$ of $50 \mathrm{X}$ TAE buffer $(242 \mathrm{~g}$ Tris base, $57.1 \mathrm{~mL}$ concentrated acetic acid, $100 \mathrm{~mL}$ of $0.5 \mathrm{M}$ EDTA in $1 \mathrm{~L}$ water, adjusted to $\mathrm{pH} \mathrm{8.5)}$ with $294 \mathrm{~mL}$ of DEPC treated water. Ethidium bromide $(0.3 \mathrm{mg} / 300 \mathrm{~mL})$ was added in the solution and the mixture was heated. The heated solution was then poured in a gel tray and the gel was allowed to cool down and solidify. A $10 \mu \mathrm{L}$ aliquot of the PCR product was mixed with $2 \mu \mathrm{L}$ of $6 \mathrm{X}$ blue/orange loading dye (Promega, USA) and the solution was loaded on the $1 \%$ agarose gel. The gel was run in $1 \mathrm{X}$ TAE buffer. After separation, the bands were visualized with ethidium bromide on a UV box. The bands from the most 
dilute cDNA sample were used for quantification purposes to make sure that the products had not reached amplification saturation. A HIF- $1 \alpha$ fragment of $\sim 800 \mathrm{bp}$ was retrieved and sequenced by Canadian Molecular Research Services (Ottawa, ON). The sequence was confirmed as encoding HIF-1 $a$ by sequence comparison in BLAST.

The 3' end of HIF-1 $\alpha$ was amplified using the BD Biosciences SMART RACE kit (Clontech, USA). The cDNA was amplified using a forward primer with the sequence 5' - CTTGTGAGGAAACTTCTGGATGCTGGTGA - 3'. The protocol used was as supplied by the manufacturer. The annealing temperature was $65^{\circ} \mathrm{C}$ and a product of $\sim 2000$ bp was obtained and sequenced. The 5' end was amplified using the same kit. The primer used was 5' - GCAAGCATCCTATACTGTCCTGTGGTGAC -3'. Annealing temperature was $63^{\circ} \mathrm{C}$ and a PCR product of $\sim 900 \mathrm{bp}$ was obtained and sequenced. Sequences were assembled and the complete transcript of S. tridecemlineatus HIF-1 $\alpha$ was obtained and submitted to Genbank.

\section{Western blotting.}

Frozen tissue samples $(\sim 500 \mathrm{mg})$ were homogenized in $2 \mathrm{~mL}$ of buffer containing 100 mM MOPS, 25 mM HEPES, 25 mM $\beta$-glycerophosphate, 5 mM EDTA, 1 mM EGTA and $250 \mu \mathrm{M} \mathrm{NaVO}_{4}$, adjusted at pH 7.4, with $1 \mathrm{mM}$ phenylmethylsulphonyl fluoride (PMSF) added immediately before homogenization. After centrifugation at $10,000 \mathrm{~g}$ for $10 \mathrm{~min}$ at $4^{\circ} \mathrm{C}$, supernatants were collected and soluble protein concentrations were determined using the Coomassie blue dye-binding method and the BioRad prepared reagent (BioRad, Hercules, CA). Samples were then diluted to the desired concentration in sample buffer containing $100 \mathrm{mM}$ Tris- $\mathrm{HCl}(\mathrm{pH}$ 6.8), 4\% SDS, $20 \% \mathrm{v} / \mathrm{v}$ glycerol, $5 \% \mathrm{v} / \mathrm{v} \beta$-mercaptoethanol, and $0.2 \% \mathrm{w} / \mathrm{v}$ bromophenol blue. Samples 
were boiled for $5 \mathrm{~min}$, cooled and then frozen at $-20^{\circ} \mathrm{C}$ until use. SDS-polyacrylamide gel electrophoresis used $10 \%$ gels ( $5 \%$ stacking gel), $20 \mu \mathrm{g}$ of protein per well, and electrophoresis at $200 \mathrm{~V}$ for $45 \mathrm{~min}$. Proteins were then wet transferred onto polyvinylidene difluoride membranes using a transfer buffer solution containing $25 \mathrm{mM}$ Tris (pH 8.5), $192 \mathrm{mM}$ glycine and $10 \% \mathrm{v} / \mathrm{v}$ methanol at $4^{\circ} \mathrm{C}$ for $1.5 \mathrm{~h}$ at $0.3 \mathrm{~mA}$. Following transfer, the PVDF membrane was blocked for $1 \mathrm{~h}$ in TBST (50 mM Tris-HCl $\mathrm{pH} 6.8,150 \mathrm{mM} \mathrm{NaCl}, 0.05 \% \mathrm{v} / \mathrm{v}$ Tween 20 ) with $2.5 \% \mathrm{w} / \mathrm{v}$ powdered skim milk. This was decanted and then membranes were incubated overnight at $4^{\circ} \mathrm{C}$ with primary antibody (polyclonal chicken anti-HIF-1 $\alpha$, kindly provided by Dr. M. Gassmann, Physiologisches Institut, Universitat Zuerich-Irchel, Switzerland) at a 1:500 v:v dilution in $5 \mathrm{~mL}$ of TBST. Subsequently, the membrane was incubated with HRP-linked antichicken IgG secondary antibody (1:2000 v:v dilution) in TBST for $1 \mathrm{~h}$ and then blots were developed using the SuperSignal West Pico Chemiluminescent Substrate (Pierce) according to the manufacturer's protocol. Bands were visualized using a ChemiGenius (Syngene, MD, USA). and band intensities were quantified using the GeneTools program (Syngene, MD, USA). Preliminary trials used two-dimensional electrophoresis to confirm that the chicken antibody cross-reacted with only a single protein in hibernator tissues, with the appropriate molecular mass and isoelectric point for HIF-1 $\alpha$.

\section{DNA Binding Assay.}

Nuclear extracts were prepared from BAT. Briefly, tissue samples were disrupted using a Dounce homogenizer in homogenization buffer $(10 \mathrm{mM}$ HEPES, $10 \mathrm{mM} \mathrm{KCl}, 10$ mM EDTA, $1 \mathrm{mM}$ DTT, $\mathrm{pH}$ 7.9) with $1 \mathrm{mM}$ PMSF was added prior to homogenization. Samples were centrifuged at $10,000 \mathrm{~g}$ for $10 \mathrm{~min}$ at $4^{\circ} \mathrm{C}$. Supernatants were discarded and 
pellets were resuspended in extraction buffer $(20 \mathrm{mM}$ HEPES, $0.4 \mathrm{M} \mathrm{NaCl}, 1 \mathrm{mM}$ EDTA, $50 \% \mathrm{v} / \mathrm{v}$ glycerol, $1 \mathrm{mM} \mathrm{DTT}, \mathrm{pH} 7.9)$. Tubes containing samples were put on ice horizontally on a rocking platform for $1 \mathrm{~h}$. Samples were then centrifuged at $10,000 \mathrm{~g}$ for $10 \mathrm{~min}$ at $4^{\circ} \mathrm{C}$. Supernatants containing nuclear extracts were collected and protein concentration was measured with the BioRad assay. Aliquots containing an equal amount of protein from each sample were then used to assess the amount of binding by HIF-1 to its response element using a DNA binding assay from ActiveMotif. This is an ELISAtype assay that uses 96 well microplates that have been coated previously with the oligonucleotide corresponding to the hypoxia response element (HRE) that is recognized by HIF-1. Binding assays were performed according to the manufacturer's protocol. HIF1 binding was carried out for $1 \mathrm{~h}$ at $21^{\circ} \mathrm{C}$ with mild agitation on a rocking platform at 100 rpm. The plates were then washed three times with phosphate buffer (10 mM phosphate buffer, $\mathrm{pH} 7.5,50 \mathrm{mM} \mathrm{NaCl}, 0.1 \%$ Tween-20) to remove unbound transcription factors. HIF-1 $\alpha$ specific primary antibody diluted $1: 1000 \mathrm{v}: \mathrm{v}$ in washing buffer was then added to each well and incubated for $1 \mathrm{~h}$ at $21^{\circ} \mathrm{C}$ without agitation. The wells were then washed three times with washing buffer and the secondary antibody HRP-linked anti-mouse IgG was added to the wells in a 1:1000 v:v dilution in washing buffer for $1 \mathrm{~h}$ at $21^{\circ} \mathrm{C}$. The wells were then washed four times with washing buffer and the manufacturer's developing solution was then added. After developing for $10 \mathrm{~min}$ in the dark, the stop solution was added and color development was quantified by absorbance readings at 460 nm using a microplate reader.

\section{Quantification and Statistics.}


RT-PCR and Western bands were scanned and densitometric analysis was performed using the GeneTools program (Syngene, MD, USA). HIF-1 $\alpha$ mRNA RT-PCR bands were normalized relative to RT-PCR bands of $\alpha$-tubulin run from the same cDNA reaction. Band intensities of immunoreactive material on Western blots were first normalized against three Coomassie stained protein bands that did not appear to change between euthermic and hibernating states. Mean normalized band densities \pm SEM were then calculated for samples from hibernating versus euthermic animals and significant differences between the groups were tested using the Student's t-test. The ratio hibernating:euthermic was calculated and plotted; error bars on the final histograms are the sum of SEM values for hibernating and euthermic trials.

\section{RESULTS}

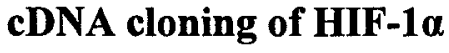

Using RT-PCR and primers derived from the consensus sequence of HIF- $1 \alpha$ from other mammalian species, a PCR product of $796 \mathrm{bp}$ was retrieved from total RNA prepared from BAT of hibernating S. tridecemlineatus. The product was confirmed as encoding a portion of the HIF- $1 \alpha$ sequence and then 5' and 3' RACE were used to extend the sequence and a final assembled sequence of $2466 \mathrm{bp}$ was achieved. The ground squirrel HIF-1 $\alpha$ sequence was submitted to GenBank with accession number AY713478. The nucleotide and deduced amino acid sequences of ground squirrel HIF-1 $\alpha$ are shown in Figure 2.2. Figure 2.3 shows the translated amino acid sequence of ground squirrel HIF-1 $\alpha$ aligned with the sequences for human, mouse and rat HIF-1 $\alpha$. The ground squirrel protein contained 821 amino acids compared with $823-836$ for the other species. 
The amplified ground squirrel HIF-1 $\alpha$ was $95 \%$ identical to the human sequence and showed $90 \%$ identity with the mouse or rat sequences. Ground squirrel HIF-1 $\alpha$ contained a few unique amino acid substitutions that were not seen in non-hibernating mammals (shown in bold underline in Figure 2.3). Figure 2.4 shows that ground squirrel HIF-1 $\alpha$ is quite similar to HIF-1 $\alpha$ from other non-hibernating species. Multiple sequencing runs used during the course of assembling the full sequence (both initial sequencing of the PCR product and sequencing of 5' and 3' RACE segments) showed that these substitutions were not artifacts due to sequencing errors. These included the substitution of a hydrophobic leucine for a basic arginine residue at position 68 , a glycine substitution for aspartic acid at residue 349 , and two serine substitutions, one for proline at position 208 and one for asparagine at position 440. In addition, there was a tryptophan substitution for proline at position 637 and a glutamine substitution for histidine at position 719 . Finally, two arginine residues at positions 713 and 715 were changed to lysine and alanine in the ground squirrel sequence, respectively.

\section{HIF-1a gene expression in $S$. tridecemlineatus}

HIF-1 $\alpha$ mRNA transcript levels were assessed in four tissues (BAT, skeletal muscle, liver, lung) from euthermic and hibernating S. tridecemlineatus using RT-PCR. HIF-1 $\alpha$ primers were designed from a consensus sequence made from human, mouse and rat sequences and were used to amplify mRNA from ground squirrel tissues. Figure 2.5 shows the relative levels of HIF-1 $\alpha$ mRNA expression in each organ. Alpha-tubulin mRNA, a constitutively expresseed gene, was also amplified from the same samples and HIF-1 $\alpha$ transcript levels were normalized against the tubulin transcript level in each sample. Figure 2.5B shows the ratio of normalized HIF- $1 \alpha$ transcript levels in tissues 
from hibernating versus euthermic animals. HIF- $1 \alpha$ transcript levels did not change significantly during hibernation in any of the four tissues analyzed.

\section{HIF-1 $\alpha$ protein levels in S. tridecemlineatus}

HIF-1 $\alpha$ protein levels were assessed via Western blotting in four tissues of euthermic and hibernating S. tridecemlineatus (Figure 2.6). The polyclonal chicken antibody crossreacted with a single protein band of $\sim 110 \mathrm{kDa}$ that corresponded with the known size of the HIF-1 $\alpha$ protein in other mammals. Figure 2.6B shows the ratio of HIF$1 \alpha$ protein levels in hibernating versus euthermic situations for BAT, skeletal muscle, liver and lung. HIF-1 $\alpha$ protein content was significantly higher $(\mathrm{P}<0.05)$ in both BAT and muscle of hibernating $S$. tridecemlineatus; values were 1.70 -and 1.55 -fold higher than in tissues from euthermic animals, respectively. HIF-1 $\alpha$ protein levels did not change significantly in either liver or lung during hibernation.

\section{HIF-1 DNA binding activity in S. tridecemlineatus}

In the nucleus HIF-1 $\alpha$ dimerizes with HIF-1 $\beta$ and stimulates the transcription of genes. Transcriptional activity is proportional to the amount of HIF-1 bound to DNA. To assess the effects of hibernation on the amount of HIF-1 dimer present, and therefore, the probable transcriptional activity of HIF-1 during torpor, changes in HIF-1 DNA binding activity between euthermic and hibernating states were assessed in nuclear extracts from BAT. Mean absorbances at $460 \mathrm{~nm}$ corresponding to HIF-1 DNA binding activity were $0.056 \pm 0.005(\mathrm{n}=3$ independent trials) for extracts from euthermic animals and 5.6-fold higher at $0.311 \pm 0.048(\mathrm{n}=3 ; \mathrm{P}<0.05)$ in extracts from hibernating animals (Figure 2.7). 


\section{DISCUSSION}

Soon after a hypoxia-inducible transcription factor was identified, studies showed that while HIF-1 $\alpha$ protein levels increased in hypoxia, hif-1 $\alpha$ mRNA transcript levels remained largely unchanged (Wenger et al., 1997). Indeed, subsequent studies suggested that HIF-1 $\alpha$ levels were regulated primarily at the protein level by post-translational modifications of the protein via phosphorylation (Wang et al., 1995) and hydroxylation (Jaakkola et al., 2001) which play roles in HIF-1 $\alpha$ activation and degradation, respectively. Modulation of HIF-1 $\alpha$ protein levels with respect to changes in oxygen availability is derived from oxygen dependent hydroxylation of two proline residues on HIF-1 $\alpha$ that target it for degradation. Under low oxygen conditions this process is inhibited so that HIF-1 $\alpha$ protein levels rise allowing increased formation of the HIF-1 dimer and enhanced HIF-1 binding activity to the hypoxia response element (HRE) of various genes (Wang and Semenza, 1993). The object of this study was to probe the potential link between HIF-1 and hibernation. Arguments have been made that suggest that this link may be present: (a) an interaction seems to exist between hypoxia and hypothermia that could participate in the mechanism of metabolic rate depression observed in hibernators, and (b) a number of hypoxia-related genes are up-regulated in various tissues of hibernating mammals (Storey, 2003).

The present study analyzed HIF-1 $\alpha$ gene and protein expression in four main organs of hibernating ground squirrels (BAT, skeletal muscle, liver, lung). The levels of hif- $1 \alpha$ mRNA remained constant in all four organs of hibernating animals compared with euthermic controls but HIF-1 $\alpha$ protein content rose significantly in two organs during torpor. Interestingly, all four organs displayed detectable HIF-1 $\alpha$ protein levels under 
euthermic conditions. Considering the rapid degradation of HIF- $1 \alpha$ under normoxic conditions, this result might be surprising at first, but in vivo HIF-1 $\alpha$ expression in tissues sampled from normoxic mice has been shown previously (Stroka et al., 2001). Furthermore, the presence of HIF-1 $\alpha$ in euthermic tissues could indicate, as reported before in euthermic Arctic ground squirrels, a state of hypoxic preconditioning prior to hibernation (Ma et al., 2005; Zhu et al., 2005). The increase in HIF-1 $\alpha$ protein levels measured here was 1.70-fold in BAT and 1.55-fold in muscle. This could result from a more active translation of hif-1 $\alpha$ transcripts during torpor. Indeed, despite a strong general suppression of translation during hibernation, the translation of a selected few proteins that aid hibernation is strongly increased (Hittel and Storey, 2002b; Storey 2003). HIF-1 $\alpha$ may be one of these. Alternatively, apnoic breathing patterns in torpor could create conditions of declining oxygen levels in ground squirrel organs during most of a torpor bout, compared with high and constant oxygenation during euthermia, and this could lead to enhanced stability of HIF-1 $\alpha$ in torpor. HIF-1 $\alpha$ protein stability might also be improved by other mechanisms such as an effect of low body temperatures on the relative rates of HIF-1 $\alpha$ synthesis versus degradation. A relative reduction in HIF-1 $\alpha$ degradation during hibernation might be suspected but, interestingly, results from cDNA array screening in our laboratory (using human $19 \mathrm{~K}$ gene chips from the Ontario Cancer Institute) have revealed that prolyl hydroxylase transcript levels are up-regulated in tissues from hibernating animals. Furthermore, mRNA and protein levels of protein disulfide isomerase, a subunit of the prolyl-4-hydroxylase enzyme family, are known to be up-regulated in several hibernating tissues of the thirteen-lined ground squirrels (Morin and Storey, unpublished data). A family of cytoplasmic prolyl 4-hydroxylases 
playing a role in the regulation of the hypoxia-inducible transcription factor $\mathrm{HIF}-1 \alpha$ has recently been identified (Bruick and McKnight, 2001). This suggests that the whole oxygen sensing mechanism may be up-regulated during hibernation, at least in the thermogenic organs that need to conduct high rates of aerobic lipid oxidation for heat production during arousal: ie. BAT that conducts nonshivering thermogenesis and skeletal muscle that contributes shivering thermogenesis. Indeed, this interpretation is also supported by the observed 6-fold increase in HIF-1 $\alpha$ DNA binding capacity in BAT from hibernating animals which strongly indicates that multiple genes under HIF-1 $\alpha$ control are probably up-regulated during hibernation. The differential between the 6-fold increase in DNA binding activity of HIF-1 and the 1.7 -fold increase in HIF- $1 \alpha$ protein levels in BAT suggests that an additional factor(s) is involved in HIF-1 activation in hibernation. This factor may be protein phosphorylation. Phosphorylation of HIF-1 $\alpha$ by p42/p44 mitogen-activated protein kinases (MAPKs; also known as ERK2 and ERK1, respectively) leads to increased transcriptional activity of the HIF-1 complex (Dery et al., 2005). Furthermore, p42/p44 MAPKs also phosphorylate the $\mathrm{p} 300 / \mathrm{CBP}$ co-activator proteins that aid HIF-1 binding to DNA (Sang et al., 2003). New studies in our lab have shown that ERK2 activity is strongly increased in skeletal muscle of hibernating ground squirrels (MacDonald and Storey, 2005), muscle being the other tissue that, like BAT, showed increased HIF-1 $\alpha$ in hibernation. Although the status of ERK activation in BAT during hibernation is not yet known, it is tempting to speculate the ERK-mediated phosphorylation of HIF-1 $\alpha$ might account for the strong increase in DNA binding to the HRE by HIF-1 in BAT of hibernating animals.

Interestingly, another mechanism of HIF-1 activation has recently been 
demonstrated and this may be important in torpor. The argument can be made that hibernators are not hypoxic; oxygen levels drop over the course of apnoic periods but metabolism remains firmly lipid-based both in torpor and during arousal which suggests that oxygen is never limiting to cellular energy metabolism. Then how and why is HIF-1 activated? New research has shown that HIF-1 can also be activated under normoxic conditions to mediate biological functions unrelated to hypoxia defense (Dery et al., 2005). A non-hypoxic activation of HIF-1 has been demonstrated as a response to various growth factors, cytokines, vascular hormones and viral proteins (Dery et al., 2005). Furthermore, in this situation, activation does not appear to result from HIF-1 $\alpha$ stabilization (e.g. hydroxylation vs phosphorylation) but rather from an increase in HIF$1 \alpha$ protein translation. This could also be the mechanism of HIF-1 $\alpha$ increase in hibernator tissues. To date, only a few gene targets of non-hypoxic HIF-1 activation are known and so it is not yet possible to suggest a potential function for non-hypoxic. HIF-1 activation in hibernation. Nonetheless, the present data, by showing that HIF-1 $\alpha$ levels are elevated in hibernation and HIF-1 DNA binding is enhanced, strongly indicates that a suite of HIF-1 regulated genes are up-regulated during torpor in selected tissues (at least BAT and skeletal muscle). Identification of the genes involved and their functions in hibernation is the next challenge.

The complete sequence of ground squirrel HIF-1 $\alpha$ was obtained and analyzed. The ground squirrel protein showed $90-95 \%$ identity with the sequences for nonhibernating mammals (human, mouse, rat) with most of the variation in the ground squirrel protein, compared with the others. Unfortunately, as this is the first HIF-1 $\alpha$ sequence reported from a hibernating source, comparison with another hibernating HIF- 
$1 \alpha$ was impossible. Specific functional groups that characterize HIF-1 $\alpha$ from other nonhibernating species were present. For example, the two proline residues of the oxygen dependent domain, Pro402 and Pro564, that are hydroxylated in order to target HIF-1 $\alpha$ for degradation (Ivan et al., 2001) were conserved in S. tridecemlineatus. Considerable variability between species was seen in the C-terminal region. In particular, four unique sequence changes occurred in the hibernator protein (residues 637, 713, 715 and 719) within the inhibitory domain (amino acids 576-785) that separates the two Cterminal transactivation domains (Jiang et al., 1997). For example, the replacement of the proline residue at 637 with a tryptophan could cause a significant change in conformation because proline residues are commonly found at turns. These four substitutions in the inhibitory domain could be important in adjusting protein conformation/function with respect to temperature change and influencing the transactivation ability of HIF-1 (e.g. transactivation domains bind with the co-activator $\mathrm{CBP} / \mathrm{p} 300$ ) under the low body temperatures of the hibernating state. On the other hand, no changes were found in the key amino acid residues that are responsible for HIF-1 $\alpha$ binding to the HRE: Ser22, Ala25, Arg30 (Michel et al., 2002) and only one unique substitution (arginine to leucine at residue 68) occurred within the $\mathrm{N}$-terminal bHLH domain. The fact that this HREbinding region is conserved in a hibernator as compared with other non-hibernating mammals highlights the importance of a conserved DNA binding region and suggests that no modifications to DNA binding capacity are needed to support HIF-1 function at the low body temperatures of the hibernating state. In the region associated with the PAS domain of HIF-1 $\alpha$, amino acids 106-526, three unique substitutions were observed (proline to serine at 208, aspartic acid to glycine at 349 , and asparagine to serine at 440). 
Due to their small size, glycine residues are also known to be located at turns in a protein and hence both the loss of the proline at 208 and the gain of the glycine at 349 could contribute to conformational changes to better sustain dimerization ability with HIF- $1 \beta$ at low body temperatures. 
Figure 2.1

(A)

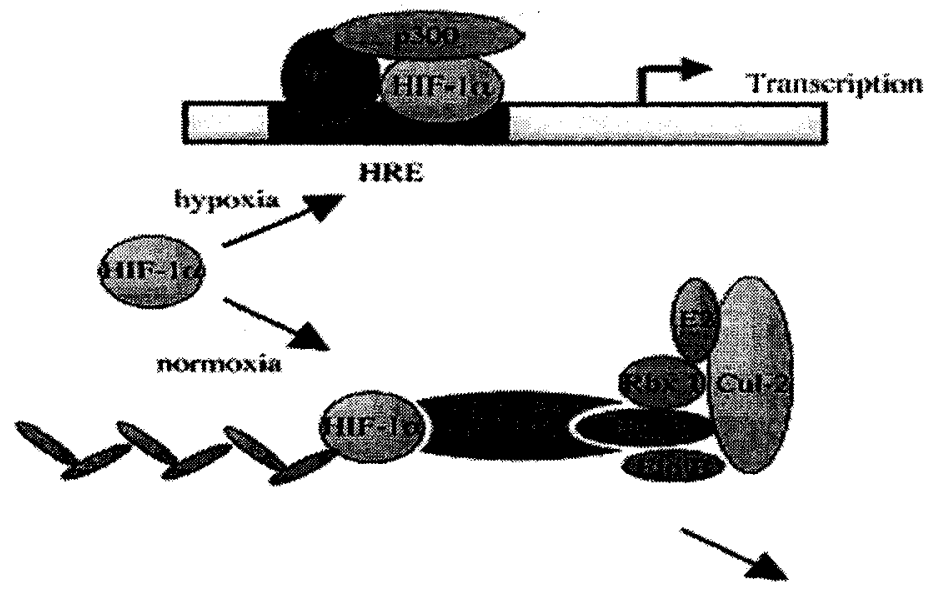

Protensomal

degrexistion

(B)

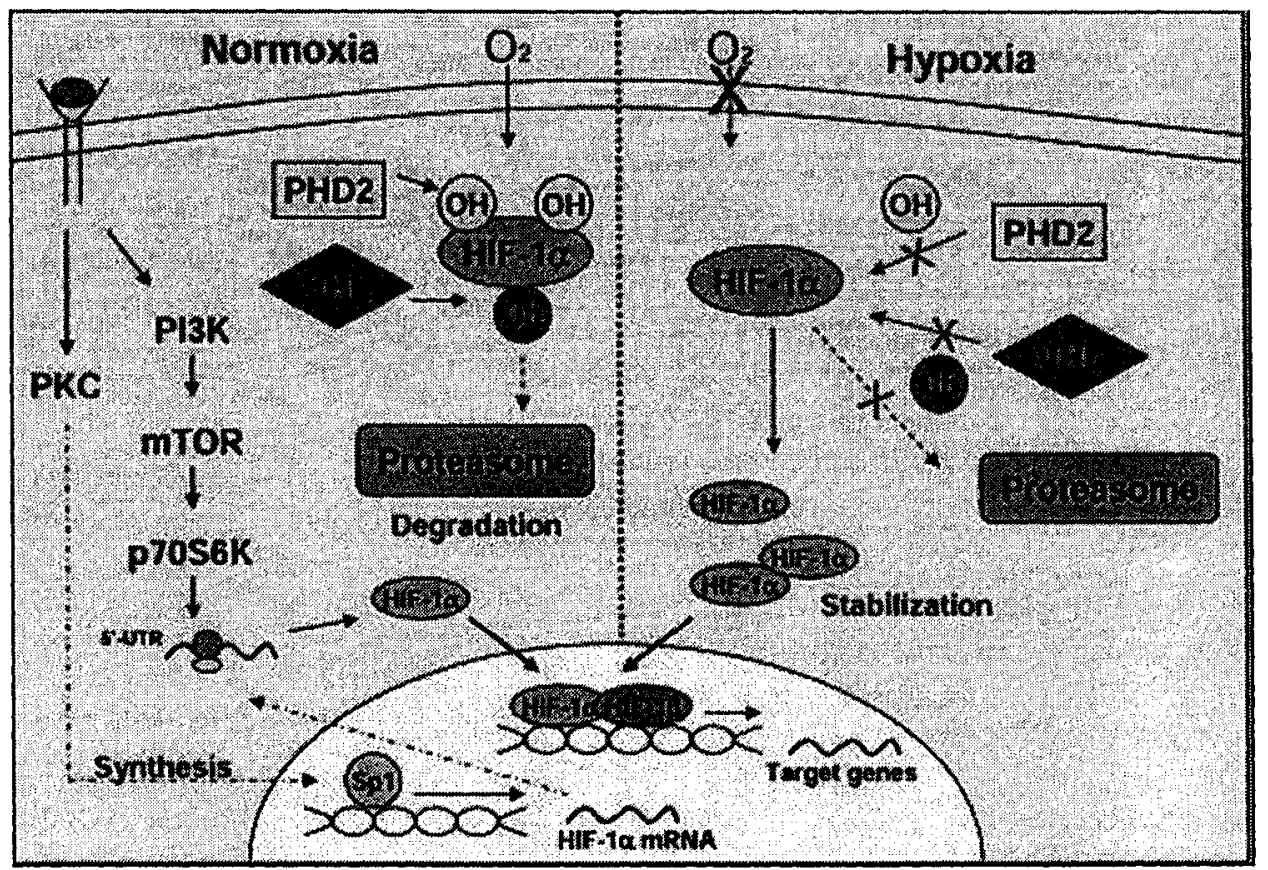




\section{Figure 2.2}

1 ATGGAGGGCGCCGGAGGCACGAACGACAAGAAAAAGATAAGTTCTGAACGTCGAAAAGAA

61 21

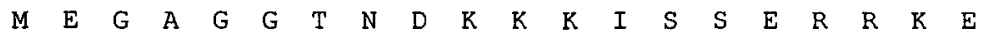




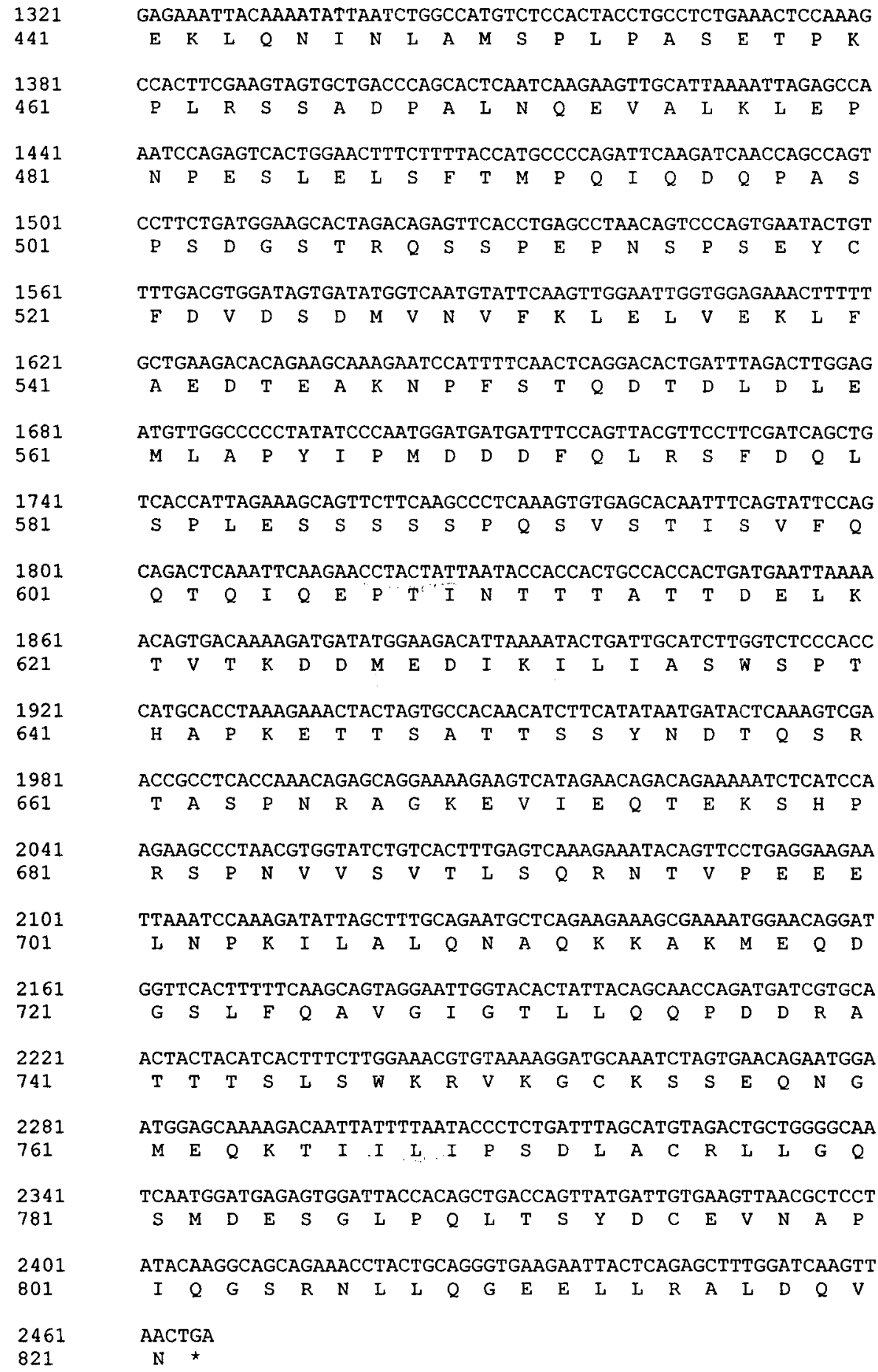




\section{Figure 2.3}

s.t MEGAGGTNDKKKI.SSERRKEKSRDAARSRRSKESEVEYELAHQLPLPHXVSSHLDKASVMRLTISYLLVRKLLDAGDLD 79

h.s -

m.m - - n- e-e-- .m- -

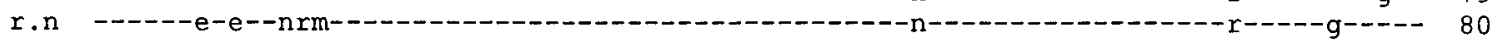

s.t IEDEMKAQMNCFYLKALDGFVMVLTDDGDMIYISDNVNKYMGLTQFELTGHSVFDFTHPCDHEEMREMLTHRNGPVKKGK 159

$\mathrm{h} . \mathrm{s}---\mathrm{d}-----------159$

m.m s---n-d--- d

r. $\mathrm{n}$

s.t EQNTQRSEFLRMKCTLTSRGRTMNIKSATWKVLHCTGHIHVYDTNSNQSQCGYKKPPMTCLVLICEPIPHPSNIEIPLDS 239

h.s -

m.m -1 -

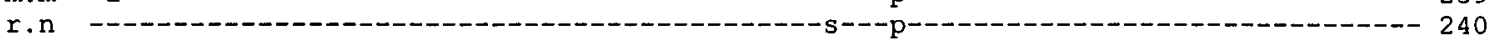

s.t KTFLSRHSLDMKFSYCDERITELMGYEPEELLGRSIYEYYHALDSDHLTKTHHDMFTKGQVTTGQYRMLAKRGGYVWVET 319

h.s -

m.m -m -

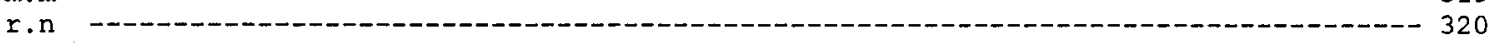

s.t QATVIYNTKNSQPQCIVCVNYVVSGIIQHGLIFSLQQTECVLKPVESSDMKMTQLFTKVESEDTSSLFDKLKKEPDALTL 399

h.s -

m.m - -

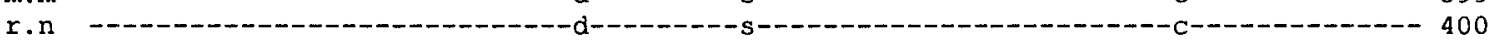

s.t LAPAAGDTIISLDFGSNDTETEDQQLEEVPLYNDVMFPSSSEKLQNINLAMSPLPASETPKPLRSSADPALNQEVALKLE 479

h.s -

m.m -

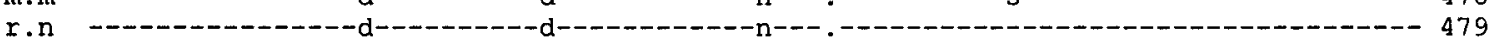

s.t PNPESLELSFTMPQIQDQPASPSDGSTRQSSPE. . . . . . . . PNSPSEYCFDVDSDMVNVFKLELVEKLEAEDTE 545

h.s -

m.m ss--- g-

$r . \mathrm{n}$ ss----g----n-

s.t AKNPFSTQDTDLDLEMLAPYIPMDDDFQLRSFDQLSPLESSSSSPQSV...STISVFQQTQIQEPTIN..TTTATTDELK 620

h.s - -

m.m - -

r.n - - - a--

s.t TVTKDDMEDIKILIASWSPTHAPKETTSATTSSYNDTQSRTASPNRAGKEVIEQTEKSHPRSPNVVSVTLSQRNTVPEEE 7O0

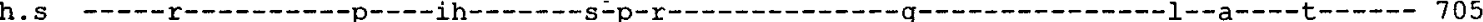

m.m -e---nk--------p-s-qv-q---t-ka-a-sg-h------d----r-----d-a-c--1kl. -a--n--- - - - 715

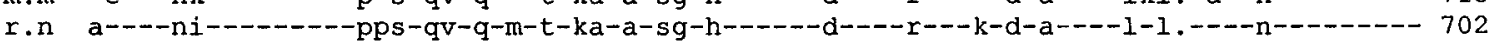

s.t LNPKILALQNAQKKAKMEQDGSLFQAVGIGTLLQQPDDRATTTSLSWKRVKGCKSSEQNGMEQKTIILIPSDLACRLLGQ 780

h.s - -

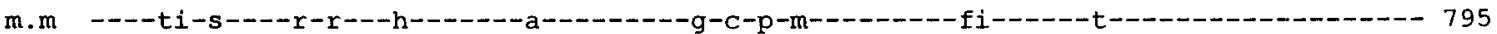

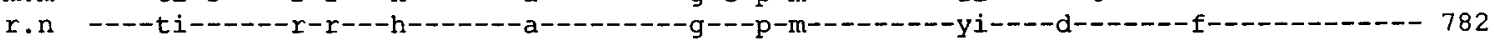

s.t SMDESGLPQLTSYDCEVNAPIQGSRNLLQGEELLRALDQVN 821

h.s -

m.m -

r.n 
Figure 2.4

A.

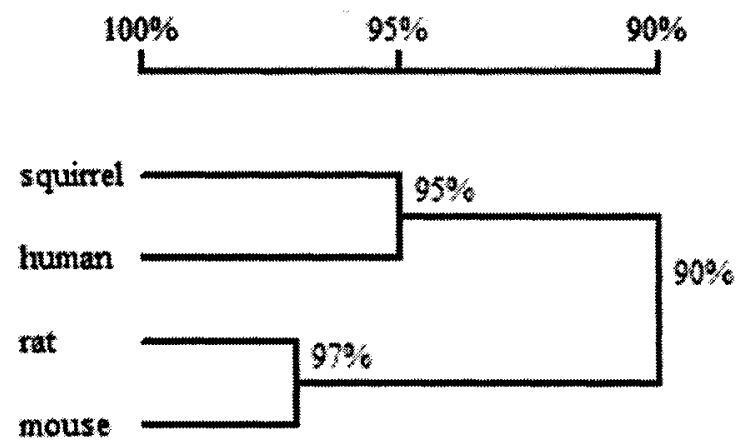

B.

$100 \% 95 \% 90 \% 85 \% 80 \% 75 \% 70 \% 65 \% 60 \%$
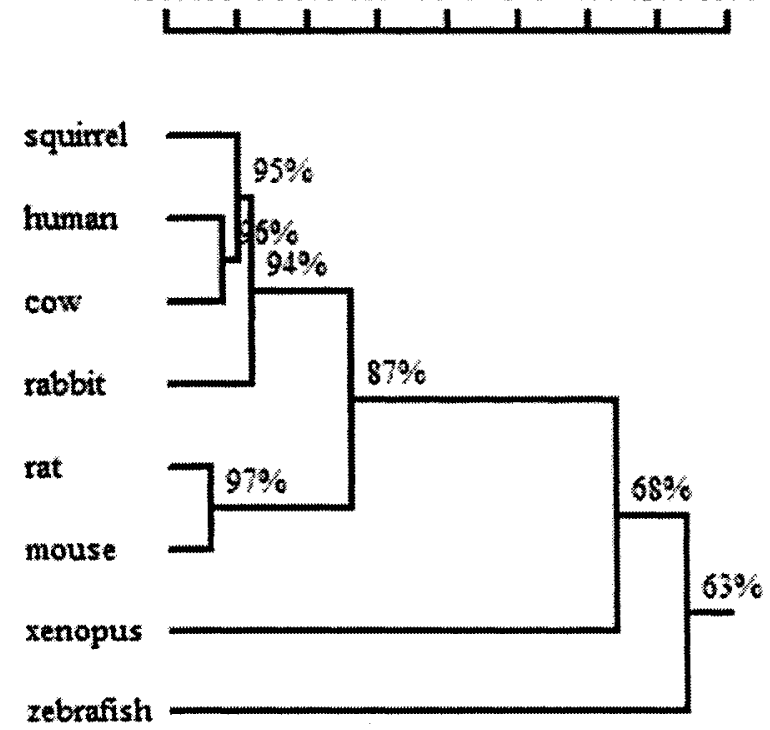
Figure 2.5

A.

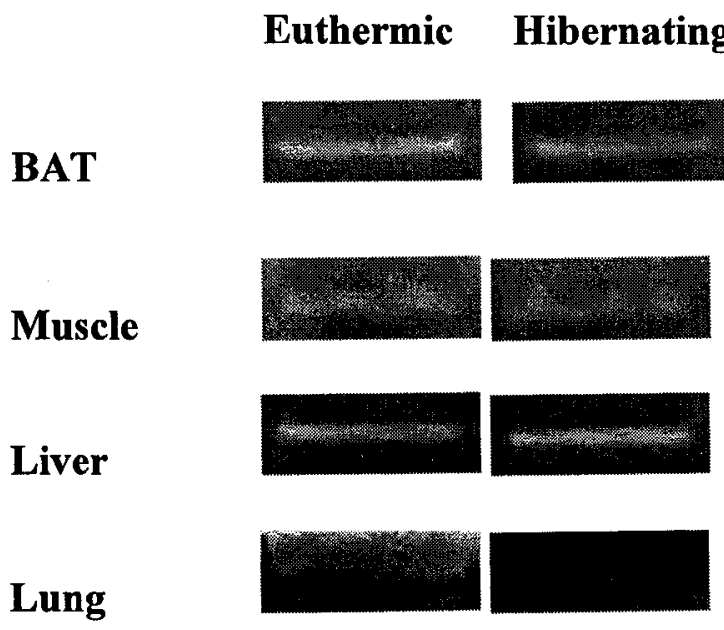

$\alpha$-Tubulin

Euthermic Hibernating
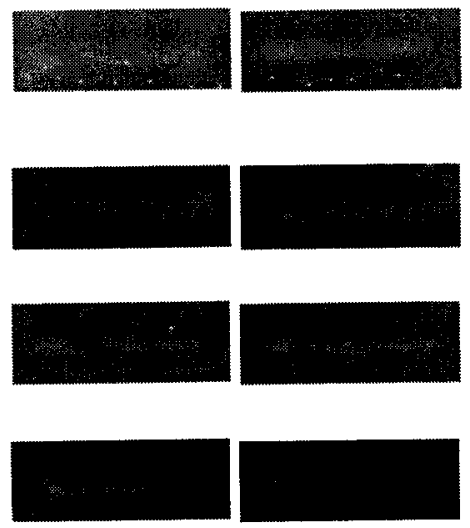

B.

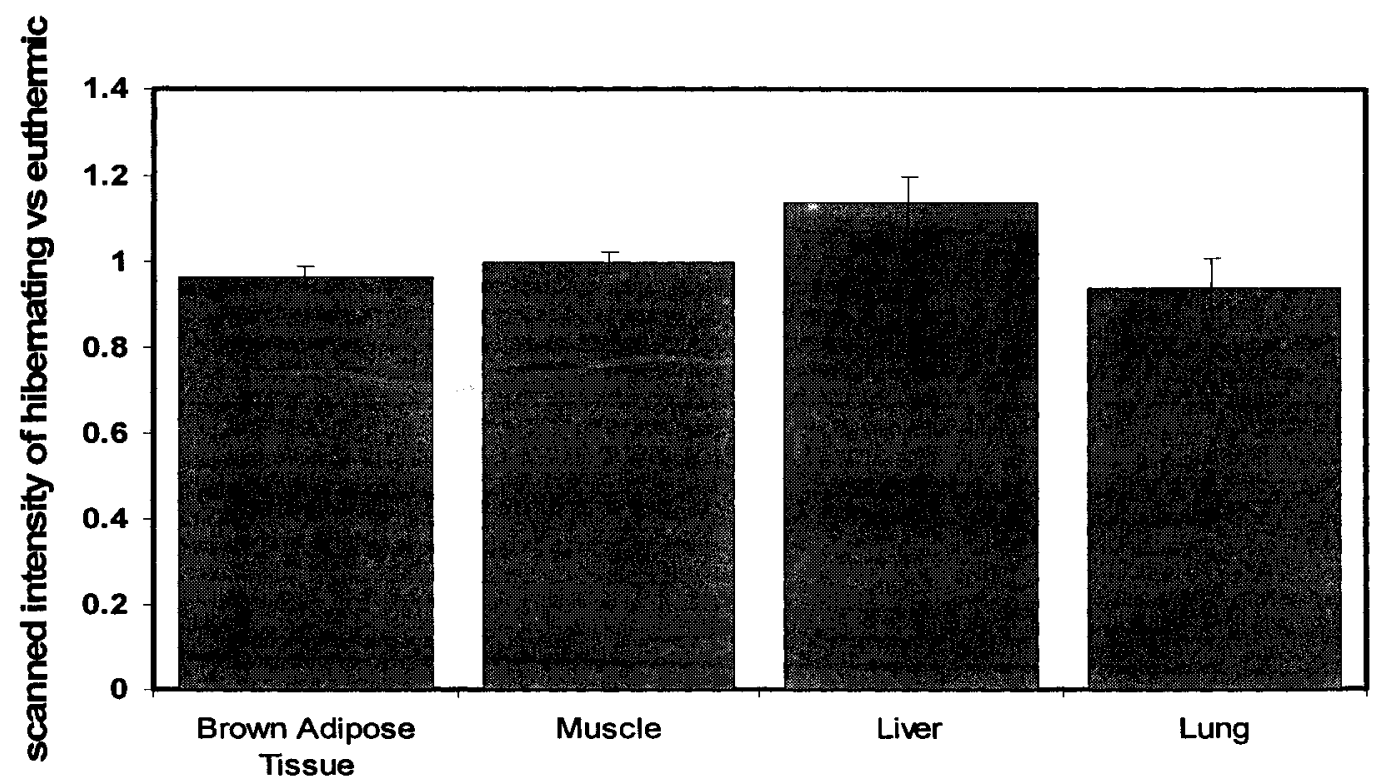


Figure 2.6

A. Euthermic Hibernating

BAT

Muscle
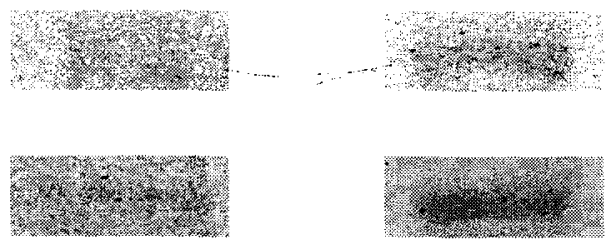

Liver
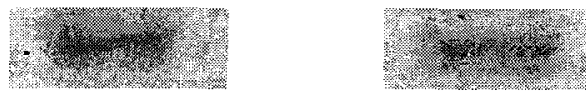

Lung
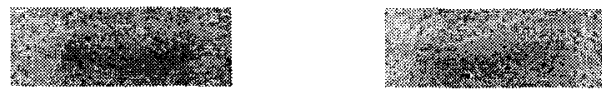

B.

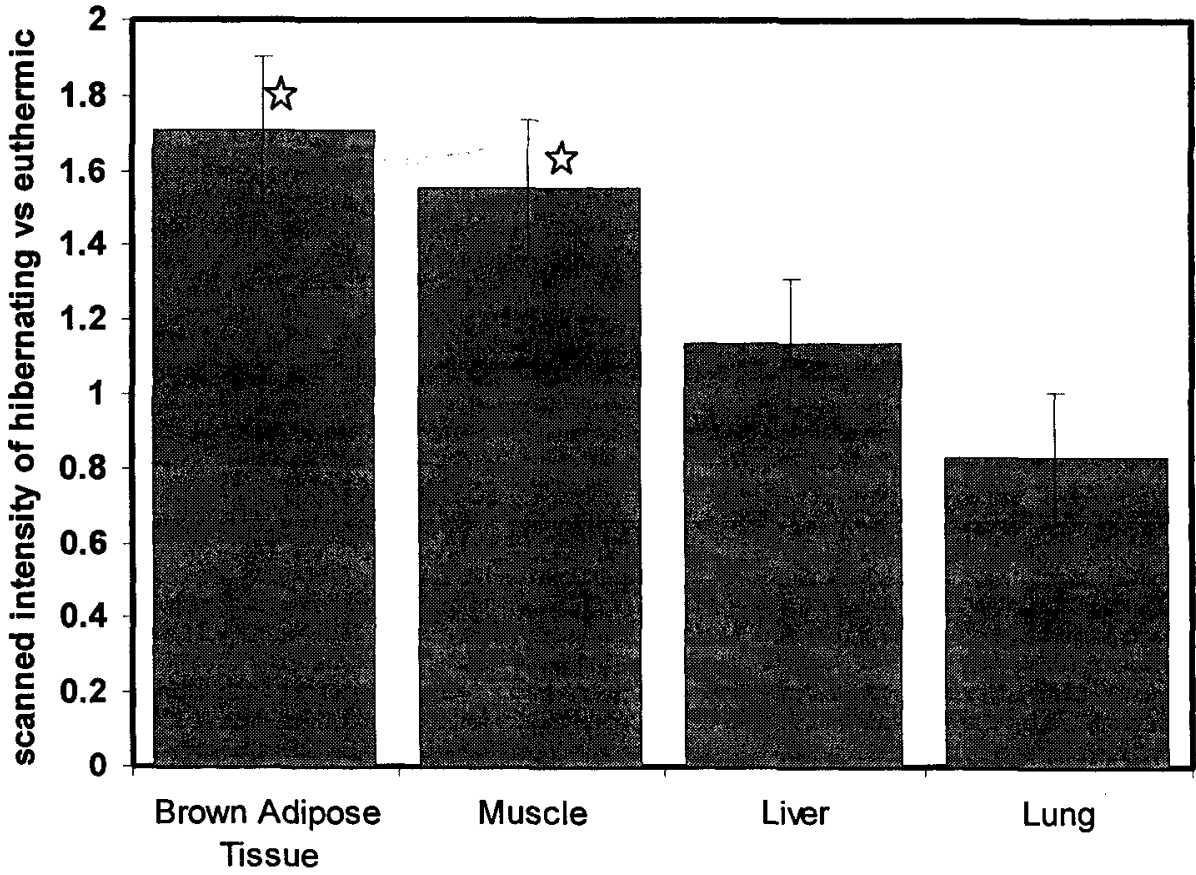


Figure 2.7

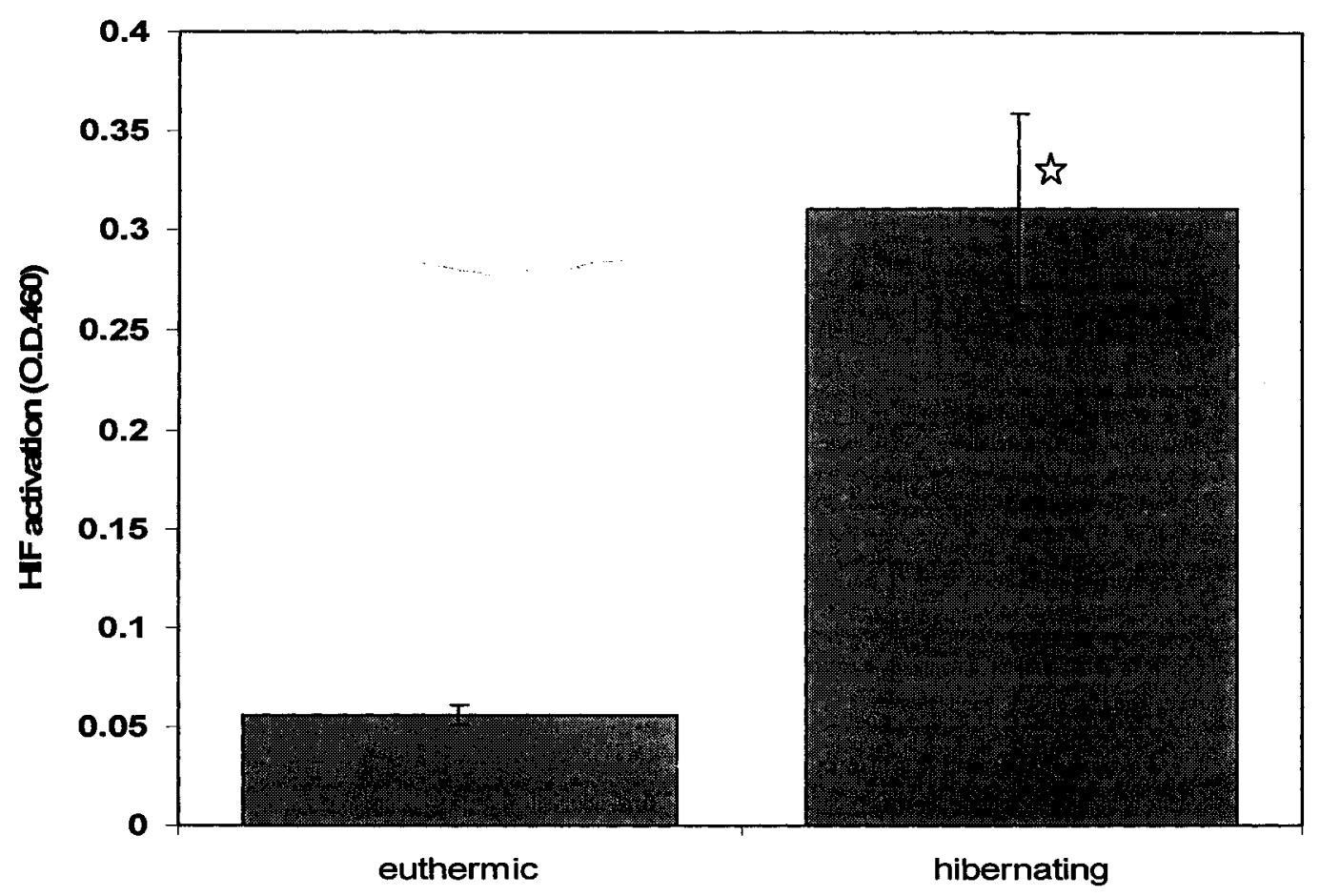




\section{Chapter 3}

\section{Evidence for a reduced transcriptional state during hibernation in ground squirrel muscle}




\section{INTRODUCTION}

The profound metabolic rate depression during hibernation is largely achieved by active controls that suppress the rates of all ATP-consuming processes in cells. Some of the major ATP-consuming processes in cells include transmembrane ion transport, gene transcription, and protein translation. Not surprisingly, then, the activity of the plasma membrane NaK-ATPase is strongly reduced during hibernation (MacDonald and Storey, 1999) as is the activity of the sarco(endo)plasmic reticulum Ca-ATPase and the levels of other proteins associated with calcium signaling (Malysheva et al., 2001). Rates of protein translation are well known to be reduced in mammals in the face of stresses such as starvation or hypoxia (Casey et al., 2002; DeGracia et al., 2002) and in hibernation the rate of protein synthesis can be reduced to extremely low levels by combining the effects of reversible phosphorylation controls on the translation apparatus with the rate effects of $\mathrm{a}>30^{\circ} \mathrm{C}$ decrease in body temperature. Indeed, the rate of radiolabelled leucine $\left({ }^{14} \mathrm{C}\right)$ incorporation in brain of torpid 13-lined ground squirrels, Spermophilus tridecemlineatus, was only $0.04 \%$ of the value measured in euthermic brain (Frerichs et al., 1998). Similar findings using polysome analysis were reported for S. tridecemlineatus kidney (Hittel and Storey, 2002b).

Gene transcription is another of the major energy consuming processes in cells, typically requiring $\sim 1-10 \%$ of the overall cell energy budget (Rolfe and Brown, 1997). Given the strong suppression of translation in hibernation, it is reasonable to propose that the overall rate of transcription would also be reduced. Indeed, studies with several different animal systems suggest that transcriptional suppression is a general component of hypometabolism (reviewed in Storey and Storey, 2004). Data for hibernating 
mammals is limited to date but tends to concur. For example, the rate of incorporation of $\left[{ }^{3} \mathrm{H}\right]$-uridine into RNA in brain decreased 8-fold in torpid compared with euthermic ground squirrels (Bocharova et al., 1992). The same principle was documented when $\left[{ }^{3} \mathrm{H}\right]$-uridine into RNA was monitored in multiple organs of hamsters (Osborne et al., 2004) and from nuclear run-on assays performed on liver extracts of S. lateralis (van Breukelen and Martin, 2002).

Multiple regulatory controls could be involved in reducing the rate of gene transcription during hibernation. It is well known that histone acetylation and deacetylation are linked to transcriptional activity and that histone deacetylases (HDACs) are associated with gene silencing. Acetylation of histones neutralizes the positive charge on the histone and leads to a modification of the higher structural organization of the chromatin. This conformational change allows transcription factors and transcriptional regulatory complexes to have easier access to DNA promoter regions. On the other hand, deacetylation of histones by histone deacetylases allows the histones to become positively charged again and this leads to transcriptional silencing (Davie, 1998). It has also been shown that HDAC activity can be affected by changes in oxygen levels and is known to be both induced under hypoxic conditions (Kim et al., 2001c) and reduced under oxidative stress (Adcock et al., 2005).

Other posttranslational modifications of histones can also affect transcriptional activity. Histones can be phosphorylated by protein kinases and phosphorylation of histone $\mathrm{H} 3$ on serine 10 is known to be present only in proliferative cells whereas cells undergoing interphase show a neglectable amount of this modification. Indeed, antibodies that target the phosphorylated form of histone $\mathrm{H} 3$ at serine 10 have been used 
as a mitotic marker (Hendzel et al., 1997). Lysine residues present on histone $\mathrm{H} 3$ can also be modified posttranslationally via acetylation to increase gene expression.

Transcriptional controls during torpor could also be applied in other ways such as by regulation of key enzymes including RNA polymerase II. Stresses that could occur during torpor have been shown to affect transcriptional activity. Hypoxic conditions can lead to an increase in the expression of specific genes that are linked with selective transcriptional repression (Denko et al., 2003). Oxidative stress seems to elicit similar a response since hydrogen peroxide can slow down the cell cycle and induce growth arrest in a variety of mammalian cell types (Wiese et al., 1995).

The study presented in this chapter looks at the transcriptional state of skeletal muscle in euthermic versus hibernating $S$. tridecemlineatus and assesses multiple parameters that could be involved in regulating the overall rate of transcription including analysis of RNA polymerase II, HDAC and histone H3. The information gathered here provides strong evidence of an overall suppression of gene transcription in ground squirrel muscle during hibernation.

\section{MATERIALS AND METHODS}

\section{Animals}

Animals were prepared and treated as described in Chapter 2.

\section{Western blotting}

Western blotting was performed as described in Chapter 2. Antibodies specific for HDAC1, HDAC4, total histone $\mathrm{H} 3$, phosphorylated histone $\mathrm{H} 3$ (serine 10) and acetylated histone $\mathrm{H} 3$ (lysine 23) were purchased from Cell Signaling. The RNA 
polymerase antibodies, $8 \mathrm{WG16}$ and $\mathrm{H} 14$, recognizing total RNA polymerase II and a phosphorylated form of RNA polymerase II (serine 5), respectively, were purchased from Covance Research.

\section{RNA Polymerase II assay}

RNA Polymerase II activity was assayed using a PCR-based approach. Nuclear extracts were prepared from skeletal muscle. Briefly, tissue samples were disrupted using a Dounce homogenizer in homogenization buffer (10 mM HEPES, $10 \mathrm{mM} \mathrm{KCl,} 10$ mM EDTA, $1 \mathrm{mM}$ DTT, pH 7.9) with $1 \mathrm{mM}$ PMSF added prior to homogenization. Samples were centrifuged at $10,000 \mathrm{~g}$ for $10 \mathrm{~min}$ at $4^{\circ} \mathrm{C}$ and then supernatants were discarded. Pellets were resuspended in extraction buffer (20 mM HEPES, $0.4 \mathrm{M} \mathrm{NaCl}, 1$ mM EDTA, 50\% v/v glycerol, $1 \mathrm{mM}$ DTT, $\mathrm{pH}$ 7.9) and then placed horizontally on ice and rocked on a rocking platform for $1 \mathrm{~h}$. Samples were then centrifuged at $10,000 \mathrm{~g}$ for $10 \mathrm{~min}$ at $4^{\circ} \mathrm{C}$. Supernatants containing nuclear extracts were collected and protein concentrations was measured with the BioRad assay. A series of samples were made up containing an amount of supernatant representing $100 \mu \mathrm{g}$ of nuclear protein combined with $100 \mu \mathrm{L}$ of transcription buffer (100 mM HEPES, $400 \mathrm{mM} \mathrm{KCl}, 25 \mathrm{mM} \mathrm{MgCl}_{2}, 5$ $\mathrm{mM}$ EDTA and $10 \% \mathrm{v} / \mathrm{v}$ glycerol), $5 \mu \mathrm{L}$ of $0.1 \mathrm{M}$ DTT, $3 \mu \mathrm{L}$ each of $100 \mathrm{mM}$ NTPs (ATP, CTP, GTP, UTP) (Fermentas), and $1 \mu \mathrm{g}$ (a saturating amount of this substrate) of a Promega PGL3-Promoter Vector containing the gene for EGFP (enhanced green fluorescent protein) with a SV40 promoter inserted in the multiple cloning site, kindly provided by Dr. W. Willmore, Carleton University. Initial trials were run in the presence of $0.1 \mathrm{mg}$ of alpha-amanitin, a RNA polymerase II inhibitor, to confirm that the activity detected was specific to RNA polymerase II action. Samples were adjusted to a final 
volume of $500 \mu \mathrm{L}$ with distilled water and then reactions were incubated at $37^{\circ} \mathrm{C}$. Individual samples were removed at 1, 5, 10, 25 and 45 min and total RNA was isolated immediately using Trizol reagent (Gibco-BRL, Bethesda, MD). Each sample was mixed in $1 \mathrm{~mL}$ Trizol followed by the addition of $200 \mu \mathrm{L}$ of chloroform and mixing. Samples were centrifuged at $10,000 \mathrm{rpm}$ at $4^{\circ} \mathrm{C}$ for $15 \mathrm{~min}$, and then the top layer was removed $(\sim 600 \mu \mathrm{L})$ and transferred into another tube. A $500 \mu \mathrm{L}$ aliquot of isopropanol was added, followed by incubation at $21^{\circ} \mathrm{C}$ for $10 \mathrm{~min}$ to precipitate the RNA. Samples were centrifuged at $10,000 \mathrm{rpm}$ for $10 \mathrm{~min}$ at $4^{\circ} \mathrm{C}$ to pellet the RNA; the supernatant was discarded and the RNA pellet was washed with $70 \%$ ethanol and then resuspended in DEPC-treated water. A $30 \mu \mathrm{g}$ aliquot of this total RNA was used for first strand cDNA synthesis using Superscript II reverse transcriptase (Invitrogen) and following the manufacturer's protocol. Primers for the EGFP gene were designed. The forward primer was 5'-GGCCACAAGTTCAGCGTGTC-3' and the reverse was 5'-

TGCCGTCCTCGATGTTGTGG-3'. PCR was conducted as described in Chapter 2. Initial PCR runs were performed with PCR products samples that had gone through 15 to 35 cycles of amplification to make sure that the amplified product used for quantification was in the linear range of the amplification curve.

PCR products were separated on a $1.0 \%$ agarose gel. Bands were visualized with ethidium bromide on a UV box. A product of $\sim 420 \mathrm{bp}$ corresponding to EGFP was obtained. Band intensities in euthermic and hibernating samples at each time point were determined. A standard curve of band intensity versus ng of DNA was constructed from a low mass DNA ladder (Invitrogen) loaded on the same gel as the sample and used to determine the ng DNA produced at each time point. Data were plotted (ng DNA vs time), 
the initial rates were calculated for euthermic and hibernating samples (ng DNA produced per minute per $\mu \mathrm{g}$ of nuclear protein, and mean rate $\pm S E M$ was determined for $\mathrm{n}=3$ individual trials on separate nuclear extracts. The ratio of hibernating to euthermic initial rates was determined.

\section{Histone deacetylase assay}

Histone deacetylase (HDAC) was assayed using the HDAC assay kit from Cayman Chemicals (Ann Harbor, USA), according to manufacturer's instructions. Briefly, $\sim 100 \mathrm{mg}$ of muscle was homogenized in $50 \mathrm{mM}$ Tris buffer, $\mathrm{pH} 7.4$, followed by centrifugation at $10,000 \mathrm{~g}$ for $10 \mathrm{~min}$ at $4^{\circ} \mathrm{C}$ and collection of the supernatant. A $15 \mu \mathrm{L}$ aliquot of sample was added to $10 \mu \mathrm{L}$ of HDAC assay buffer and equilibrated at room temperature for 10 minutes before addition of $15 \mu \mathrm{L}$ of HDAC assay substrate and incubation for $1 \mathrm{~h}$ at $30^{\circ} \mathrm{C}$. Then $20 \mu \mathrm{L}$ of the diluted activator solution was added and the mixture was incubated at room temperature for $10 \mathrm{~min}$. Fluorescence of samples was then measured in a microplate reader (excitation $=350-380 \mathrm{~nm}$, emission $=440-460 \mathrm{~nm})$. Data are reported as means \pm SEM for $n=3$ independent trials using separate preparations. Significant differences between euthermic and hibernating groups were tested using the Student's t-test.

\section{RESULTS}

\section{Histone deacetylase protein levels}

HDAC protein was assessed via Western blotting in skeletal muscle from euthermic and hibernating $S$. tridecemlineatus using polyclonal antibodies recognizing HDAC1 and HDAC4, a class I and class II HDACs, respectively (Figure 3.1). Each 
antibody crossreacted with a single protein band on the blot at $62 \mathrm{kDa}$ and $140 \mathrm{kDa}$, respectively, the known molecular weights of these two isozymes. The histogram in Figure 3.1B shows the ratio of HDAC1 and HDAC4 protein levels in hibernating versus euthermic muscle. The amounts of HDAC1 and HDAC4 protein were significantly higher in muscle from hibernating squirrels; levels were 1.21-and 1.48-fold higher, respectively, compared with euthermic controls $(\mathrm{P}<0.05)$.

\section{Histone deacetylase activity in 13-lined ground squirrel muscle}

Histone deacetylase (HDAC) activity has been associated with the silencing of genes ( $\mathrm{Ng}$ and Bird, 2000). Total HDAC activity was assayed using a kit from Cayman Chemicals following the manufacturer's protocol. Mean HDAC activity in muscle from euthermic ground squirrels was $31,878 \pm 2135$ relative fluorescence units per gram fresh weight (RFU/gfw) and significantly higher, 57,972 $\pm 7471 \mathrm{RFU} / \mathrm{gfw}$, in hibernating squirrels, a 1.82-fold increase (data are mean $\pm S E M, n=3 ; P<0.05$ ).

\section{Histone $\mathbf{H 3}$ protein levels in S. tridecemlineatus muscle}

Histone $\mathrm{H} 3$ also seems to play a role in the silencing of genes. Polyclonal antibodies for total histone $\mathrm{H} 3$, phosphorylated histone $\mathrm{H} 3$ (Ser 10), and acetylated histone $\mathrm{H} 3$ (Lys 23) were used to quantify histone $\mathrm{H} 3$ expression during hibernation (Figure 3.2). Total histone $\mathrm{H} 3$ protein did not change in muscle of hibernating animals

compared with euthermic samples. However, both the amount of phosphorylated histone $\mathrm{H} 3$ and the amount of acetylated protein decreased significantly in muscle during hibernation to values that were $61 \%$ and $62 \%$ of the comparable values in euthermic muscle $(\mathrm{P}<0.05)$.

\section{RNA Polymerase II protein expression in $S$. tridecemlineatus}


RNA polymerase II protein levels were measured in ground squirrel muscle. Both total protein and the amount of phosphorylated RNA polymerase II were measured using Western blotting (Figure 3.3). Figure 3.3B shows the ratio of RNA polymerase protein levels in muscle from hibernating versus euthermic animals. Total protein content of RNA polymerase II remained unchanged during hibernation whereas, interestingly, the amount of phosphorylated enzyme (phospho-Ser 5 in the heptapeptide repeat YSPTSPS in the C-terminal domain) increased significantly by 1.79 -fold $(\mathrm{P}<$ $0.05)$ in torpid animals.

\section{RNA Polymerase II activity in S. tridecemlineatus}

RNA polymerase II activity was measured by its ability to transcribe the EGFP gene with the mRNA product which was then amplified by PCR before visualization on ethidium bromide stained agarose gels. The purpose of this assay was to compare the state of RNA polymerase II activity in euthermic and hibernating muscle samples and $37^{\circ} \mathrm{C}$ was chosen as the standard temperature at which all the assays would be conducted. Typical assay results are shown in Figure 3.4. Initial trials used a series of incubation times $\left(1,5,10,25\right.$ and $45 \mathrm{~min}$ at $\left.37^{\circ} \mathrm{C}\right)$ but Figure $3.4 \mathrm{~b}$ shows that DNA production reached a plateau after $5 \mathrm{~min}$ and a $5 \mathrm{~min}$ incubation was used in all subsequent analyses and for calculations of enzyme activity. Calculated RNA polymerase II activity in nuclear extracts from euthermic muscle was $0.63 \pm 0.03 \mathrm{ng}$ DNA produced $/ \mathrm{min} / \mu \mathrm{g}$ nuclear protein. The value in muscle from hibernating squirrels was significantly lower, $0.36 \pm$ $0.01 \mathrm{ng}$ DNA produced $/ \mathrm{min} / \mu \mathrm{g}$ nuclear protein, or $57 \%$ of the euthermic value (data are mean $\pm \mathrm{SEM}, \mathrm{n}=3 ; \mathrm{P}<0.05)$. 


\section{DISCUSSION}

While many recent studies have shown that the rates of protein translation are strongly suppressed during hibernation, much less is known about transcription during torpor. Selected genes are clearly up-regulated (as is the synthesis of selected proteins) (Storey, 2003; Storey and Storey, 2004) and several studies indicate that the overall rate of transcription is reduced in torpor (Bocharova et al., 1992; van Breukelen and Martin, 2002; Osborne et al., 2004). However, the mechanisms of transcriptional control in hibernation have not previously been explored. The data in this chapter provide the first exploration of transcriptional regulation in hibernating $S$. tridecemlineatus and identify several mechanisms that could contribute to global transcriptional suppression in torpor.

Histone acetylation has been linked with transcriptionally active chromatin (Hebbes et al., 1988). The principle behind this is that acetylation of histones can make chromatin more accessible to the transcriptional machinery (Lee et al., 1993) due to modification of nucleosomal conformation (Norton et al., 1989). Phosphorylation of histone $\mathrm{H} 3$ at serine residue 10 has also been linked with transcriptional activation (Cheung et al., 2000). Examination of both of these modifications of histone $\mathrm{H} 3$ in ground squirrel muscle are consistent with a state of reduced transcriptional activity in the torpid state. Hence, although histone $\mathrm{H} 3$ total protein levels remained constant between euthermic and hibernating states, both the amount of phosphorylated histone $\mathrm{H} 3$ (Ser 10) and the amount of acetylated histone H3 (Lys 23) were reduced by $38-39 \%$ in hibernation as compared with euthermia. These findings suggest that at least two forms of posttranslational modification contribute to regulating histones during hibernation and 
that the actions of both of these mechanisms on histone $\mathrm{H} 3$ are consistent with an overall decrease in transcriptional activity in skeletal muscle during hibernation. Histones $\mathrm{H} 2 \mathrm{~A} / \mathrm{H} 2 \mathrm{~B}$ and $\mathrm{H} 4$ are also subject to acetylation that regulates their activity (O’Neill and Turner, 1995; Puerta et al., 1995) and these may also be modified in a parallel way during hibernation.

To further analyze transcriptional control in hibernation, histone deacetylase activity and protein levels were measured. Since histone acetylation is associated with active transcription, an increase in histone deacetylase activity would predictably result in a slow down of transcriptional activity. Three major classes of mammalian histone deacetylases are known. Class I consists of HDAC 1, HDAC 2, HDAC 3 and HDAC 8 and these are known to be recruited by DNA binding factors and to act as transcriptional repressors (Knoepfler and Eisenman, 1999). Class II histone deacetylases consist of HDAC 4, HDAC 5, HDAC 6 and HDAC 7 and function as transcriptional corepressors (Bertos et al., 2001). A third class of HDAC consists of enzymes that are analogous to the yeast Sir2 protein which is also involved in transcriptional silencing (Imai et al., 2000). Total HDAC activity was 1.82-fold higher in skeletal muscle of hibernating squirrels versus euthermic controls. Furthermore, both HDAC 1 and HDAC 4 protein levels were elevated in hibernation (by 1.21- and 1.48-fold, respectively); other Class I and class II HDACs may similarly increase in torpor. Both the increase in HDAC activity and in HDAC protein levels point to a regulated reduction in transcriptional activity in muscle of thirteen-lined ground squirrels during hibernation.

RNA polymerase II activity was also measured in muscle of euthermic and hibernating ground squirrels. Previous data gathered from nuclear run-on assays in 
golden-mantled ground squirrels or from rates of ${ }^{3} \mathrm{H}$-uridine incorporation into RNA in hamsters indicated that the overall rate of transcription was reduced in organs of torpid animals (Bocharova et al., 1992; van Breukelen and Martin, 2002; Osborne et al., 2004). Direct analysis of RNA polymerase II in the present study showed a substantial reduction in enzyme activity in muscle from torpid animals; the activity in nuclear extracts from hibernator muscle was only $57 \%$ of the value in euthermic muscle. Note that these values are for polymerase activity measured in $37^{\circ} \mathrm{C}$ incubations; polymerase activity in vivo during hibernation would be very much lower due to the effects of a body temperature that could be as much as $35^{\circ} \mathrm{C}$ lower than euthermic values. The present data showing a change in polymerase activity between the euthermic and torpid states (when measured at a constant assay temperature) is consistent with transcriptional repression during hibernation by stable molecular modification(s). Total polymerase protein did not change in hibernation so this argues that the change in activity is the result of a modification of the enzyme protein. RNA polymerase II is known to be covalently modified by phosphorylation at Ser 2 and Ser 5 of a peptide sequence (YSPTSPS) that is repeated multiple times in the $\mathrm{C}$ terminal domain (CTD) and phosphorylation at these sites has been linked with transcriptional control. The Pol II H14 Ab used in the present study recognizes enzyme that is phosphorylated on the $5^{\text {th }}$ serine residue in this sequence. The data show that the amount of phosphorylated (Ser5) RNA polymerase II protein rose by 1.79-fold during hibernation suggesting that transcriptional control during hibernation may also be applied by modifying the phosphorylation state of RNA polymerase II. This specific form of RNA polymerase II is interesting. It was initially thought that the phosphorylated form of the enzyme was associated with active transcription (Kranias and 
Jungmann, 1978); if this were so, the change in phosphorylation state measured in hibernation would contradict our other findings. However, subsequent studies have monitored RNA polymerase II phosphorylation states at both transcriptionally active and inactive stages of the cell cycle and showed that hyperphosphorylation of the RNA polymerase II CTD could not be used as an indicator of transcriptional activity (Kim et al., 1997). While it seems that a hyperphosphorylated CTD correlates with polymerase being located at the transcription initiation position of genes, phosphorylation of Ser 2 and Ser 5 is not a prerequisite for transcription. In fact, it has been shown that inhibiting the kinases responsible for phosphorylating the CTD did not lead to transcription inhibition (Serizawa et al., 1993) and that CTD-less RNA polymerase II can still transcribe genes (Buratowski and Sharp, 1990). The increase in phosphorylated RNA polymerase content measured here may just mean that RNA polymerase II in hibernating muscle is positioned at the initiation position, waiting to transcribe selected genes, but without necessarily being transcriptionally active.

Overall, then, the results presented in this chapter point towards a decrease in transcriptional activity in skeletal muscle of hibernating S. tridecemlineatus. This supports the idea that metabolic rate depression during hibernation involves a coordinated and regulated suppression of the rates of multiple energy-expensive cellular activities including the overall rate of gene transcription. 
Figure 3.1

A.

Euthermic Hibernating Euthermic Hibernating
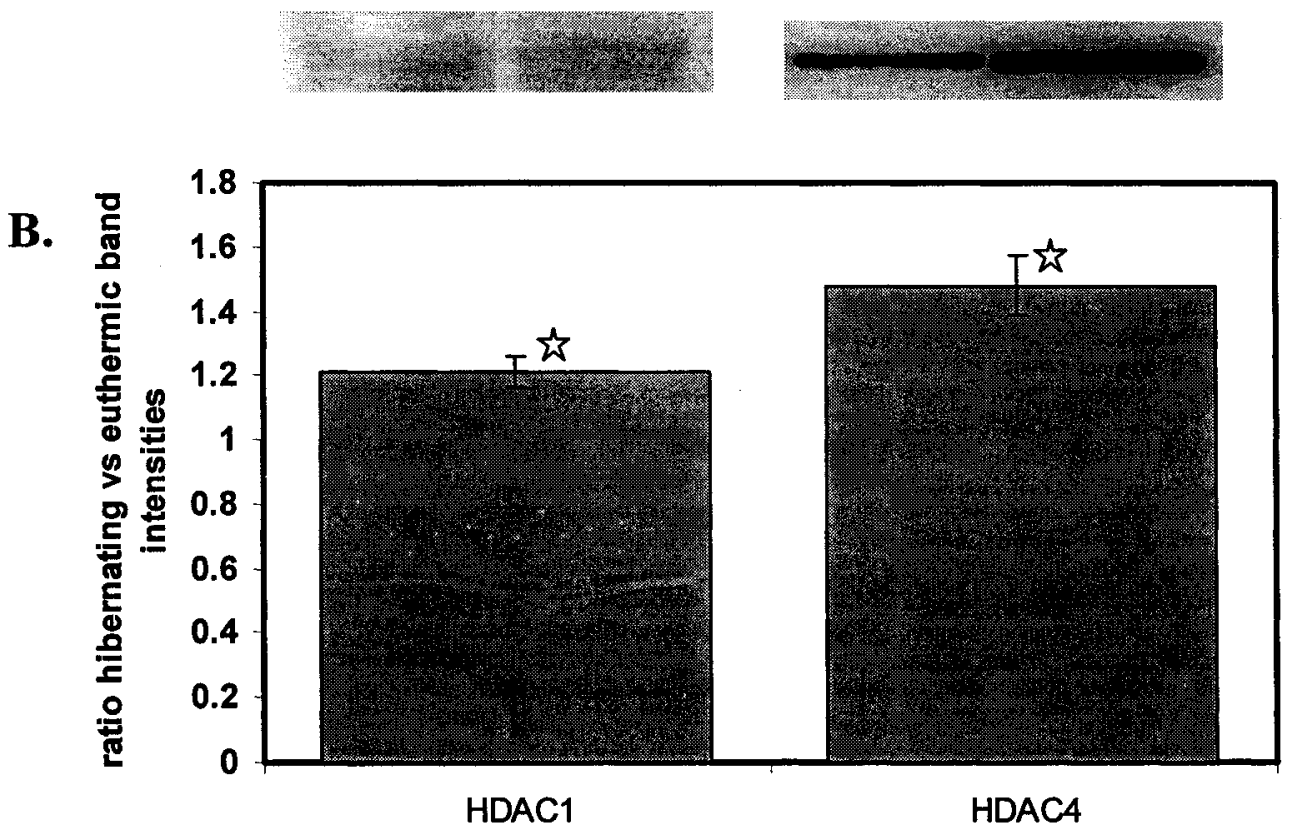
Figure 3.2

A.

Euthermic

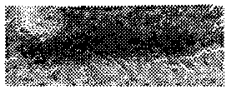

Total H3

Phospho-H3 (Ser10)

Acetyl-H3 (Lys23)
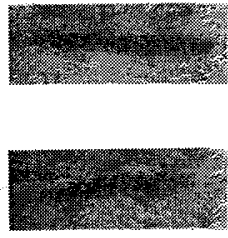

\section{Hibernating}
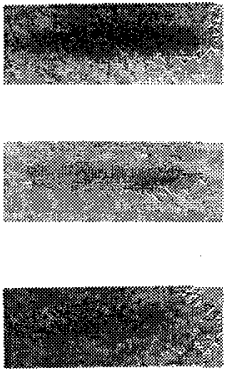

B.

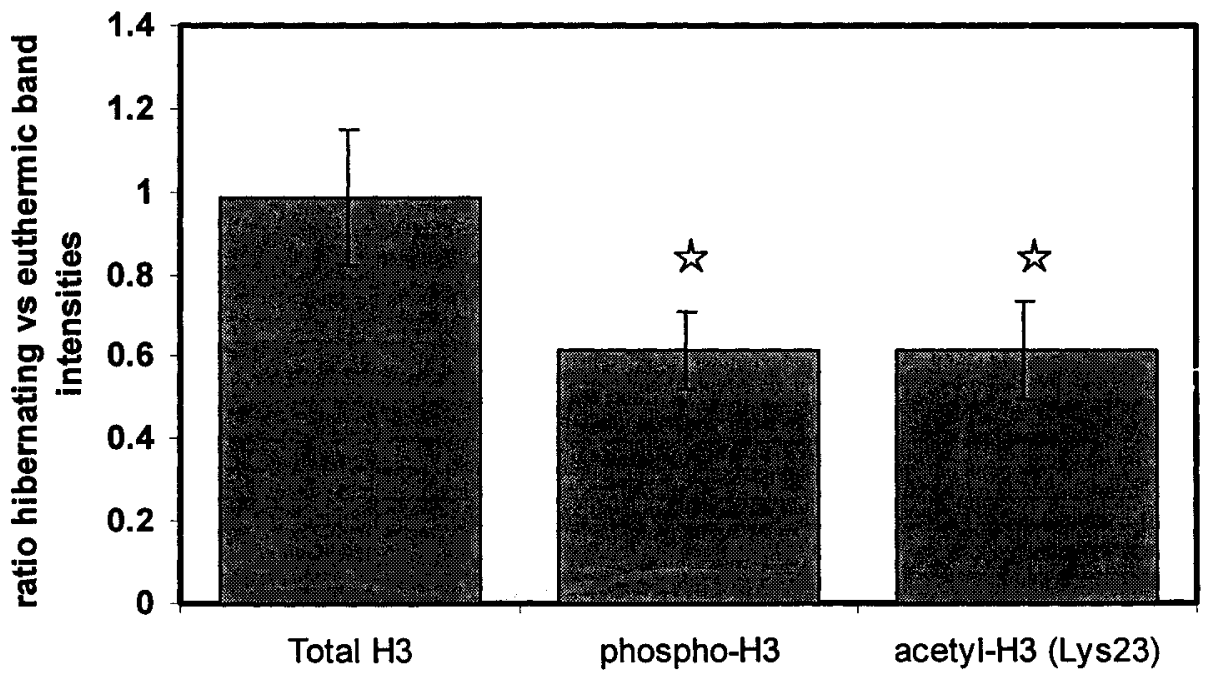


Figure 3.3

A.

Euthermic Hibernating Euthermic Hibernating
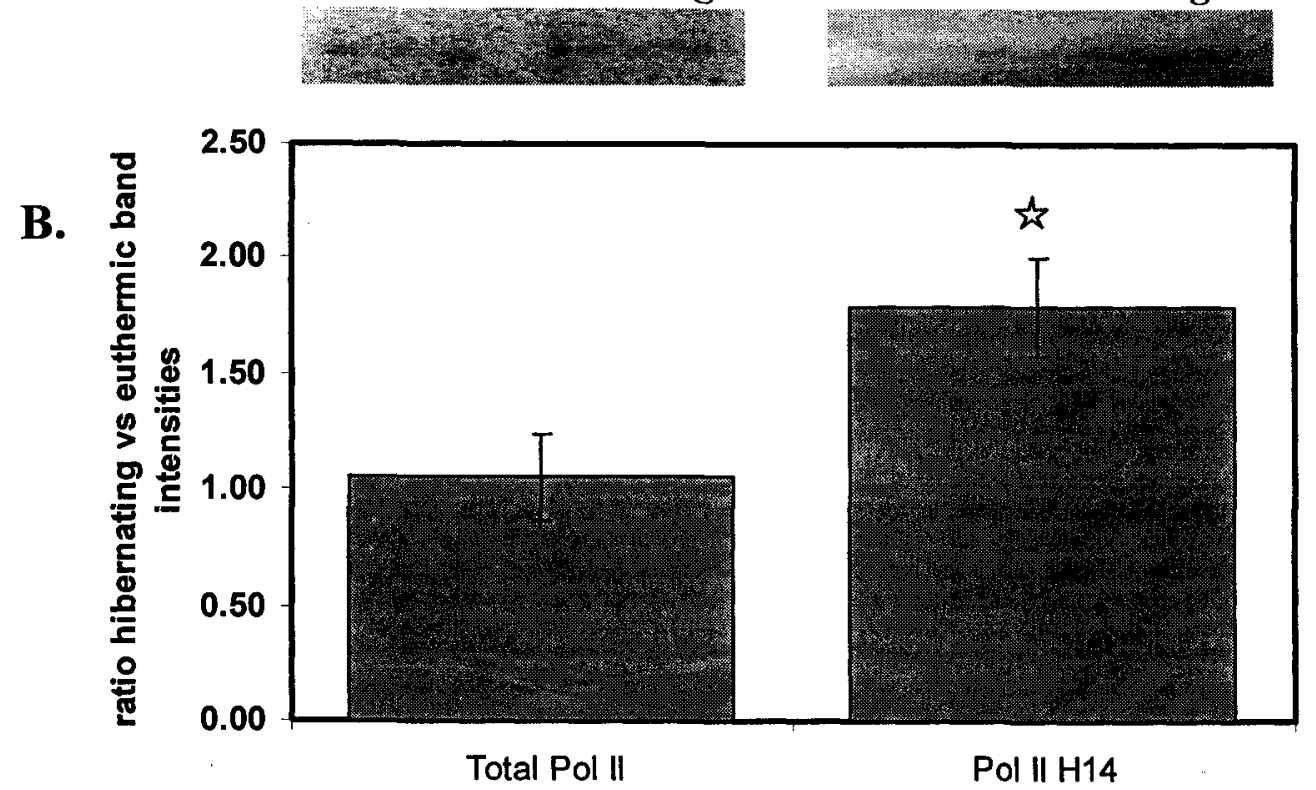
Figure 3.4

Time

$1 \mathrm{~min}$

$5 \mathrm{~min}$

$10 \mathrm{~min}$

Euthermic

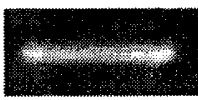

(1)

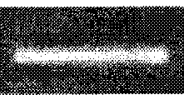

Hibernating
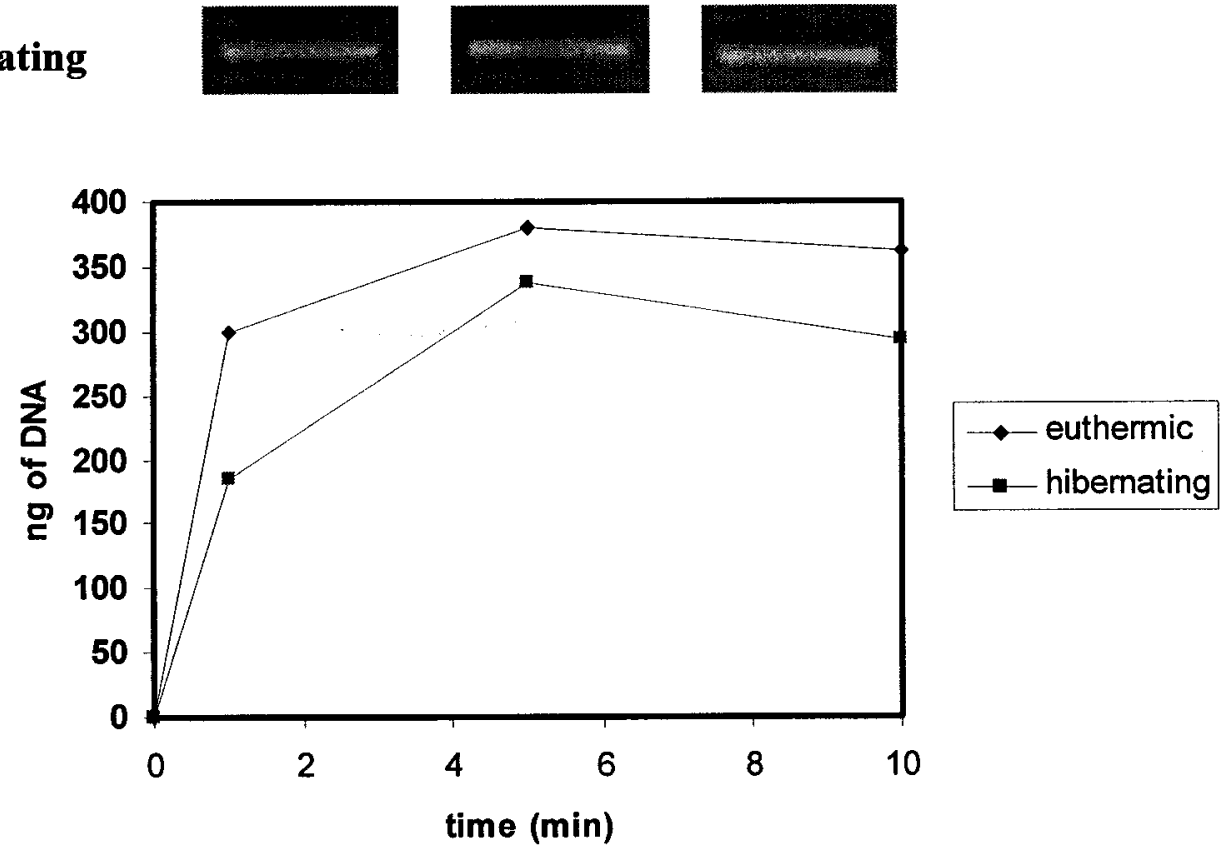


\section{Chapter 4 \\ Expression of Nrf2 and downstream targets in ground squirrel heart}




\section{INTRODUCTION}

Hibernating mammals show a strong reduction of heart rate and blood flow during torpor bouts that can last for weeks. These conditions would be considered severely ischemic for non-hibernating mammals. During arousal from torpor, hibernators rewarm their bodies very rapidly, a situation that leads to a sudden increase in oxygen levels and oxygen consumption by tissues. Thus, the torpor-arousal cycle has multiple features of an ischemia-reperfusion cycle which is well-known to lead to oxidative stress in other systems (e.g. human heart attack or stroke). Another factor that can contribute to the generation of reactive oxygen species (ROS) in the hibernator is the altered composition of lipid reserves that is necessary to maintain lipid fluidity at low body temperatures. For hibernation to be optimal, lipid depots must be high in polyunsaturated fatty acids (PUFAs) such as linoleic acid (Frank, 1992) but PUFAs are highly susceptible to free radical attack leading to autoxidation and the generation of lipid peroxide radicals (Gunstone, 1996). Hence due to multiple factors that increase susceptibility to ROS damage during the hibernating season, mammalian hibernators must set up efficient antioxidant defenses that will efficiently deal with wide variations in ROS generation over torpor-arousal cycles.

Regulation of antioxidant defenses is under the control of specific transcription factors that alter the expression of antioxidant genes in response to various stimuli on cells. One of the most prominent signal transduction pathway involved in regulating antioxidant enzymes is the Nrf2/ARE pathway. Nrf2, the NF-E2-related factor-2, is a basic leucine zipper transcription factor that can bind to a cytoplasmic repressor, Keap1, or to different nuclear binding partners. Generally, $\mathrm{Nrf} 2$ is attached to Keap 1 and 
sequestered in the cytoplasm where it is unable to stimulate transcriptional actions.

Furthermore, it was recently shown that Nrf2 can be degraded by proteasomes via interaction with Keap1 (Stewart et al., 2003). However, under oxidative stress conditions, Nrf2 is released from Keap 1 and translocates into the nucleus (Itoh et al., 1999). Once inside the nucleus, Nrf2 has been shown to dimerize with proteins such as the small Mafs, Jun and activating transcription factor-4 (ATF-4) which are all basic leucine zipper proteins (Itoh et al., 1997; Venugopal et al., 1996; He et al., 2001). It then binds to the antioxidant response element (ARE) that is present in the promoter regions of genes that are known to respond to oxidative stress such as thioredoxin and GSTs (Chanas et al., 2002; Kim et al., 2001b).

$\mathrm{Cu} / \mathrm{Zn}$ superoxide dismutase $(\mathrm{Cu} / \mathrm{Zn} \mathrm{SOD})$ and heme oxygenase-1 (HO-1) are two enzymes that have been linked to the Nrf2 pathway. HO- 1 is an inducible enzyme that is involved in heme degradation and the subsequent production of biliverdin, a known antioxidant (Tenhunen et al., 1968). This enzyme has been shown to be activated under many conditions that lead to ROS generation such as anoxia, hypoxia and ischemia (Lee et al., 1997; Semenza, 2000). HO-1 is activated by transcription factors involved in mediating responses to changes in oxygen such as HIF-1 and Nrf2 (Alam et al., 1999; Lee et al., 1997). Cu/Zn SOD is an enzyme that catalyzes the breakdown of harmful superoxide into hydrogen peroxide and water. It is involved in regulation of ROS generation and the $\mathrm{Cu} / \mathrm{Zn} \mathrm{SOD}$ gene has been shown to be up-regulated in response to oxidative stress. Furthermore, $\mathrm{Cu} / \mathrm{Zn}$ SOD promoter region analysis has lead to the discovery of an ARE that Nrf2 could bind to in order to activate its gene transcription (Park et al., 2002). It has also been shown that $\mathrm{Cu} / \mathrm{Zn}$ SOD can help to reduce cellular 
injury following reperfusion of tissues that were previously ischemic (Wang et al., 1998). Besides these two enzymes, the enzyme aflatoxin aldehyde reductase, AFAR1, is an aldo-keto reductase that is involved in the detoxification of various aldehydes and ketones including the environmental carcinogen aflatoxin $B_{1}$ (Ellis et al., 1995). A recent study has shown that the enzyme contains multiple AREs in its promoter region (Ellis $e t$ al., 2003). Preliminary work in our $\mathrm{lab}(\mathrm{Ni}, 2004)$ has also shown that Nrf2 and HO-1 were elevated in tissue samples from ground squirrels that had been hibernating for more than 3 days.

The potentially harmful oxidative stress conditions that hibernators may experience over the course of torpor-arousal cycles lead me to hypothesize that the Nrf2 pathway, well-known to be involved in ROS detoxification in mammals, should play a role in providing the hibernator with the necessary antioxidant defenses required to deal with hibernation-related oxidative stress. This could potentially be done by an increase in levels of the transcription factor $\mathrm{Nr} 2$ and an associated increase in the downstream gene products that are under Nrf2 control such as $\mathrm{Cu} / \mathrm{Zn}$ SOD and HO-1. The results presented in this chapter substantiate this hypothesis: Nrf2 gene and protein expression in ground squirrel heart were elevated throughout the hibernating cycle and this correlated with a significant increase in the expression of downstream antioxidant enzymes that are known targets of Nrf2.

\section{MATERIALS AND METHODS}

\section{Animals}

Initial trials to characterize organ-specific expression of $n r f 2$ were done 
comparing control vs hibernating animals as described in Chapter 2. Subsequent studies monitored changes in the protein levels of $\mathrm{Nrf} 2$ and associated proteins under $\mathrm{Nrf} 2$ control using tissues from ground squirrels sampled over a detailed time course of torpor and arousal. Pre-hibernation treatment of these squirrels was the same as described in Chapter 2 but animals were sampled at the following time points: (1) active in the $4^{\circ} \mathrm{C}$ cold room (ACR) euthermic squirrels that had not yet entered a torpor bout after 3 days in the cold as determined from body temperature readings, (2) early entrance into torpor with falling $\mathrm{Tb}$, (3) early in the stable torpid state $(<24 \mathrm{~h})$ with a stable $\mathrm{Tb}$ at $\sim 5-7^{\circ} \mathrm{C},(4)$ later in the stable torpid state (at least $3 \mathrm{~d}$ ) with $\mathrm{Tb}$ at $\sim 5-7^{\circ} \mathrm{C},(5)$ early in arousal with rising $\mathrm{Tb}$, and (6) fully aroused in interbout with $\mathrm{Tb}$ back at $37^{\circ} \mathrm{C}$ for at least $18 \mathrm{~h}$ before sampling (after at least $3 \mathrm{~d}$ in continuous torpor). All animals were sacrificed by decapitation and tissues were excised, frozen immediately in liquid nitrogen and then transported to Ottawa on dry ice where they were then placed at $-80^{\circ} \mathrm{C}$ until use.

\section{cDNA synthesis and PCR amplification of Nrf2.}

Total RNA isolation and assessment of its quality were conducted as described in Chapter 2. The amplification of $n r f z$ via PCR was performed as in Chapter 2 using the following primers: the forward primer was 5'- TCCCAGGTTGCCCACAT - 3' and the reverse primer was 5'- AATGCCRGAGTCAGARTC - 3'. A nrf2 fragment of 717 bp was found and sequenced by Canadian Molecular Research Services (Ottawa, ON). The sequence was confirmed as encoding Nrf2 by sequence comparison in BLAST.

\section{Western blotting}

Western blotting was performed as described in Chapter 2. An antibody specific to Nrf2 was purchased from Santa Cruz Biotechnologies. Antibodies specific to $\mathrm{Cu} / \mathrm{Zn}$ 
SOD and to HO-1 were purchased from Stressgen. AFAR1 antibody was a gift from Dr. John D. Hayes, University of Dundee, Scotland.

\section{RESULTS}

\section{cDNA cloning of Nrf2}

Using RT-PCR and primers derived from the consensus sequence of $n r f 2$ from other mammalian species, a PCR product of $717 \mathrm{bp}$ was retrieved from total RNA prepared from heart of hibernating $S$. tridecemlineatus. The nucleotide and deduced amino acid sequences are shown in Figure 4.1. The product was confirmed as encoding a portion of the $n r f 2$ sequence and the sequence was submitted to GenBank with accession number DQ328859. Figure 4.2 shows the translated amino acid partial sequence of ground squirrel Nrf2 aligned with the sequences for the human, mouse and rat protein. The full Nrf2 sequence has 605 residues in humans and 597 residues in mice and rats whereas the amplified portion of $S$. tridecemlineatus $\mathrm{Nrf} 2$ encoded 239 amino acids residues, corresponding to approximately $40 \%$ of the full sequence. Figure 4.3 shows that ground squirrel Nrf2 is quite similar to Nrf2 from other mammals. The homology tree and homology matrix show that the ground squirrel Nrf2 amino acid sequence shares $87.9 \%, 77.4 \%$ and $78.3 \%$ identity to human, mouse and rat $\mathrm{Nrf} 2$ over the amplified region, respectively. Ground squirrel Nrf2 contained a few unique amino acid substitutions that were not seen in non-hibernating mammals; these are shown in bold underline in Figure 4.2. These included substitutions of two proline residues at positions 111 and 230 of the human sequence. One asparagine residue was substituted for a tyrosine residue at position 226 and one tyrosine residue was substituted for a histidine 
residue at position 227.

\section{Nrf2 gene expression in S. tridecemlineatus}

Levels of $n r f 2$ mRNA transcripts were measured in three tissues of euthermic and hibernating S. tridecemlineatus (BAT, heart and lung). Specific primers for $n r f 2$ were designed based on known mammalian $n r f 2$ gene sequences and a partial $n f r 2$ sequence from ground squirrel was amplified using RT-PCR. Figure 4.4 shows the relative levels of $n r f 2$ mRNA expression in each organ. Alpha-tubulin mRNA, a constitutively expressed gene, was also amplified from the same samples and $n f r 2$ transcript levels were normalized against the tubulin transcript level in each sample. Figure 4.4B shows the ratio of normalized $n r f 2$ transcript levels in tissues from hibernating versus euthermic animals. Levels changed significantly only in heart, with a 1.6-fold increase in transcript levels during hibernation.

\section{Nrf2 protein levels in S. tridecemlineatus}

Nrf2 protein expression was measured at 6 different points over the course of the hibernation cycle: (1) active in the cold room (ACR) euthermic squirrels that had not yet entered hibernation, (2) early entrance into torpor with falling $\mathrm{Tb}$, (3) early in the torpid state ( $<24 \mathrm{~h}$ ) with a stable $\mathrm{Tb}$ at $\sim 5-7^{\circ} \mathrm{C}$, (4) later in the stable torpid state (at least $3 \mathrm{~d}$ ) with $\mathrm{Tb}$ at $\sim 5-7^{\circ} \mathrm{C}$, (5) early in arousal with rising $\mathrm{Tb}$, and (6) fully aroused in interbout with $\mathrm{Tb}$ back at $37^{\circ} \mathrm{C}$ (Figure 4.5). Nrf2 protein content in ground squirrels entering hibernation rose to levels that were 1.4-fold higher than the values in ACR controls. Levels remained high throughout torpor and arousal but declined back to control levels in fully aroused animals.

\section{$\mathrm{Cu} / \mathrm{Zn}$ SOD protein levels in S. tridecemlineatus}


$\mathrm{Cu} / \mathrm{Zn}$ SOD protein levels were measured over the same time course as for $\mathrm{Nrf} 2$ (Figure 4.6). Cu/Zn SOD protein levels rose significantly during entrance into torpor and peaked during early hibernation with a 1.6-fold increase over the ACR control value $(\mathrm{P}<$ 0.05). $\mathrm{Cu} / \mathrm{Zn}$ SOD protein levels declined during longer term hibernation and after full arousal were reduced to a mean value that was $30 \%$ lower than control.

\section{AFAR1 protein levels in $S$. tridecemlineatus}

Figure 4.7 shows AFAR1 protein levels over the hibernation time course. Levels rose significantly during entrance into torpor (1.5-fold higher than in ACR controls) and remained high in early hibernation. AFAR1 protein levels then gradually decreased and were not significantly different from controls when the animals were fully aroused.

\section{Heme Oxygenase-1 protein levels in S. tridecemlineatus}

HO-1 protein levels also changed over the hibernation cycle. Levels in the early stable torpid state were 1.3-fold higher than ACR control samples $(\mathrm{P}<0.05)$ (Figure 4.8). Subsequently, HO-1 protein content declined at later time points.

\section{DISCUSSION}

Direct evidence that oxidative stress occurs during hibernation has been produced from studies with intestine of 13-lined ground squirrels (Carey et al., 2000). Studies with black bears have also highlighted increases in a marker for lipid peroxidation during hibernation (Chauhan et al., 2002). Indirect evidence of oxidative stress comes from analysis of antioxidant defense mechanisms in hibernators which has shown specific activation of selected antioxidant enzymes such as glutathione peroxidase in the ground squirrel Citellus citellus liver and BAT (Buzadzic et al., 1990) as well as elevation of low 
molecular weight antioxidants (e.g. ascorbate). Plasma ascorbate levels build up by 3-5 fold during each torpor bout and are then rapidly depleted during arousal, the highest rate of decrease correlating with the time when oxygen consumption is maximal (Drew et al., 2002). Microanalysis of tissue and extracellular fluid in brain of hamsters also showed depletion of ascorbate during arousal, consistent with oxidative stress in this stage of the hibernation cycle (Osborne and Hashimoto, 2006).

Clearly, then, hibernators need well-developed antioxidant defenses and this includes increased expression of the genes coding for various antioxidant enzymes. One way to stimulate the antioxidant response is through activation of transcription factors that regulate these genes and this chapter looked at the expression of the transcription factor Nrf2. Many studies have shown the importance of this transcription factor in protecting cells against oxidative stress. For example, studies using Nrf2 knockout mice showed that expression of several detoxification enzymes is strongly reduced in the knockout strain (Chan and Kan, 1999). Similar mice submitted to hyperoxic stress were shown to have considerably reduced amounts of antioxidant enzymes such as NAD(P)H:quinone oxidoreductase 1 (NQO1) and HO-1 to deal with the resulting ROS produced (Cho et al., 2002). Hence, Nrf2 and its downstream enzymes are good indicators of the oxidative stress status of hibernator tissues.

The Nrf2 transcription factor from ground squirrel heart was partially cloned in the $\mathrm{N}$-terminal region of the protein. The amplified fragment was 239 amino acids long and started at position 103 of the human Nrf2 sequence. Several amino acids substitutions were identified when the ground squirrel partial Nrf2 sequence was compared to Nrf2 sequences from non-hibernating mammals. It has been previously 
reported that Nrf2 can be phosphorylated by PKC at serine 40 and that this could lead to its detachment from Keap1 in the cytoplasm and potentially facilitate its nuclear translocation (Huang et al., 2000; Huang et al., 2002). Unfortunately, the amplified ground squirrel Nrf2 fragment did not include that particular serine residue so it was impossible to tell if this amino acid was different in the hibernator. Nonetheless, the Nrf2 segment that was retrieved did contain two key domains, Neh4 (within residues 98-156) and Neh5 (within residues 153-227), which have both been shown to act synergistically to allow Nrf2 transactivation through CREB binding (Katoh et al., 2001). Deletion of these domains leads to a severe disruption in Nrf2 transactivation activity. It has also been demonstrated that phosphorylation of residues within these domains by mitogenactivated kinase family members, ERK and/or JNK, leads to a positive regulation of Nrf2 transactivational activity (Shen et al., 2004). Only a few minor modifications were seen in the Neh4 and Neh5 domains of the ground squirrel suggesting that the transactivational process is largely conserved in the hibernator. Two changes of interest occurred near these regions; the substitutions of two proline residues for a serine or arginine residue at position 111 and for a serine residue at position 230 . These modifications, along with the other substitutions that were not exclusive to the ground squirrel, could result in a conformational change to the hibernator $\mathrm{Nrf} 2$ protein that might aid its transcriptional activity at low body temperatures.

Levels of $n r f 2$ mRNA transcripts were measured in different ground squirrel tissues using RT-PCR. Of the three tissues analyzed, $n r f 2$ transcript levels were significantly elevated only in hibernating heart (by 1.6-fold) whereas amounts in other tissues appeared to be down-regulated. Data presented in the literature have shown 
contradictory results as to whether or not $n r f 2$ transcript levels rise under oxidative stress conditions. While Cho et al. (2002) reported an induction of $n r f 2$ transcripts by 2.0 - and 2.6-fold in lungs of mice subjected to 48 and 72 hours of hyperoxia, a more recent study by Papaiahgari et al. (2004) points toward the contrary. Data gathered here seems to agree with the former group as a $n r f 2$ gene induction was observed.

Western blotting was then performed to determine if the increase in $n r f 2$ mRNA levels correlated with an increase in Nrf2 protein in ground squirrel heart. Nrf2 protein levels were assessed over a cycle of hibernation and showed a significant increase in the level of this transcription factor over all heterothermic portions of the time-course: entry into torpor, early and late torpor, and arousing from torpor. $\mathrm{Nrf2}$ protein levels increased by 1.4 -fold over controls as the animal's body temperature started to drop and remained elevated until the animal was completely aroused. Reports have suggested that Nrf2 protein levels increase under oxidative stress (Pi et al., 2003; Qiang et al., 2004). Hence, the general elevation of $\mathrm{Nrf} 2$ protein over the torpor portions of the hibernation cycle suggests that hibernator heart is trying to increase its antioxidant defenses via the Nrf2 regulatory pathway throughout the stress period.

Based on these results, it was reasonable to think that genes under the control of Nrf2 would also show increased expression over the hibernation cycle. Three enzymes that have ARE binding sites in their promoter regions were chosen for study: $\mathrm{Cu} / \mathrm{Zn}$ SOD, AFAR1 and HO-1. These enzymes all play important roles in the detoxification of either ROS (SOD, HO-1) or aldehydes and ketones (AFAR1) in cells and they could all be used to protect the animal against oxidative stress. Since the Nrf2 transcription factor was elevated at both the mRNA and protein levels over the hibernation time-course, 
protein levels of these enzymes were measured over the same cycle to see if they correlated with the measured Nrf2 levels. In all three cases, Western blotting showed that the protein content of these enzymes was significantly increased at the early hibernation time point (ie. $<24 \mathrm{~h}$ in full torpor with $\mathrm{Tb} \sim 5-7^{\circ} \mathrm{C}$ ). In the case of $\mathrm{Cu} / \mathrm{Zn}$ SOD and AFAR1, protein levels had already increased significantly as the animals were entering torpor which suggests that induction of the synthesis of these AOE proteins is triggered as one of the first events when animals begin to suppress metabolic rate. This highlights the possibility that the hibernator increases antioxidant defenses as an anticipatory response in order to deal with the oxidative stress that is sure follow either over prolonged torpor or during arousal. Furthermore, the levels of the Nrf2 transcription factor probably remained elevated in case the synthesis of more of these antioxidant enzymes was required. It is important to point out that none of these proteins were upregulated at the early arousal time point when the animal's body temperature is returning to euthermic values. This is the point at which one would predict that antioxidant defenses would be needed the most and the fact protein levels of these three enzymes did not increase during that time stands out. One explanation might be that their activities are actually higher even if their protein levels are unchanged; further studies to assess regulatory parameters and/or post-translational modifications of the proteins would be necessary to evaluate this possibility. Alternately, it is possible that other Nrf2 gene targets that were not measured in this study could be up-regulated or activated as a result of the continued high Nrf2 levels that are maintained into the early arousal phase.

Overall, these results have highlighted a few amino acid changes in the sequence of ground squirrel Nrf2 that might cause a conformational change in the transcription 
factor and which could affect the function of the transcription factor at low $\mathrm{Tb}$. Nrf2 gene and protein levels were both found to be upregulated in hibernation. In addition, the protein levels of selected Nrf2 gene targets showed a significant increase at the beginning of the time course, as the animal entered hibernation. This further reinforces the idea that hibernators, as a preventative measure, increase their antioxidant defenses at the onset of torpor. 


\section{Figure 4.1}

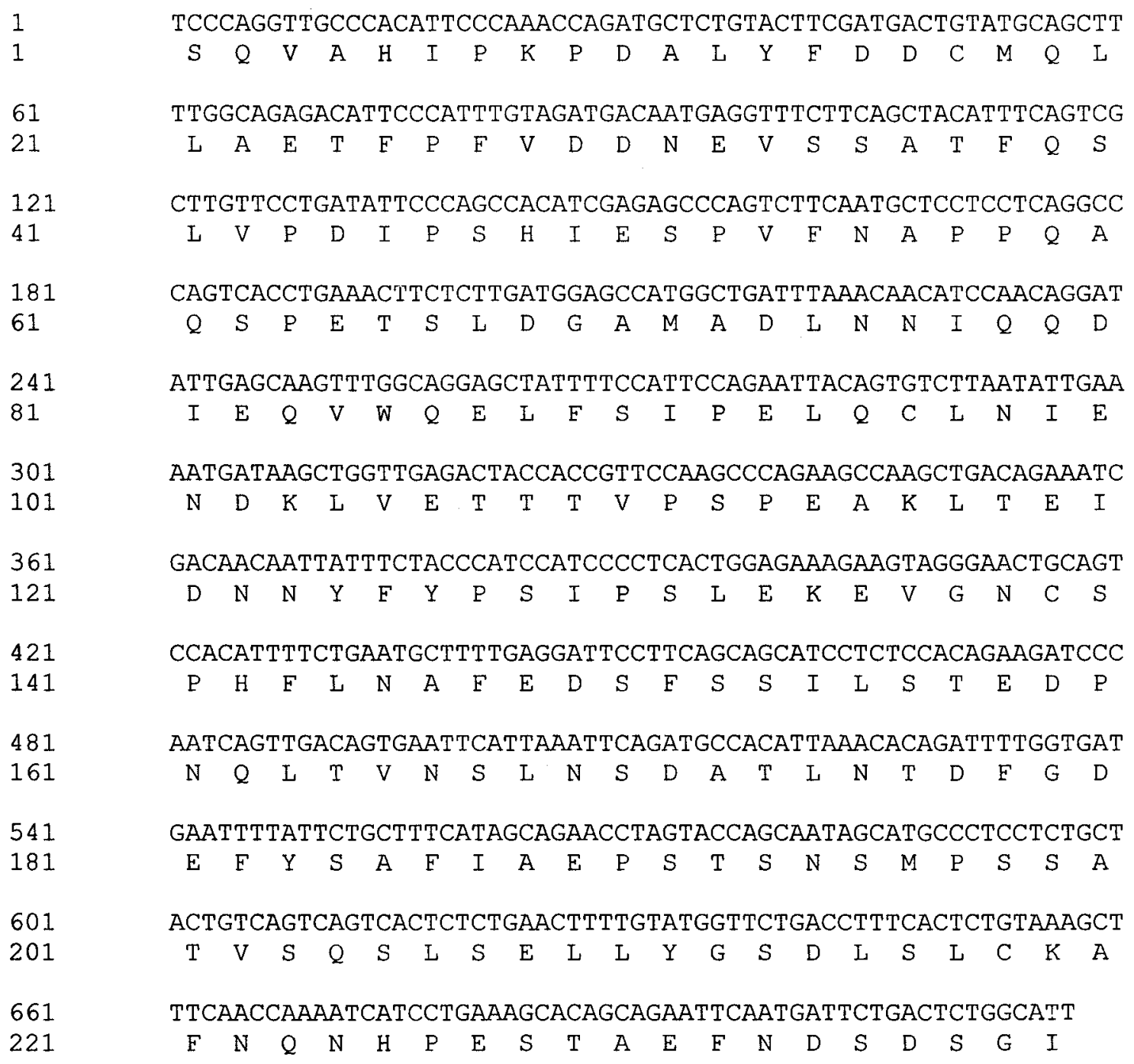




\section{Figure 4.2}

\begin{tabular}{|c|c|c|}
\hline squirrel & . & 0 \\
\hline human & mmdlelpppglpsqqdmdlidilwrqdidlgvsrevfdfs & 40 \\
\hline mouse & mmdlelpppglqsqqdmdlidilwrqdidlgvsrevfdfs & 40 \\
\hline rat & mmdlelpppglqsqqdmdlidilwrqdidlgvsrevfdfs & 40 \\
\hline squirrel & . . & 0 \\
\hline human & qrrkeyelekqkklekerqeqlqkeqekaffaqlqldeet & 80 \\
\hline mouse & qrqkdyelekqkklekerqeqlqkeqekaffaqfqldeet & 80 \\
\hline rat & qrqkdyelekqkklekerqeqlqkeqekaffaqlqldeet & 80 \\
\hline squirrel & $\ldots \ldots \ldots \ldots \ldots \ldots \ldots$ SQVAHIPK $\ldots \ldots D A L Y E D D C M$ & 18 \\
\hline human & geflpiqpaqhiqsetsgsany-n-- & 120 \\
\hline mouse & geflpiqpaqhiqtdtsgsasy------- q-----e--- & 120 \\
\hline rat & geflpiqpaqhiqtdtsgsvsy--------qu-----e--- & 120 \\
\hline squirrel & QLLAETFPFVDDNEVSSATEQSLVPDIPSHIESPVENAPP & 58 \\
\hline human & 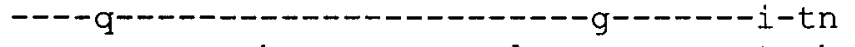 & 160 \\
\hline mouse & $----------h-\ldots \ldots .--a l-----a--s--t--h$ & 153 \\
\hline rat & 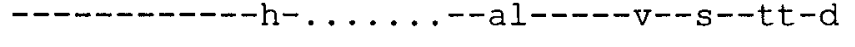 & 153 \\
\hline squirrel & QAQSPETSLDGAMA. DLNNIQQDIEQVWQELFSI PELQCL & 97 \\
\hline human & ------ vaqvapv--dgm-------e- $-1------$ & 200 \\
\hline mouse & $---\ln s--e a--t .--s s-e-m--------\cdots--$ & 192 \\
\hline rat & $----1 \mathrm{~d} s--\mathrm{et}--\mathrm{t} .--\mathrm{ss}----\mathrm{m}---------------$ & 192 \\
\hline squirrel & NIENDKLVETTTVPSPEAKLTEID. NNYEYPSIPSLEKEV & 136 \\
\hline human & $----------m---------v-.-y h--s----m--n$ & 239 \\
\hline mouse & $-t--k q-a d--a-c----t---m-s-y h--s--s------$ & 232 \\
\hline rat & $-\mathrm{t}--\mathrm{kqqa}-\cdots-------\mathrm{t}---\mathrm{m}-\mathrm{s}-\mathrm{yh}--\mathrm{s}----\cdots-\cdots$ & 232 \\
\hline squirrel & GNCSPHFLNAFEDSFSSILSTEDPNQLTVNSLNSDATLNT & 176 \\
\hline human & 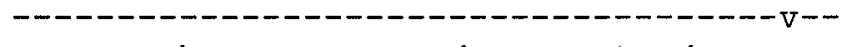 & 279 \\
\hline mouse & $---g----h g----------d-a s--. . t--d-n p----$ & 270 \\
\hline rat & ds ----- hg $-------1--d-a s-\ldots---d-n p----$ & 270 \\
\hline squirrel & DFGDEFYSAFIAEPSTSNSMPSSATVSQSLSELLYG . . . & 212 \\
\hline human & $-----------1-----p--1-h-----n-p i d v$ & 319 \\
\hline mouse & 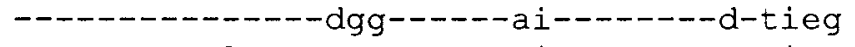 & 310 \\
\hline rat & $---------1----g g g-----a i--n----g-p i e g$ & 310 \\
\hline squirrel & SDLSLCKAFNQNHPESTAEFNDSDSGI $\ldots \ldots \ldots \ldots$ & 239 \\
\hline human & 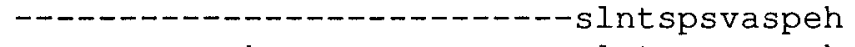 & 359 \\
\hline mouse & c-------- pk-a-g-m--------slntspsraspeh & 350 \\
\hline rat & $\mathrm{c}--------\mathrm{k}-\mathrm{t}-\mathrm{g}-\mathrm{v}--------\sin t \mathrm{sps} r a s p e h$ & 350 \\
\hline squirrel & 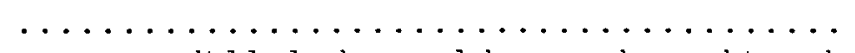 & 239 \\
\hline human & svesssygdtllglsdseveeldsapgsvkqngpktpv.h & 398 \\
\hline mouse & svessiygdpppgfsdsemeeldsapgsvkqngpkaqpah & 390 \\
\hline rat & svessiygdpppgfsdsemeeldsapgsvkqngpkaqpth & 390 \\
\hline squirrel & $\cdots \cdots \cdots \cdots \cdots \cdots \cdots \cdots \cdots \cdots \cdots \cdots \cdots \cdots$ & 239 \\
\hline human & ssgdmvqplspsqgqsthvhdaqcentpekelpvspghrk & 438 \\
\hline mouse & spgdtvqplspaqghsapmresqcenttkkevpvspghqk & 430 \\
\hline rat & ssgdtvqplspaqghsaavhesqcenttkkevpvspghqk & 430 \\
\hline
\end{tabular}




\begin{tabular}{|c|c|c|}
\hline squirrel & & 239 \\
\hline human & tpftkdkhssrleahltrdelrakalhipfpvekiinlpv & 478 \\
\hline mouse & apftkdkhssrleahltrdelrakalhipfpvekiinlpv & 470 \\
\hline rat & vpftkdkhssrleahltrdelrakalhipfpvekiinlpv & 470 \\
\hline squirrel & & 239 \\
\hline human & vdfnemmskeqfneaqlalirdirrrgknkvaaqnerkrk & 518 \\
\hline ouse & ddfnemmskeqfneaqlalirdirrrgknkvaaqnorkrk & 510 \\
\hline rat & ddfnemmskeqfneaqlalirdirrrgknkvaaqnorkrk & 510 \\
\hline quirrel & & 239 \\
\hline uman & leniveleqdldhlkdekekllkekgendkslhllkkqls & 558 \\
\hline ouse & leniveleqdlghlkderekllrekgendrnlhllkrrls & 550 \\
\hline rat & leniveleqdlghlkderekllrekgendrnlhllkrkls & 550 \\
\hline squirrel & & 239 \\
\hline גman & tlylevfsmlrdedgkpyspseyslqqtrdgnvflvpksk & 598 \\
\hline buse & tlylevfsmlrdedgkpyspseyslqqtrdgnvflvpksk & 590 \\
\hline at & tlylevfsmlrdedgkpyspseyslqqtrdgnvflvpksk & 590 \\
\hline rrel & & 239 \\
\hline nan & kpdvkkn & 605 \\
\hline & kpdtkkn & 597 \\
\hline & kpdtkkn & 597 \\
\hline
\end{tabular}


Figure 4.3

A.
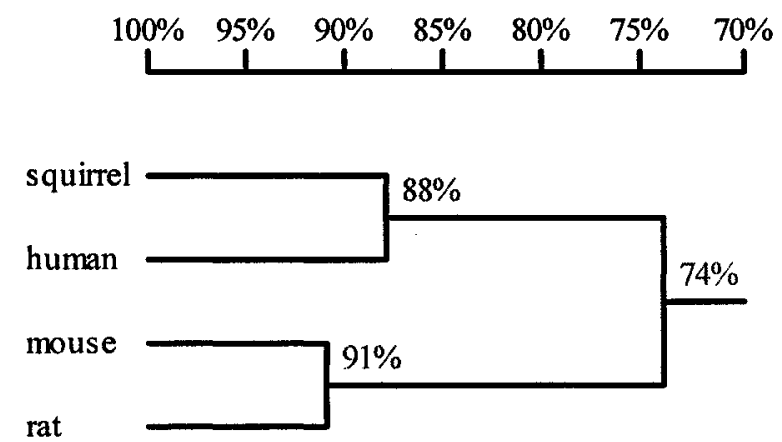

B.

$\begin{array}{llll}\text { Homology matrix of } 4 & \text { sequences } & \\ & & & \\ \text { squirrel } & 100 \% & & \\ \text { human } & 87.9 \% & 100 \% & \\ \text { mouse } & 77.4 \% 70.5 \% & 100 \% & \\ \text { rat } & 78.3 \% & 71.4 \% 91.1 \% & 100 \%\end{array}$


Figure 4.4
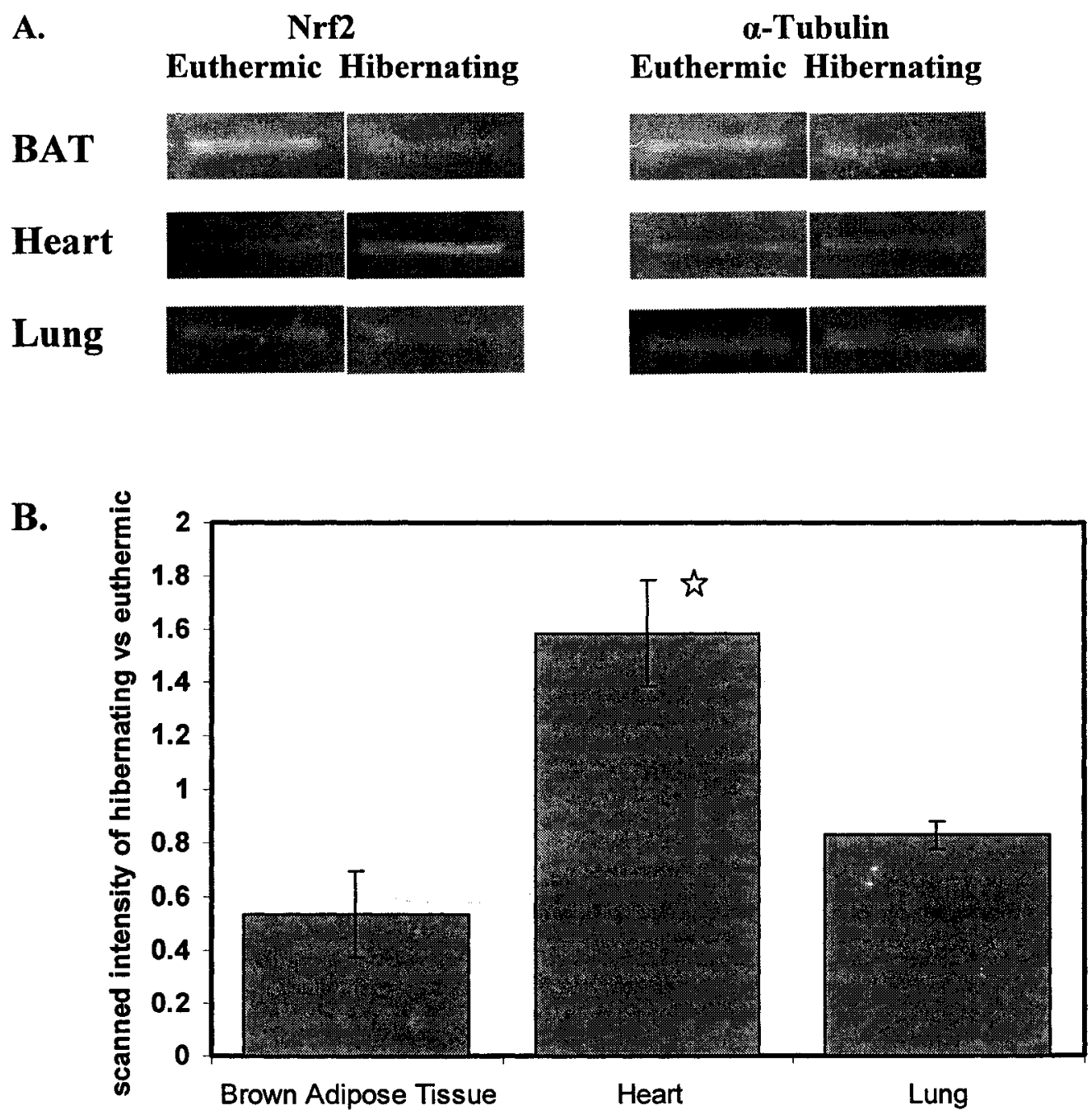
Figure 4.5

A.

ACR ENT HIB-E HIB-L AR-E AR

B.
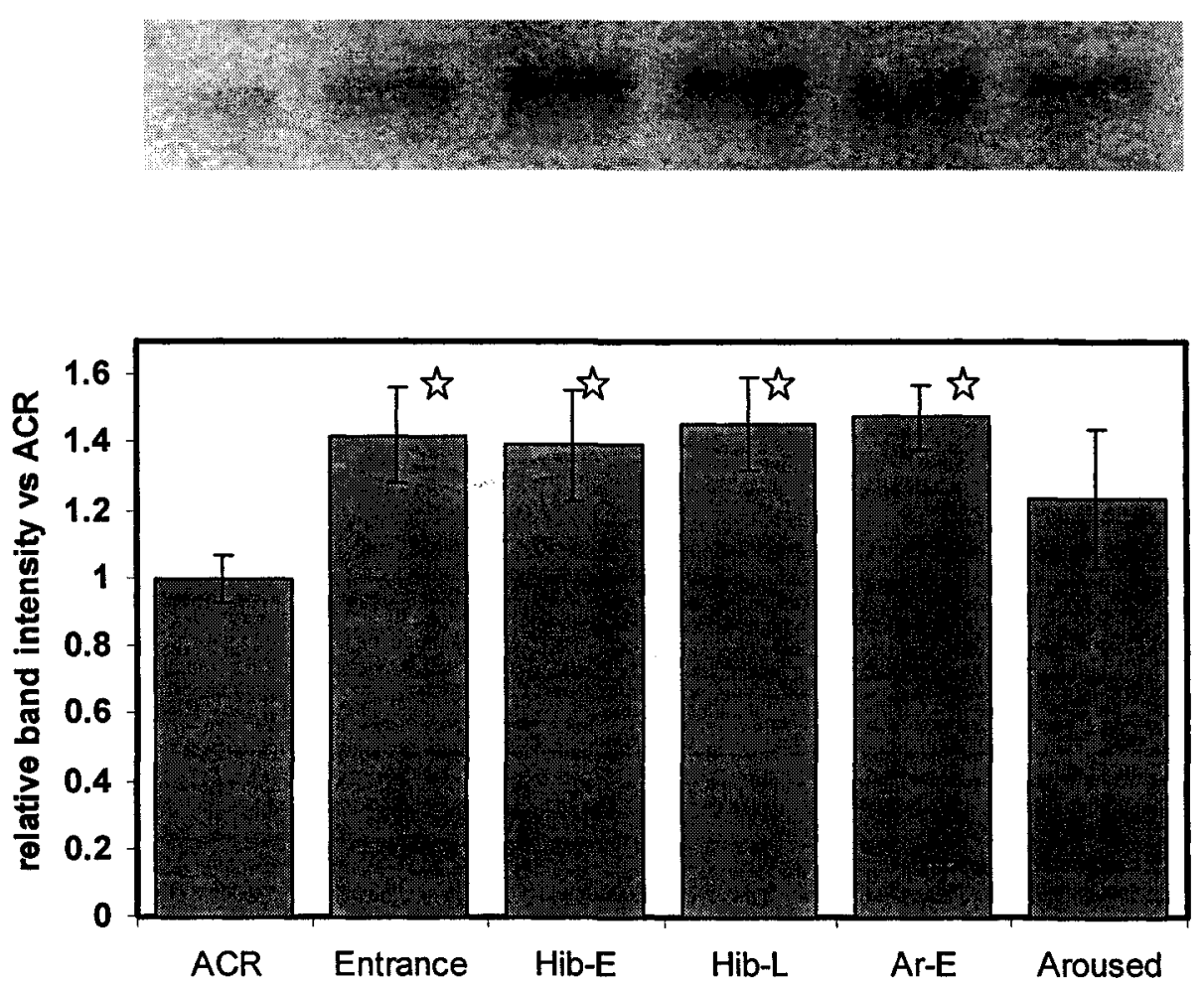
Figure 4.6

A. ACR ENT HIB-E HIB-L AR-E AR

B.

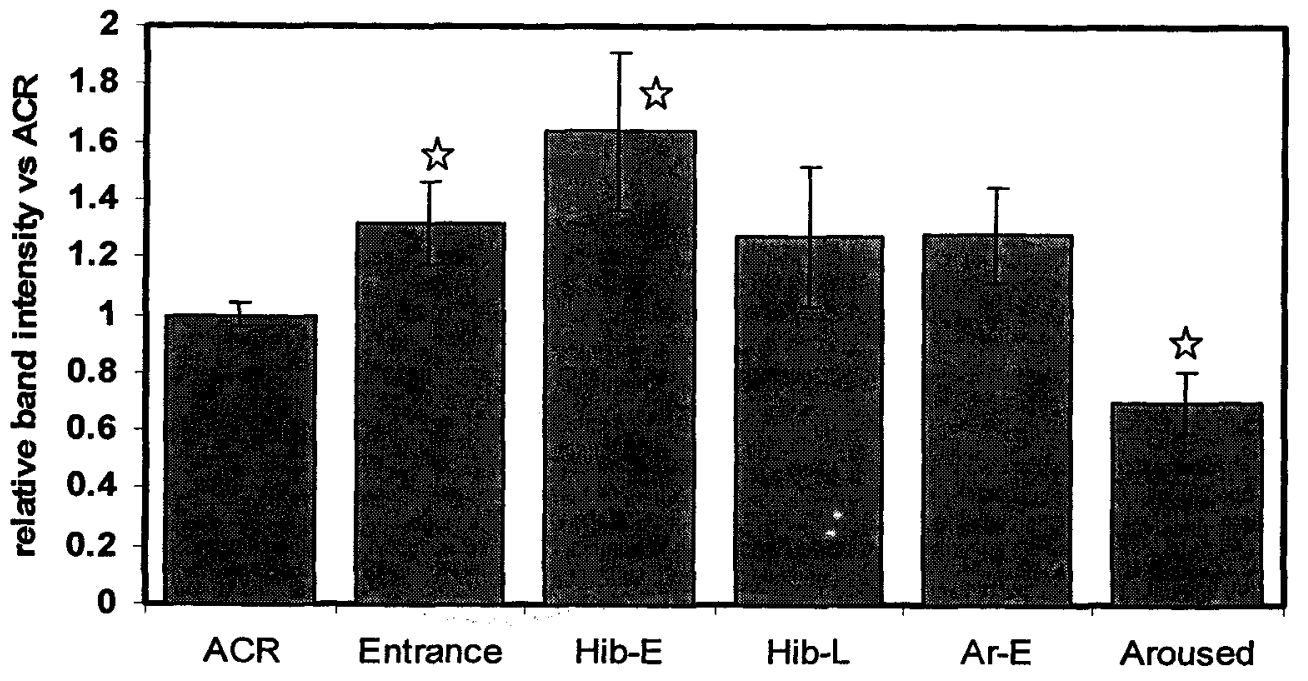


Figure 4.7

A. ACR ENT HIB-E HIB-L AR-E AR

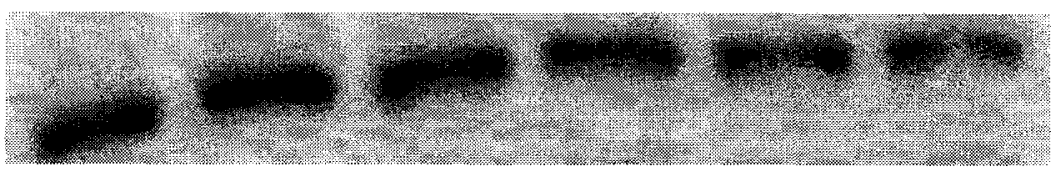

B.

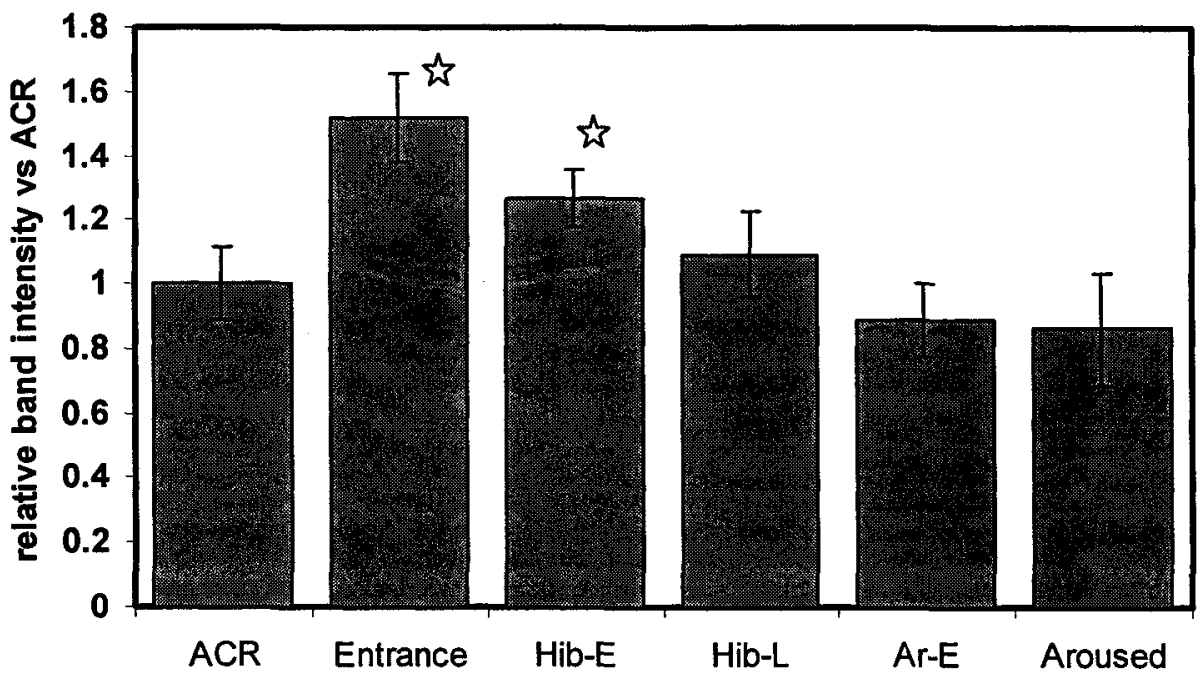


Figure 4.8

A. ACR ENT HIB-E HIB-L AR-E AR

B.

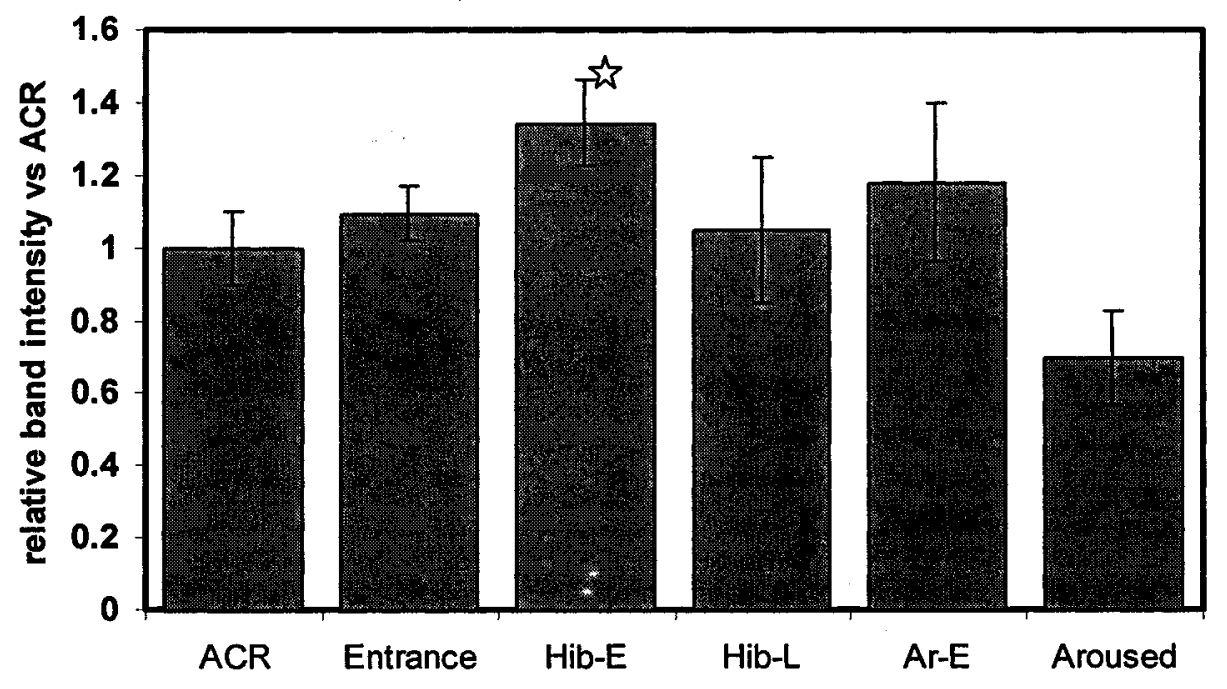




\section{Chapter 5 \\ Peroxiredoxins and antioxidant defense in mammalian hibernation}




\section{INTRODUCTION}

One need that the hibernator has is to protect its cells against oxidative damage occurring both over the long term while in torpor, as highlighted in Chapter 4 , and as a result of the huge increase in oxygen consumption that occurs during arousal. Previous studies performed with brown adipose tissue (BAT) of rats have shown that prolonged exposure to cold leads to an activation of the antioxidant defense system, presumably to defend against high rates of reactive oxygen species (ROS) generation associated with the very high oxygen consumption of this organ during the uncoupled respiration that provides thermogenesis (Spasic et al., 1993). Lipid-fueled thermogenesis by BAT of hibernators results in a huge increase in oxygen consumption, often overshooting normal euthermic rates, and raises $\mathrm{Tb}$ back to euthermic values within minutes. The potential for ROS generation during this time is very high and requires that hibernators are protected with well-developed antioxidant defenses. Indeed, studies of hibernator BAT provided some of the first examples of adaptive change in antioxidant enzyme activities in response to physiological oxidative stress (Buzadzic et al., 1990; Barja de Quiroga, 1992). Recently, a new group of antioxidant enzymes has been discovered: the peroxiredoxins. These intracellular enzymes reduce and detoxify a wide range of hydroperoxides in cells, typically using thioredoxin as the electron donor (Hofmann $e t$ al., 2002; Rhee et al., 2005). Peroxiredoxins are actually major components of cells, representing about $0.1-0.8 \%$ of the total soluble protein fraction in most mammalian cell types (Chae et al., 1999). The six known family members in mammals are divided into two classes, 1-Cys and 2-Cys peroxiredoxins, depending on the number of cysteine 
residues involved in catalyzing the reaction (Chae et al., 1994) and recent data suggests that the 2-Cys peroxiredoxin subclass can be further divided into two more categories based on mechanistic and structural differences. Studies have shown that peroxiredoxins can counteract oxidative stress arising from a variety of sources in different organisms (Akerman and Muller, 2003; Kim et al., 2001a; Mitsumoto et al., 2001). Apart from their role in antioxidant defense in the detoxification of hydroperoxides (in the presence of thioredoxin and thioredoxin reductase) (Chae et al., 1999), recent studies have also shown strong evidence that $\mathrm{H}_{2} \mathrm{O}_{2}$ is involved in intracellular signal transduction (Rhee et al., 2003; Wood et al., 2003). For example transient elevations of intracellular $\mathrm{H}_{2} \mathrm{O}_{2}$ occur in response to various cytokines and peptide growth factors, elevated $\mathrm{H}_{2} \mathrm{O}_{2}$ affects the function of various protein kinases and phosphatases, transcription factors, and $\mathrm{G}$ proteins, and inhibition of $\mathrm{H}_{2} \mathrm{O}_{2}$ generation results in a complete blockage of signaling by various growth factors (Rhee et al., 2003). Studies that have looked at $\mathrm{H}_{2} \mathrm{O}_{2}$ generated as a result of membrane receptor activation have shown that 2-Cys peroxiredoxins not only eliminate the intracellular $\mathrm{H}_{2} \mathrm{O}_{2}$ produced during receptor activation but also prevent further downstream signaling events from occurring (Kim et al., 2000). A report has even shown that overexpression of peroxiredoxins could ultimately suppress the transcriptional activity of the nuclear factor (NF)- $\mathrm{kB}$ transcription factor (Kang et al., 1998). This ability of peroxiredoxins to affect transcriptional activity made them an even more interesting set of enzymes to study in the hibernator model.

Given the importance of antioxidant defenses to successful hibernation, we reasoned that hibernation-responsive changes in peroxiredoxins may be part of the adaptive strategy that provides defense against oxidative stress for the hibernating 
mammal. The present chapter examines the responses to hibernation by peroxiredoxin 1 , 2 and $3(\operatorname{Prdx} 1, \operatorname{Prdx} 2, \operatorname{Prdx} 3)$, all 2-Cys subfamily members, in BAT and heart of thirteen-lined ground squirrels, Spermophilus tridecemlineatus. Western blotting was used to quantify Prdx protein levels in tissue samples from euthermic versus torpid animals, a partial $p r d x 2$ sequence was amplified and used to assess $p r d x 2$ transcript levels by RT-PCR, and total 2-Cys peroxiredoxin enzymatic activity was measured. The data highlight the importance of peroxiredoxins in the defense mechanisms for dealing with oxidative stress in hibernator organs and their potential involvement in intracellular signaling over torpor-arousal cycles.

\section{MATERIALS AND METHODS}

\section{Animals}

Animals were prepared and treated as described in Chapter 4.

\section{Total RNA isolation and quality assessment.}

Total RNA and the assessment of its quality were performed as described in Chapter 2.

cDNA synthesis and PCR amplification of prdx2.

The amplification of $p r d x 2$ was performed as described in Chapter 2 but with different primers. The forward primer sequence was 5'- CKGTSGACTCTCAGTTCA 3' and the reverse primer sequence was 5'- TATTCCTTGCTGTCRTCCAC - 3'. A $\operatorname{prd} 22$ fragment of $303 \mathrm{bp}$ was retrieved and sequenced by Canadian Molecular Research Services (Ottawa, ON). The sequence was confirmed as encoding $p r d x 2$ by sequence comparison in BLAST. 


\section{Western blotting}

Western blotting was performed as described in Chapter 2. Antibodies specific for Prdx1, Prdx2 and Prdx3 (polyclonal rabbit antibodies raised against human Prdx1, $\operatorname{Prdx} 2$ or Prdx3) were purchased from LabFrontier, Korea.

\section{Peroxiredoxin activity assay}

The assay was performed as described in Kim et al. (2005). Extracts for enzyme assay were prepared by homogenizing weighed samples of frozen tissue 1:10 w:v in lysis buffer (20 mM HEPES buffer, pH 7.0, 1 mM EDTA, 1 mM EGTA, $150 \mathrm{mM} \mathrm{NaCl}, 1 \%$ v/v Triton X-100) with a few crystals of PMSF added immediately before homogenization. Samples were centrifuged at $10,000 \mathrm{~g}$ for $15 \mathrm{~min}$ at $4^{\circ} \mathrm{C}$ and supernatants were collected, stored on ice and assayed for 2-Cys peroxiredoxin activity. Protein concentration was determined using the Coomassie blue dye-binding method and the BioRad prepared reagent (BioRad, Hercules, CA). A pre-reaction cocktail was prepared that contained $50 \mathrm{mM}$ HEPES-NaOH (pH 7.0), $1 \mathrm{mM}$ EDTA, $200 \mu \mathrm{M}$ NADPH, $1.5 \mu \mathrm{M} E$. coli thioredoxin and $0.8 \mu \mathrm{M}$ thioredoxin reductase (kindly provided by Dr. Sylke Muller, University of Glasgow). Then $100 \mu \mathrm{M} \mathrm{H}_{2} \mathrm{O}_{2}$ and $15 \mu \mathrm{L}$ of enzyme extract were added into reaction wells on a 96-well microplate. The reaction was started by adding $180 \mu \mathrm{L}$ of the pre-reaction cocktail to the wells and NADPH oxidation was monitored for $30 \mathrm{~min}$.

\section{RESULTS}

cDNA cloning of peroxiredoxin 2 in $S$. tridecemlineatus

Using RT-PCR and primers derived from the consensus sequence of $p r d x 2$ from 
other mammalian species, a PCR product of 303 bp was retrieved from total RNA prepared from heart of hibernating $S$. tridecemlineatus. The product was confirmed as encoding a portion of the $p r d x 2$ sequence and the sequence was submitted to GenBank with accession number DQ201844. Figure 5.1 shows the nucleotide sequence of ground squirrel $\operatorname{prd} d \times 2$ and its translated amino acid partial sequence. In Figure 5.2 the amino acid sequence of ground squirrel $\operatorname{Prdx} 2$ is aligned with the sequences for the human, mouse and rat protein. The full mammalian Prdx2 sequence has 198 residues whereas the amplified portion of $S$. tridecemlineatus prdx 2 encoded 101 amino acids residues, corresponding to $51 \%$ of the full sequence. Figure 5.3 shows that ground squirrel Prdx2 is quite similar to Prdx2 from other mammals. The homology tree and homology matrix showed $96 \%$ identity with human and rat $\operatorname{Prdx} 2,95 \%$ identity with mouse $\operatorname{Prdx} 2$ and 92 $\%$ identity with cow $\operatorname{Prdx} 2$ over the amplified region. Ground squirrel $\operatorname{Prdx} 2$ contained a few unique amino acid substitutions that were not seen in non-hibernating rodents; these are shown in bold underline in Figure 5.2. These included substitutions of an arginine residue for a lysine residue at position 109 of the rat sequence. Other substitutions included a serine for an asparagine residue substitution at position 120 and a glycine for alanine substitution at position 134 .

\section{Peroxiredoxin 2 gene expression in $S$. tridecemlineatus}

Transcript levels of $p r d x 2$ mRNA were assessed in BAT and heart from euthermic

and hibernating $S$. tridecemlineatus using RT-PCR. Primers for $p r d x 2$ were designed from a consensus sequence made,from human, mouse and rat sequences and were used to amplify mRNA from ground squirrel tissues. Figure 5.4 shows the relative $p r d x 2$ mRNA expression in each organ. $\alpha$-Tubulin mRNA, a constitutively expressed gene, was also 
amplified from the same samples and $p r d x 2$ transcript levels were normalized against the tubulin transcript level in each sample. Figure $5.4 \mathrm{~B}$ shows the ratio of normalized prdx2 transcript levels in hibernation . versus euthermia. $\operatorname{Pr} d x 2$ transcript levels increased significantly during hibernation in both organs; levels were 1.7-fold and 3.7-fold higher in BAT and heart, respectively, from hibernating versus euthermic animals $(\mathrm{P}<0.05)$.

\section{Peroxiredoxin protein levels}

Protein levels of peroxiredoxin isozymes 1,2 and 3 were measured by immunoblotting (Figure 5.5). Each antibody crossreacted with only a single protein band at 23,25 or $28 \mathrm{kDa}$ for $\operatorname{Prdx} 1, \operatorname{Prdx} 2$ and $\operatorname{Prdx} 3$, respectively. Figure 5.5B shows the ratio of Prdx1, Prdx2 and Prdx3 protein in BAT and heart from hibernating versus euthermic ground squirrels. Prdx 1 and Prdx2 protein content increased significantly in both tissues of hibernating animals, compared with euthermic ground squirrels $(\mathrm{P}<0.05)$. Prdx 1 protein content increased by 4.0 - and 12.9 -fold in BAT and heart, respectively, during hibernation whereas Prdx2 protein was 2.4-fold and 3.7-fold higher in the same tissues. Prdx3 protein levels increased significantly only in heart during hibernation by 3.1 -fold $(\mathrm{P}<0.05)$.

\section{2-Cys peroxiredoxin activity assay}

Total 2-Cys peroxiredoxin activity was assayed in ground squirrel BAT and heart using a spectrophotometric assay that follows the decrease in absorbance at $340 \mathrm{~nm}$ due to NADPH oxidation. Peroxiredoxin catabolism of $\mathrm{H}_{2} \mathrm{O}_{2}$ oxidizes thioredoxin which is then regenerated via thioredoxin reductase with the consumption of NADPH. Mean enzymatic activity in BAT was $0.45 \pm 0.18 \mathrm{mU} / \mathrm{g}$ fresh weight $(\mathrm{n}=3)$ in samples from euthermic ground squirrels and significantly higher, $1.52 \pm 0.14 \mathrm{mU} / \mathrm{gfw}(\mathrm{n}=3, \mathrm{P}<0.05)$ 
in samples from hibernating animals, a 3.4-fold increase. In heart, activity increased significantly $(\mathrm{P}<0.05)$ by 1.5 fold during hibernation, from $1.96 \pm 0.09 \mathrm{mU} / \mathrm{gfw}$ in euthermia to $2.96 \pm 0.16 \mathrm{mU} / \mathrm{gfw}$ in hibernation (both $\mathrm{n}=3$ ).

\section{DISCUSSION}

Oxidative stress is a condition that affects small mammalian hibernators. Cycles of torpor-arousal result in huge differences in tissue oxygenation and oxygen consumption by tissues that will also cause associated wide variation in ROS generation. Studies with ground squirrel intestine have shown that this assumption could be true as a redox-sensitive transcription factor is up-regulated during both short and long torpor (Carey et al., 2000). ROS are highly damaging to biomacromolecules and, hence, effective antioxidant defense mechanisms are needed. Indeed, it has been reported earlier that arousing hibernators showed an increase in superoxide dismutase and glutathione peroxidase activities, two well-known antioxidant enzymes (Buzadzic et al., 1990). Recent studies have also shown that organs of hibernating bats (Myotis lucifugus) are responding to oxidative stress; both message and protein levels of $\operatorname{Prdx} 1$ were upregulated during hibernation and other oxidative stress markers, $\mathrm{p}-\mathrm{IkB}-\alpha$ (Ser 32) and pHSP27 (Ser 78/82), were also up-regulated in heart and skeletal muscle during hibernation (Eddy et al., 2005). The peroxiredoxins have been linked to the oxidative stress response in a variety of situations and the data in this chapter also suggest that they are part of the antioxidant defense of organs during hibernation. Besides responding to oxidative stress, 2-Cys peroxiredoxins have also recently been linked with intracellular signaling (Kang et al., 2005). Increased levels of peroxiredoxins seem to inhibit certain 
pathways. Such is the case of $\operatorname{Prdx} 2$ and the platelet-derived growth factor (PDGF) receptor. Reports have shown that increased levels of $\operatorname{Prdx} 2$ can successfully inhibit the initiation of the signaling cascade that would normally originate from this receptor (Choi et al., 2005). Studies using $\operatorname{Prdx} 2$ gene knockout have also previously reported activation of JNK and p38 MAP kinase pathways (Guyton et al., 1996). Hence, modification of Prdx levels in hibernator organs could also result in changes in signal transduction and cellular responsiveness to growth factors and other signals at different stages of the hibernation cycle (euthermia-entry-torpor-arousal).

It is well-known that brown fat activated during thermogenesis can experience oxidative stress due to the sudden increase in oxygen consumption and the generation of ROS that ensues (Barja de Quiroga, 1992). Heart has also been linked to oxidative stress following ischemia and reperfusion cycles (Marczin et al., 2003). Hibernating mammals, which have to deal with multiple bouts of torpor and arousal (and possibly associated ischemia and reperfusion as well), would also be confronted with cycles of free radical generation and therefore require substantial antioxidant defenses in these two tissues. Transcript levels of $p r d \times 2$ were measured in BAT and heart of hibernating ground squirrels. $\operatorname{Pr} d x-2$ transcripts were up-regulated in both BAT and heart (by 1.7- and 3.7fold, respectively) in torpid squirrels as compared with euthermic controls (Figure 5.4). Furthermore, Western blotting with a $\operatorname{Prdx} 2$ antibody confirmed that the transcriptional up-regulation led to significant increases in Prdx2 protein levels in these tissues, by 2.4and 3.7-fold in BAT and heart, respectively (Figure 5.5). These data suggest the importance of $\operatorname{Prdx} 2$ in the oxidative stress response associated with hibernation. 
$\operatorname{Prdx} 2$ is a member of the 2-Cys peroxiredoxin family and to determine if the Prdx2 response was a specific or a general response by the whole family, I decided to evaluate the protein levels of other 2-Cys Prdx family members to see if they also responded to hibernation. Western blotting confirmed that a general elevation of 2-Cys Prdxs occurred during hibernation. Thus, Prdx1 protein content increased significantly during torpor by 4.0- and 12.9-fold in BAT and heart, respectively, whereas Prdx3 protein rose by 3.1-fold in heart (Figure 5.5). This elevation of Prdx1 protein correlates with previous work undertaken on hibernating bats (Myotis lucifugus) that showed that levels of the protein PAG (now known as Prdx1) rose by $\sim 2.0$-fold in bat heart during hibernation (Eddy and Storey, 2005). Furthermore, studies performed with bovine aortic endothelial cells submitted to different oxidative stresses showed comparable increases Prdx3 protein under stress (Araki et al., 1999). Hence, it appears that up-regulation of 2Cys Prdx family members is an integral response to hibernation, and given that these proteins are known to respond to oxidative stress in other mammalian systems, we can postulate that their up-regulation in hibernation is due to either direct or anticipated oxidative stress associated with torpor-arousal cycles. Indeed, an anticipatory enhancement of antioxidant defenses is a commonly seen adaptive response by species that endure frequent bouts of oxidative stress as a result of exposure to various environment stresses (Hermes-Lima et al., 2001).

Increased levels of Prdx protein in ground squirrel tissues during torpor does not necessarily mean that the enzyme is more active since the activities of enzymes can be modified in may different ways.. For example, it has been recently shown that Prdx can be overoxidized and inactivated when dealing with oxidative stress (Rabilloud et al., 2002). 
This phenomenon was subsequently shown to be reversible in radiolabelling studies (Woo et al., 2003). Hence, I decided to quantify 2-Cys activity and, using a newly devised assay for 2-Cys Prdx activity (Kim et al., 2005), activities in brown adipose and heart tissues were assayed. In both cases, a significant increase in 2-Cys Prdx activity was found during torpor, as compared with euthermia, with a 3.4- and 1.5-fold increase in brown adipose and heart, respectively. Thus, the hibernation-responsive gene and protein up-regulation of Prdx seen in ground squirrels was paralleled by increased Prdx activity. This increase in activity further indicates the potential importance of peroxiredoxins during hibernation. This activity is most likely directed towards $\mathrm{H}_{2} \mathrm{O}_{2}$ detoxification, but it could also be a means for hibernators to turn down certain signaling pathways that would not be needed in the torpid state. Studies performed with Prdx2 gene knockouts have revealed that deleting $\operatorname{Prdx} 2$, can affect activity of a variety of protein kinases (Guyton et al., 1996). Previous work from our laboratory has revealed the importance of signaling cascades via protein kinase activities in the hibernating Richardson's ground squirrels, Spermophilus richardsonii (MacDonald and Storey, 2005). Therefore, the differential regulation of 2-Cys peroxiredoxins might also be used by hibernators to tightly regulate protein kinase cascades that are sensitive to hydrogen peroxide signals during torpor.

Analysis of the putative protein sequence of ground squirrel Prdx2 revealed strong identity with the protein from non-hibernating mammals (rat, mouse, human) (Figures 5.2 and 5.3). The cysteine residue in the C-terminal region, a feature of 2-Cys Prdx family members (Kang et al., 2005), was conserved in the ground squirrel protein. However, a few specific substitutions were noted when the ground squirrel sequence was 
compared with other rodents: substitution of an arginine residue for a lysine occurred position 109 , serine was substituted for asparagine at position 120 , and a glycine replaced alanine at position 134. Unique amino acid substitutions in the sequences of ground squirrel proteins have been identified in several cases, for example in fatty acid binding proteins (Hittel and Storey, 2001), and these appear to cause protein conformational changes that benefit low temperature function in the torpid animal. The substitutions in ground squirrel Prdx2, as compared with the rat or mouse enzyme, might also be important for sustained function of the enzyme at low $\mathrm{Tb}$ but since these substitutions were not seen when human and ground squirrel $\operatorname{Prdx} 2$ were compared, the purpose of these amino acid changes can not yet be determined.

In conclusion, while the cloning of a partial $p r d \times 2$ from ground squirrel highlighted the high identity of the ground squirrel protein sequence with other mammals, the strong increase in both $p r d x 2$ transcript and $\operatorname{Prdx} 2$ protein expression in heart and BAT suggested an important role for this antioxidant enzyme in hibernation. Indeed, the concurrent increase in $\operatorname{Prdx} 1$ and $\operatorname{Prdx} 3$ protein levels as well as the strong increase in total 2-Cys Prdx activity during torpor, suggests that the entire 2-Cys Prdx family has a key role to play in hibernation success. This data further reinforce the fact that small hibernators such as the thirteen-lined ground squirrel are confronted with oxidative stress during hibernation and must up-regulate their antioxidant defenses to prevent oxidative injuries. Furthermore, peroxiredoxin activity might also be solicited to control certain signaling pathways during deep torpor. 


\section{Figure 5.1} AAGGAAGGAGGCTTGGGCCCCCTGAACATCCCCCTGCTTGCTGACGTGACCAGAAGCTTG $\begin{array}{llllllllllllllllllll}K & E & G & G & L & G & P & L & N & I & P & L & L & A & D & V & T & R & S & L\end{array}$ TCCCATAATTATGGCGTGCTGAAAAGCGATGAGGGCATTGCCTACAGGGGCCTCTTCATC $\begin{array}{llllllllllllllllllll}S & H & N & Y & G & V & L & K & S & D & E & G & I & A & Y & R & G & L & F & I\end{array}$ ATTGATGGCAAGGGAGTCCTTCGCCAGATCACTGTTAATGATTTGCCCGTGGGGCGCTCT GTGGATGAGGCTTTGCGGCTGGTCCAGGCCTTCCAATACACAGATGAGCATGGGGAAGTT TGCCCCGCTGGCTGGAAGCCTGGCAGTGACACAATCAAGCCCAACGTGGACGACAGCAAG 
Figure 5.2

S. tridecemlineatus

$R$. norvegicus

M. musculus

H. sapiens

$\ldots \ldots \ldots \ldots \ldots \ldots \ldots \ldots \ldots \ldots \ldots \ldots \ldots \ldots \ldots \ldots \ldots \ldots$

0

masgnahigkpapdftgtavvdgafkeiklsdyrgkyvvl

40

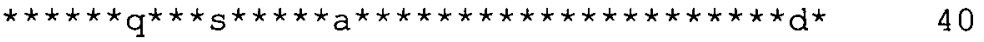

S. tridecemlineatus

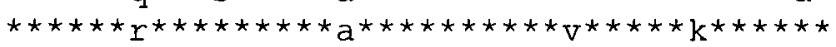

40

$R$. norvegicus

M. musculus

H. sapiens

$\ldots \ldots \ldots \ldots \ldots \ldots \ldots \ldots \ldots \ldots \ldots \ldots \ldots \ldots \ldots$

0

ffypldftfvcpteiiafsdhaedfrklgcevlgvsvdsq 80

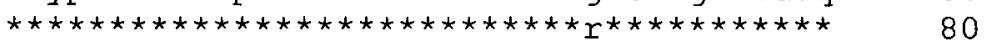

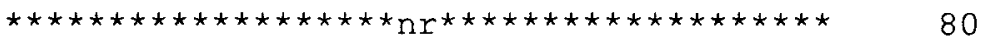

S. tridecemlineatus

$R$. norvegicus

M. musculus

....... KEGGLGPLNIPLLADVTRSLSHNYGVLKS

29

fthlawintpr--------------- $\overline{\mathrm{k}}---\mathrm{q}------\overline{\mathrm{n}} \quad 120$

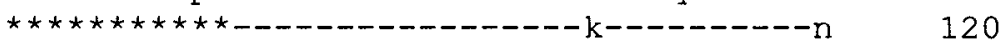

H. sapiens

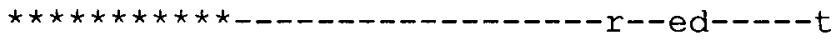

120

S. tridecemlineatus

DEGIAYRGLEIIDGKGVLRQITVNDLPVGRSVDEALRLVQ

69

$R$. norvegicus

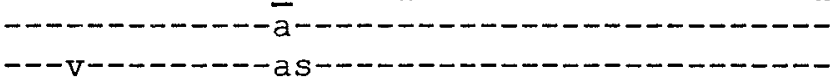

160

M. musculus

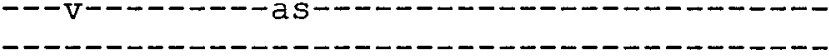

160

H. sapiens

AFQYTDEHGEVCPAGWKPGSDTIKPNVDDSKE . . . . .

160

S. tridecemlineatus

101

$R$. norvegicus

M. musculus

198

H. sapiens

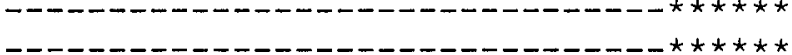

198

198 
Figure 5.3

A.
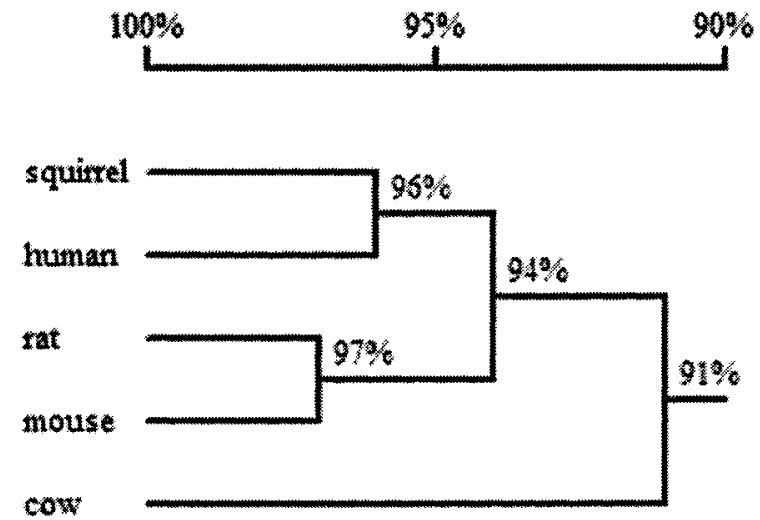

B.

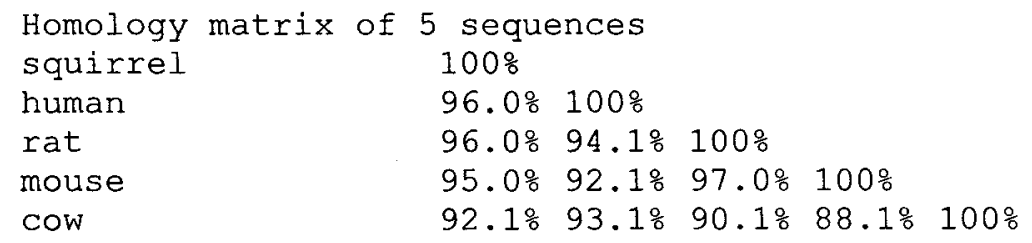


Figure 5.4

A.

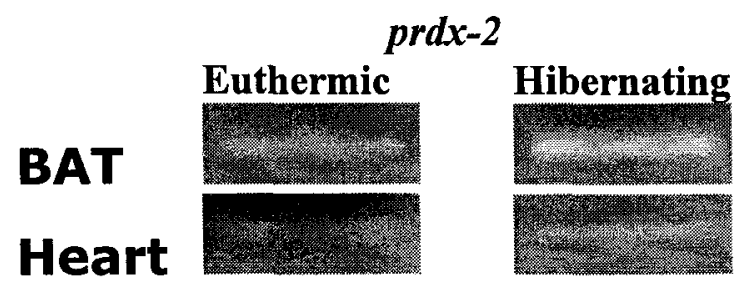

a-Tubulin

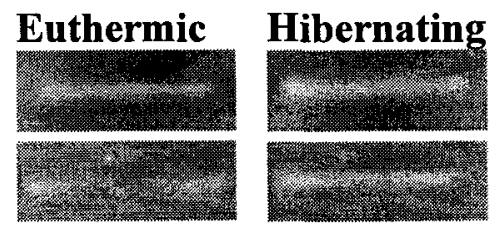

B.

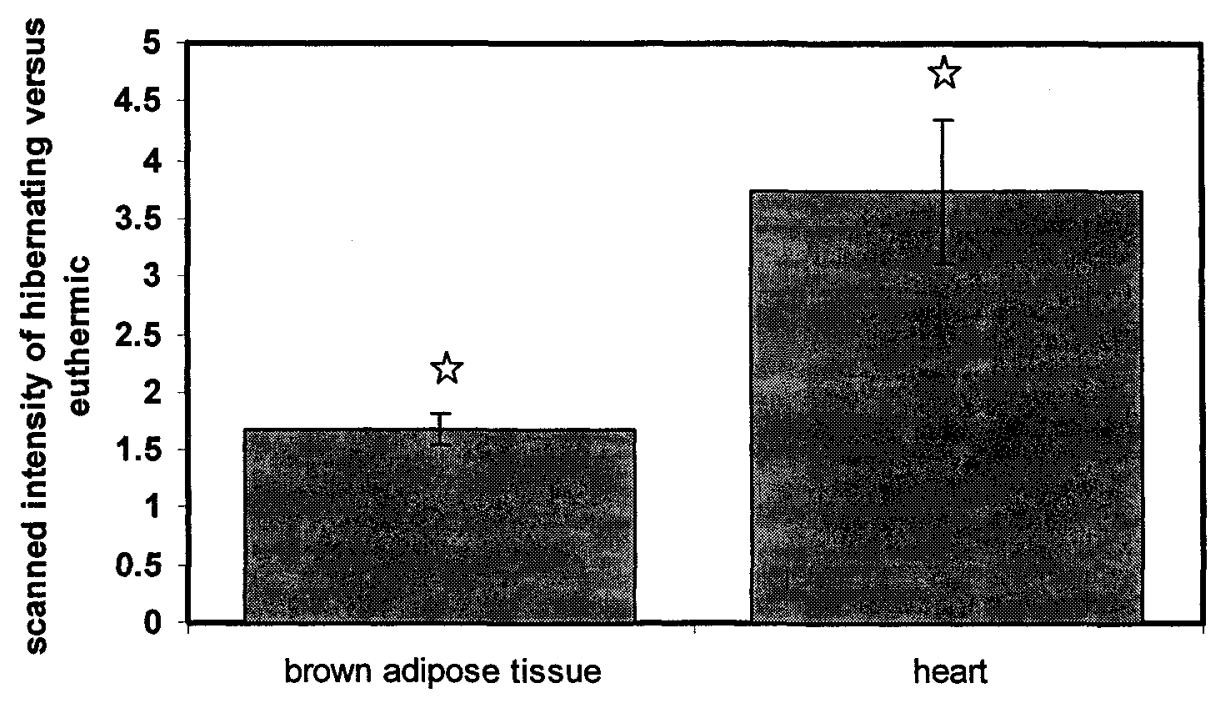


Figure 5.5

\section{Prdx-1}

A.

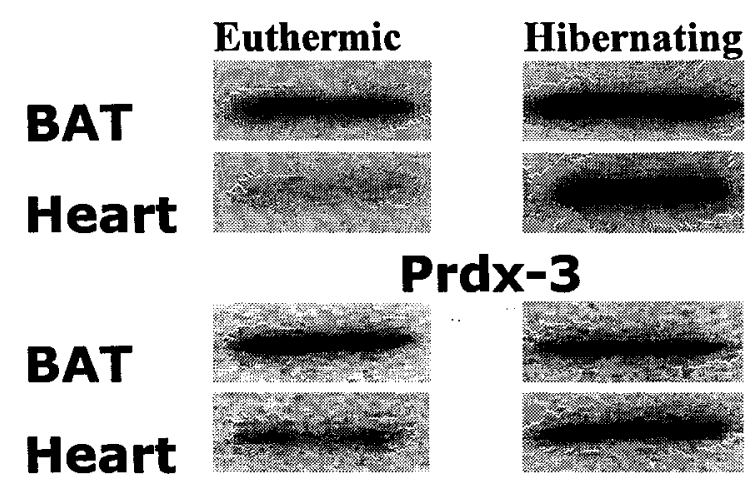

B.

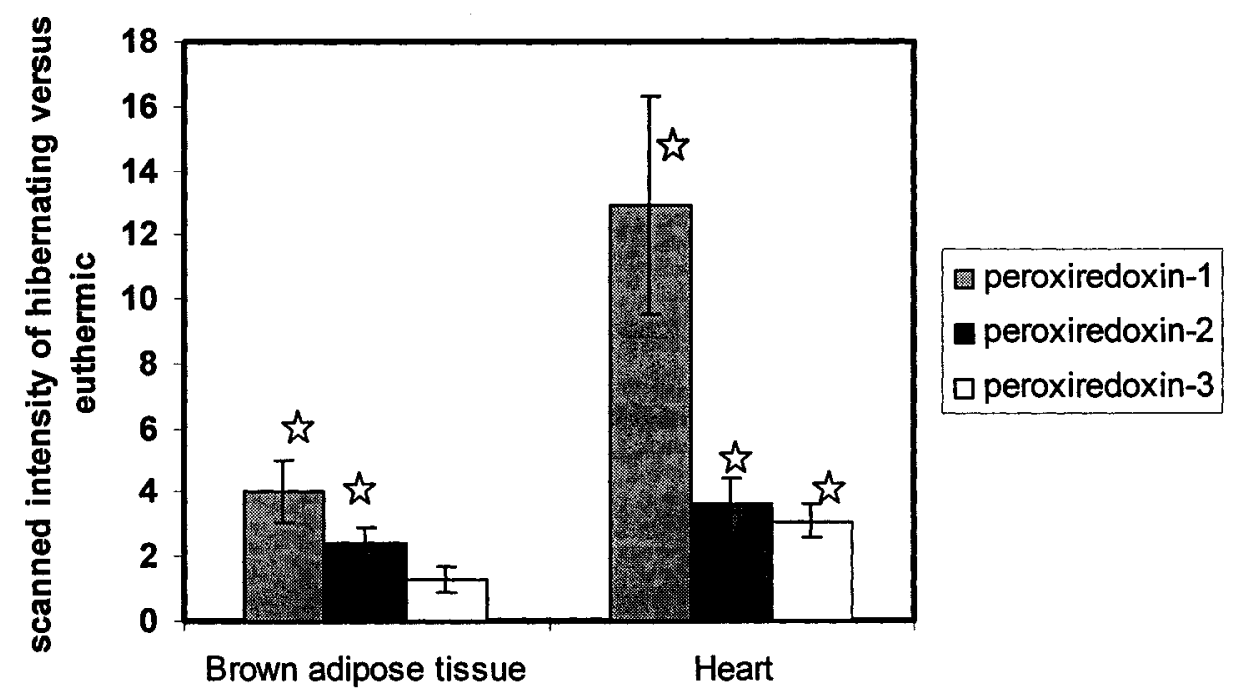

\section{Prdx-2}

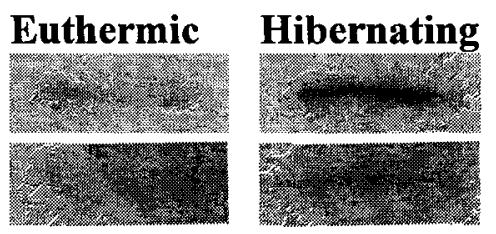




\section{Chapter 6}

\section{General Discussion}


The work presented in this thesis highlights two themes in hibernation biochemistry: overall transcriptional repression and selective transcriptional activation. These two themes are obviously opposite and, hence, regulating them requires a complex suite of tools. The hibernating animal undergoes an overall strong decrease in metabolic rate in order to save as much energy as possible over the winter months. This is accomplished by turning down or turning off the vast majority of metabolic functions that are not needed in the torpid state. However, a subset of metabolic functions is directly linked to survival in the cold and must be up-regulated as the animal enters torpor. For example, metabolic pathways involved in thermogenesis and fatty acid catabolism are crucial for the hibernating animal. One way to make selective changes to individual metabolic functions is to control the expression of specific genes via the use of specific transcription factors. By increasing the binding activity of these proteins, hibernators can increase the transcription of a group of genes by turning on one transcription factor "switch". Whether it is activation of the transcription factor via phosphorylation or a suppression of transcription factor degradation, hibernating mammals are able to use selected changes in the amount of these factors to control a range of genes that will elicit the various responses needed for hibernation success.

The importance of two different transcription factors in hibernation was first examined by looking at their protein levels in tissues of euthermic versus hibernating ground squirrels. Following identification of the organs that showed up-regulation of these transcription factors, further experiments were conducted to verify that elevated protein levels of these factors also correlated with an increase in DNA-binding activity and active gene transcription. To do this, DNA-binding studies and Western blotting of 
known downstream gene protein products under the control of these transcription factors were performed. Levels of mRNA transcripts of the two transcription factors were then measured by RT-PCR to determine if the hibernator also turned on the transcription factor genes during torpor. It is known that hibernators exert tight control over multiple energy-consuming processes in order to suppress overall metabolic rate by $>95 \%$. To determine if this included transcriptional suppression, an analysis of the transcriptional state in skeletal muscle of euthermic versus torpid ground squirrels was performed. By looking at protein levels via Western blotting and activity of selected enzymes involved in transcription control using enzymatic approaches including fluorometric and PCRbased assays, it was determined that hibernating ground squirrels showed transcriptional suppression during torpor. These results further highlight the importance of transcription factor control of specific genes during torpor because it allows for selective up-regulation of specific genes that aid hibernation survival against a background of overall transcriptional suppression. Together these different techniques provided insights on the use of transcription factors to activate specific pathways that are required by animals to make smooth transitions into and out of their hibernation cycles.

\section{Transcriptional control during hibernation}

In chapter 2, I looked at the involvement of the transcription factor HIF-1 in ground squirrel hibernation. HIF- $1 \alpha$ gene and protein levels were measured in different organs of hibernating versus euthermic squirrels using RT-PCR and Western blotting, respectively. Interestingly, significant changes were seen at the protein level in two tissues involved in thermogenesis; muscle and BAT. However, unlike HIF-1 $\alpha$ protein 
levels, levels of HIF- $1 \alpha$ mRNA transcripts were stable across the tissues examined. This suggests that HIF- $1 \alpha$ protein degradation could be reduced during hibernation leading to more HIF-1 $\alpha$ protein remaining intact in the cytoplasm. HIF-1 DNA-binding activity was assessed in BAT, the tissue that showed the biggest increase in HIF-1 $\alpha$ protein. It was shown that HIF-1 DNA-binding activity went up 6.0-fold in hibernating BAT, demonstrating that HIF-1 is more transcriptionally active during torpor versus euthermia. This fold-increase in DNA-binding activity was substantially greater than the measured 1.7-fold rise in HIF-1 $\alpha$ protein levels during torpor which suggests that an additional activation of existing HIF-1 $\alpha$ protein could occur during hibernation that allows for the greatly increased DNA binding activity.

One such mechanism that has been reported is protein phosphorylation of HIF-1 $\alpha$ (Dery et al., 2005). HIF-1 transcriptional activity and downstream gene activation can be increased following stimulation of the p42/44 MAPK pathway (Richard et al., 1999). Stimulation of this pathway can also result in phosphorylation of the co-activator p300/CBP and this also leads to an increase in HIF-1 transcriptional activity (Sang et al., 2003). Indeed, this pathway is solicited during hibernation; recent studies showed that the p42/44 MAPK (ERK1 and ERK2) is activated in selected tissues of hibernating Richardson's ground squirrels, Spermophilus richardsonii (MacDonald and Storey, 2005). This significant increase in HIF-1 binding to the HRE reported here further confirms that this transcription factor plays a role in hibernation. But what exact role does HIF-1 play?

HIF-1 is best known for its actions in mediating gene responses to hypoxia, triggering the expression of numerous genes involved in increasing oxygen delivery to 
tissues (VEGF, EPO, etc) or in enhancing glycolytic capacity. But while oxygen delivery and blood flow are strongly reduced in hibernators, the argument can be made that torpid animals are not subjected to hypoxic conditions since metabolism in torpor remains lipidbased and oxygen does not seem to be a limiting factor. Recent discoveries on the subject might explain what seems to be a contradiction. Studies are now showing that HIF-1 can also be activated under normoxic conditions in response to non-hypoxic stimuli including growth factors and cytokines (Dery et al., 2005). The mechanism in this case relies on an increase in HIF- $1 \alpha$ translation via activation of the PI 3 kinase (PI3K) pathway and its downstream effectors mTOR and p70S6 kinase. Not much is known about the expression of these two proteins during hibernation, but it is tempting to speculate that they could play a role in the non-hypoxic activation of HIF-1. Data from this thesis could support this mechanism since stable levels of HIF-1 $\alpha$ gene transcripts and increased levels of HIF-1 $\alpha$ protein were measured. Further studies on these potential HIF- $1 \alpha$ activators in hibernating ground squirrels are warranted to better define the role that HIF-1 plays in hibernation.

Using 3' and 5'RACE techniques, the research in this thesis also reported the first amplification and sequencing of HIF-1 $\alpha$ from a hibernating mammal. When ground squirrel HIF-1 $\alpha$ was compared to the protein from non-hibernating mammals, it was found that this transcription factor is well-conserved among mammals. No major changes were found in the domains responsible for dimerization with HIF-1 $\beta$ or for HIF$1 \alpha$ degradation in normoxia. On the other hand, key substitutions were found in the HIF$1 \alpha$ transactivation domain and further studies into whether or not these changes improve the transactivation properties of HIF-1 at low temperatures is needed. 
In general, the results gathered on the HIF-1 pathway in ground squirrel provide novel insights into the biochemical mechanisms of survival under conditions of hypothermia and hypometabolism that would be lethal to most other mammals, including man. That HIF-1 $\alpha$ plays an important role in cold tolerance and mammalian hibernation is also supported by additional studies that I have undertaken but are not reported in this thesis. Analysis of HIF-1 $\alpha$ protein responses during hibernation in selected tissues of a distinctly different type of hibernator, the little brown bat Myotis lucifugus, showed that HIF-1 $\alpha$ protein levels are also elevated during torpor in this species (Figure 6.1), indicating a possible universal role for HIF-1 $\alpha$ in hibernation. Furthermore, a positive response by HIF-1 to cold exposure also occurs in cold-hardy insects. My studies with the freeze-tolerant goldenrod gall fly Eurosta solidaginis showed that HIF-1 $\alpha$ protein levels increased over the midwinter months when the larvae must endure severe subzero temperatures and freezing exposures (Figure 6.2) (Morin et al., 2005). Finding the exact purpose of the increased expression of this important transcription factor under what seems to be non-hypoxic conditions will be the next challenge.

The specific activation of selected transcription factors is only one side of the hibernating story. In fact, the profound metabolic rate suppression in hibernation is associated with such a decrease in the major metabolic pathways that an increase in a specific transcription factor and its pathway is the exception rather than the rule in hibernating animals. Hibernators use these DNA-binding proteins to activate only a small set of metabolic functions that address very specific problems in torpor survival. Therefore, it is reasonable to think that the overall rate of transcription is strongly decreased during hibernation and, indeed, the results presented in Chapter 3 strongly 
suggest this. Using an approach that combined enzyme assays and Western blots, the transcriptional state of ground squirrel muscle during hibernation was assessed. The major part of the analysis consisted of an examination of the state of nuclear proteins called histones. Posttranslational modifications of histones by acetylation or phosphorylation lead to chromatin remodeling that facilitates transcription (Lee et al., 1993). Histone $\mathrm{H} 3$ protein levels were shown to remain constant during hibernation, but levels of the modified protein forms were significantly reduced. Both reduced phosphorylation and reduced acetylation of histones is associated with a reduction in the overall transcription rate of DNA. Other data that concurred with this evidence came from the measurement of histone deacetylase (HDAC) protein levels and enzymatic activity. The function of histone deacetylases is to remove the acetyl groups attached to the histone proteins which then facilitates transcriptional silencing. My data showed that both the total amount of these proteins and their activity were increased in skeletal muscle of hibernating ground squirrels. The last step designed to evaluate transcriptional activity during hibernation involved the measurement of RNA Polymerase II activity. Using a PCR-based approach, it was shown that the ability of the enzyme to transcribe a pre-selected gene on a plasmid was significantly reduced in samples from hibernating ground squirrels compared with euthermic controls. All these data indicate a decrease in overall transcriptional rate in ground squirrel muscle during torpor. These finding are in line with previous work that used other methodologies to also indicate a decrease in gene transcriptional rates in torpid animals (van Breukelen and Martin, 2002; Osborne et al., 2004). The data reported here clearly support a change in the transcriptional state of the muscle genome during hibernation and reinforces the importance of transcription factor- 
mediated gene transcription for the selective expression of key genes against the background of overall strong transcriptional suppression during torpor.

\section{Evidence for oxidative stress in hibernating $\boldsymbol{S}$. tridecemlineatus}

Hibernators also go through phases during a hibernation bout that are associated with oxidative stress. Indeed, whether because of autoxidation of PUFAs during the period of deep torpor or high rates of ROS generation during arousal periods when blood flow, oxygen delivery and oxygen consumption increase markedly, hibernators need to tightly regulate their antioxidant defenses. Several studies have reported increased antioxidant enzyme activities in hibernating ground squirrels (Buzadzic et al., 1990; Carey et al., 2000), but not much was previously known about the expression of transcription factors involved in the oxidative stress response in hibernation. One transcription factor known to play a role in the response to oxidative stress is Nrf2. Using a similar experimental approach to that taken in the HIF-1 study, Nrf2 gene and protein levels were measured and presented in Chapter 4 along with an examination of the responses of various downstream proteins. In this case, Nrf2 protein levels were quantified over a full hibernation cycle consisting of animals that were active in cold room versus entrance in hibernation, early and deep hibernation, early arousal and fully arousal. This allowed me to locate the time in the torpor-arousal cycle when Nrf2controlled antioxidant defenses were activated. Nrf2 transcript and protein levels increased significantly during entry into torpor in heart of S. tridecemlineatus (Figures $4.4,4.5)$. Nrf2 protein levels were significantly elevated during entry into torpor and remained high throughout torpor, dropping back to initial levels only in fully aroused 
animals. Using Western blotting, the protein content of three enzymes known to have the Nrf2-binding antioxidant response element (ARE) in their promoter regions were measured; $\mathrm{Cu} / \mathrm{Zn}$ SOD, AFAR1 and HO-1 (Figures 4.6, 4.7 and 4.8). Protein levels of all three increased during entry into or early torpor in heart. Overall, these results demonstrated that while Nrf2 levels are sustained at high levels throughout the hibernation cycle, the genes under its control, albeit their protein products, are apparently up-regulated only as a very early response in torpor. This suggests that these responses act to build up the hibernator's antioxidant defenses before going into deep torpor. It is also interesting to note that the antioxidant enzymes measured here were not further elevated during arousal when one might think that they would be. This suggests that other types of antioxidant defenses may be up-regulated to meet ROS challenge during arousal.

Another group of enzymes that is involved in detoxifying ROS is the peroxiredoxins. Chapter 5 looked at the gene and protein expression of selected peroxiredoxins in S. tridecemlineatus organs. The gene for one of them, $\operatorname{Prdx} 2$, has also been shown to possess ARE binding sites in its promoter region. Using RT-PCR, $p r d x 2$ transcript levels were shown to be up-regulated in hibernating heart and BAT and subsequent Western blotting showed that the increase in mRNA levels was also correlated with elevated protein levels. Indeed, $\operatorname{Prdx} 1, \operatorname{Prdx} 2$ and $\operatorname{Prdx} 3$ proteins were all significantly up-regulated during torpor in the two tissues, with the exception of $\operatorname{Prdx} 3$ in BAT. Measurement of 2-Cys peroxiredoxin activity further confirmed that elevated protein content led to an increase in enzymatic activity. These data further suggest that 
hibernators are exposed to conditions of elevated ROS generation and that up-regulation of peroxiredoxins is one of the ways used by the animals to deal with this problem.

Furthermore, peroxiredoxins might also play a role in hydrogen peroxide signaling in hibernators. Recent studies suggest that intracellular protein kinase pathways are affected when peroxiredoxin levels are altered. Considering the fact that these signaling pathways are often used to activate transcription factors by phosphorylation, an increase in peroxiredoxins during hibernation could have a direct impact on the transcription of selected genes. Indeed, peroxiredoxins can inhibit the activity of transcription factors such as NFkB (Kang et al., 1998). Added to this, it is known that activity of this redox-sensitive transcription factor is low in BAT of hibernating ground squirrels (Carey et al., 2000). Thus, elevated 2-Cys peroxiredoxins activity in BAT during hibernation could lead to altered regulation of $\mathrm{NF} \kappa \mathrm{B}$ and/or other transcription factors in torpor. This ability of peroxiredoxins in hibernation remains to be clarified. Overall, peroxiredoxins do show an increase in protein levels and activity during hibernation and this, along with the results presented in Chapter 4, further highlights the importance of well-developed antioxidant defenses during hibernation.

\section{Outlook}

The data gathered in this thesis focused mainly on the transcriptional status of hibernating ground squirrels. Two transcription factors; HIF-1 and Nrf2, were identified that showed differential expression during hibernation. These transcription factors were chosen initially because of the molecular pathways that they are known to regulate. Variations in oxygen levels along with the generation of ROS during the various phases 
of hibernation lead me to propose that these transcription factors could have important roles to play over the cycles of torpor and arousal that occur during the winter season. An examination of DNA microarray data gathered by our laboratory was another means to verify if these projects were viable. An increase in the expression of downstream genes is usually a good sign that the upstream transcription factor is activated and, notably, microarray data comparing euthermic and torpid ground squirrels indicated putative up-regulation of several downstream genes of HIF-1 and Nrf2 during torpor. Following this initial lead, Western blotting to measure transcription factor protein levels was performed and subsequent studies involving RT-PCR and measurement of downstream gene targets were performed to highlight the activity of the transcription factor at different points in the hibernation cycle. Future studies involving transcription factor control in hibernation will also now be able to rely on specific transcription factorDNA microarrays which allow a complete screening of all known transcription factors that might be involved during hibernation (or in other states of metabolic depression). This approach will allow researchers to identify transcription factors that have never before been considered as contributing to hibernation and, by identifying those transcription factors, whole new groups of downstream genes may be highlighted and suggest new avenues of research into the metabolic functions that define the hibernation phenotype. Transcription factor-DNA arrays basically function as a modified EMSA (electrophoretic mobility shift assay) and rely on the fact that the response elements to which individual transcription factors bind are now known in most cases. These response elements are typically highly conserved across species and this allows for cross-species hybridization. Following this analysis, traditional EMSAs can then be performed to 
validate, quantify and monitor the pattern of stress-induced changes in transcription factors. This approach, along with DNA microarrays, is a powerful tool to generate leads and to get a good overview of the metabolic pathways and functions involved in creating the hibernation phenotype. Techniques such as these will surely be needed to perform a thorough search of the transcription factors involved in the hibernating response.

This thesis looked at four hypotheses related to the molecular control of mammalian hibernation. The expression and the potential role of the transcription factor HIF-1 was addressed first. HIF-1 $\alpha$ was shown to be elevated at the protein level and activated in tissues of hibernating ground squirrels. HIF-1 $\alpha$ sequence analysis, the first HIF-1 $\alpha$ from a mammalian hibernator, revealed key amino acid substitutions that could lead to significant conformational changes that might enhance HIF-1 $\alpha$ function at the low body temperatures in the torpid state. Secondly, transcriptional status was analyzed in skeletal muscle during hibernation. Enzymatic analysis revealed that RNA Polymerase II activity was significantly reduced during torpor. Additional studies looked at the protein levels and activity of histone deacetylases (HDACs), enzymes involved with transcriptional repression. In both cases, the levels were significantly elevated in hibernating samples. Post-translational modifications of histone $\mathrm{H} 3$ were also assessed and the results also supported a reduction in the transcriptional state in muscle during hibernation. Overall, the data were consistent with significant transcriptional repression during hibernation. The third hypothesis dealt with the transcriptional response to oxidative stress during hibernation. Analysis of levels of the Nrf2 transcription factor as well as several of its downstream gene targets in ground squirrel tissue revealed that this pathway was indeed turned on during hibernation. While levels of Nrf2 were elevated 
over all heterothermic portions of the hibernation time course, increased protein levels of $\mathrm{Nrf2}$ downstream genes were elevated only as an early response to torpor, suggesting that elevation of antioxidant defenses is an anticipatory response as animals enter torpor. Finally, a need to deal with another aspect of ROS stress, hydrogen peroxide production, was hypothesized and led to an examination of 2-Cys peroxiredoxins in BAT and heart. This group of enzymes was recently identified as playing a key role in detoxifying ROS and is also involved in the down-regulation of specific transcription factors. Results presented here showed that these enzymes were increased at the protein level during hibernation and that this correlated with an increase in activity. This suggests that hibernators use this class of enzymes to detoxify certain ROS generated during torpor and this highlights a possible new means used by hibernators to control transcription factors by interfering with certain signaling pathways.

In summary, this thesis examined transcriptional control during hibernation by studying transcription factors and downstream genes targets that are differentially regulated in selected tissues of hibernating thirteen-lined ground squirrels. The overall transcriptional state of gene expression was shown to be suppressed during torpor but selected transcription factors were activated including the oxygen-sensitive HIF-1 and the ROS-sensitive Nrf2. Elevated levels of antioxidant proteins that are downstream targets of Nrf2 as well as enhanced levels of 2-Cys peroxiredoxins in organs during torpor document the key importance of antioxidant defenses to hibernation success. 


\section{Figure 6.1}

\section{Myotis lucifugus HIF-1 $\alpha$}

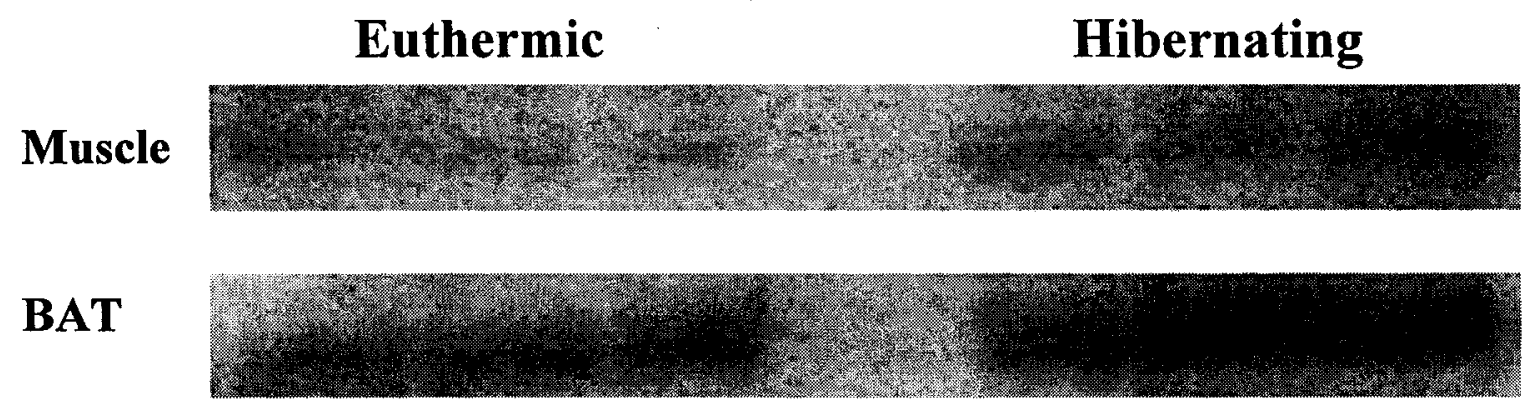


Figure 6.2

\section{Eurosta solidaginis HIF-1a}

A. Sep Oct Dec

Feb

Mar

Apr

B.

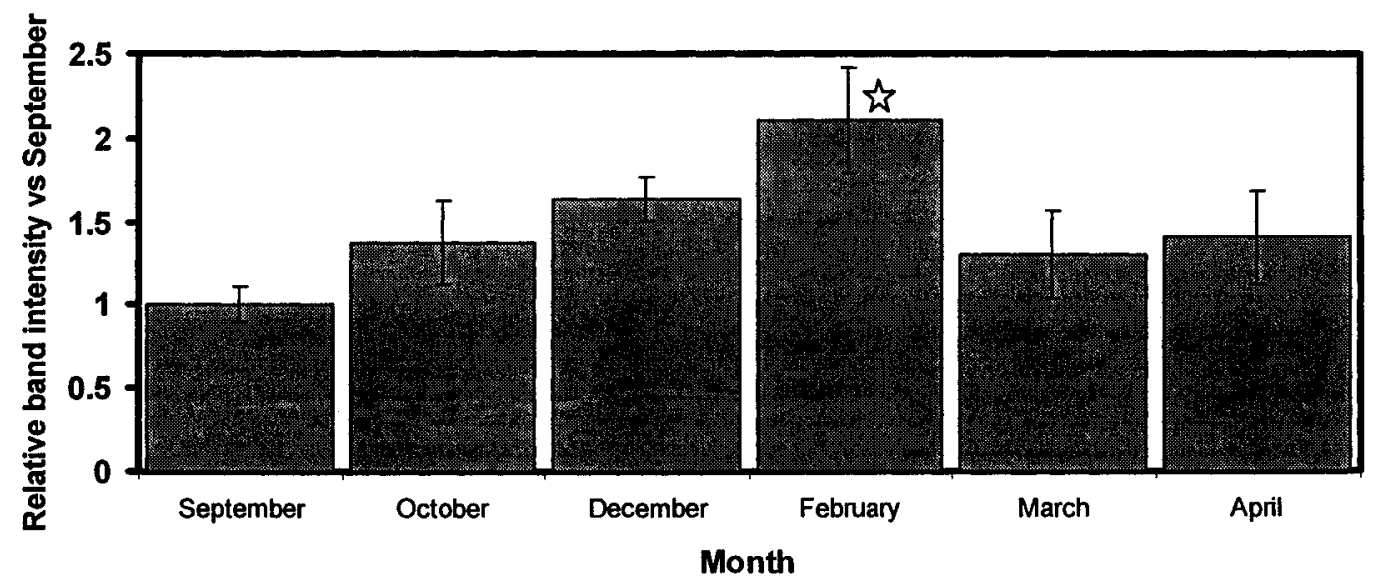




\section{PUBLICATION LIST}




\section{Research Articles Published}

Morin, P. Jr and Storey, K.B. (2005) Cloning and expression of hypoxia-inducible factor lalpha from the hibernating ground squirrel, Spermophilus tridecemlineatus. Biochim. Biophys. Acta. 1729: 32-40.

Morin, P. Jr, McMullen D.C. and Storey, K.B. (2005) HIF-1alpha involvement in low temperature and anoxia survival by a freeze tolerant insect. Mol. Cell. Biochem. 280: 99-106.

Eddy, S.F., Morin, P. Jr and Storey, K.B. (2005) Cloning and expression of PPARgamma and PGC-1alpha from the hibernating ground squirrel, Spermophilus tridecemlineatus. Mol. Cell. Biochem. 269: 175-182.

\section{In press}

Eddy, S.F., Morin, P. Jr and Storey, K.B. 2006. Differential expression of selected mitochondrial genes in hibernating little brown bats, Myotis lucifugus. J. Exp. Zool., in press.

\section{Submitted}

Morin, P. Jr and Storey, K.B. Evidence for a reduced transcriptional state during hibernation in ground squirrels.

\section{Research Articles in Preparation}

Morin, P. Jr and Storey, K.B. A key role for peroxiredoxins in the hibernating ground squirrel, Spermophilus tridecemlineatus. 
Morin, P. Jr., Ni, Z., and Storey, K.B. Expression of the transcription factor Nrf2 and of its downstream genes over a hibernating cycle in heart tissue of the 13-lined ground squirrel, Spermophilus tridecemlineatus.

\section{GenBank Submissions}

Spermophilus tridecemlineatus hypoxia-inducible factor 1 alpha subunit mRNA, complete cds. AY713478

Spermophilus tridecemlineatus peroxiredoxin 2 (prdx2) mRNA, partial cds. DQ201844 Spermophilus tridecemlineatus nrf2 mRNA, partial cds. DQ328859

Eurosta solidaginis SIMA (sima) mRNA, partial cds. AY845427

\section{Communications at Scientific Meetings}

\section{Poster Presentations}

Morin, P. Jr and Storey, K.B. Oxygen sensing in mammalian hibernation: does HIF play a role? Canadian Federation of Biological Societies, Ottawa, June 11 - 15, 2003.

Morin, P. Jr and Storey, K.B. Oxygen sensing in mammalian hibernation: does HIF play a role? 39th International Union of Pure and Applied Chemistry, Ottawa, August 10-15, 2003.

Morin, P. Jr and Storey, K.B. Oxygen sensing in mammalian hibernation: does HIF play a role? 6th Annual Chemistry \& Biochemistry Graduate Research Conference, Concordia University, Montreal, November 14-15, 2003.

Morin, P. Jr and Storey, K.B. Oxygen sensing in mammalian hibernation: does HIF play a role? Ottawa Life Sciences Council: BioNorth 2003, Ottawa, November 17-19, 
2003.

Morin, P. Jr and Storey, K.B. Oxygen sensing in mammalian hibernation: does HIF play a role? Life in the Cold, $12^{\text {th }}$ International Symposium, Vancouver, BC-Seward, Alaska, July 25-August 1, 2004.

Morin, P. Jr and Storey, K.B. Oxygen sensing in mammalian hibernation: does HIF play a role? The $3^{\text {rd }}$ International Conference of Comparative Physiology and Biochemistry in Africa: Animals and Environments at the Ithala Game Reserve, KwaZulu-Natal, South Africa, August 7-13, 2004.

Morin, P. Jr and Storey, K.B. Oxygen sensing in mammalian hibernation: does HIF play a role? Canadian Federation of Biological Societies, Guelph University, Guelph, June 2005.

\section{Oral Presentations}

Morin, P. Jr and Storey, K.B. Mammalian hibernation: Is HIF-1 involved? 7th Annual Chemistry \& Biochemistry Graduate Research Conference, Concordia University, Montreal, November 2004.

Morin, P. Jr and Storey, K. B. Mammalian hibernation: Is HIF-1 involved? Canadian Society of Zoologists Conference, Queens University, May 10-14, 2005. 


\section{REFERENCES}


Adcock, I.M., Cosio, B., Tsaprouni, L., Barnes, P.J., and Ito, K. (2005) Redox regulation of histone deacetylases and glucocorticoid-mediated inhibition of the inflammatory response. Antiox Redox Signal 7: 144-152.

Akerman, S.E., and Muller, S. (2003) 2-Cys peroxiredoxin PfTrx-Px1 is involved in the antioxidant defence of Plasmodium falciparum. Mol Biochem Parasitol 130: 7581.

Alam, J., Stewart, D., Touchard, C., Boinapally, S., Choi, A.M.K., and Cook, J.L. (1999) Nrf2, a Cap'n'Collar transcription factor, regulates induction of the heme oxygenase-1 gene. J. Biol. Chem. 274: 26071-26078.

Andrews, M.T., Squire, T.L., Bowen, C.M., and Rollins, M.B. (1998) Low-temperature carbon utilization is regulated by novel gene activity in the heart of a hibernating mammal. Proc Natl Acad Sci USA 95:8392-8397.

Araki, M., Nanri, H., Ejima, K., Murasato, Y., Fujiwara, T., Nakashima, Y., and Ikeda, M. (1999) Antioxidant function of the mitochondrial protein SP-22 in the cardiovascular system. $J$ Biol Chem 274: 2271-2278.

Barja de Quiroga, G. (1992) Brown fat thermogenesis and exercise: two examples of physiological oxidative stress? Free Radic Biol Med 13: 325-340.

Barros, R.C.H., Zimmer, M.E.; Branco, L.G.S., and Milsom, W.K. (2001) Hypoxic metabolic response of the golden-mantled ground squirrel. J Appl Physiol 91: 603-612.

Bertos, N.R., Wang, A.H., and Yang, X.J. (2001) Class II histone deacetylases: structure, function, and regulation. Biochem Cell Biol 79: 243-252. 
Bocharova, L.S., Gordon, R., and Arkhipov, V.I. (1992) Uridine uptake and RNA synthesis in the brain of torpid and awakened ground squirrels. Comput Biochem Physiol B 101: 189-192.

Boyer, B.B., Barnes, B.M., Lowell, B.B., and Grujic, D. (1998) Differential regulation of uncoupling protein gene homologues in multiple tissues of hibernating ground squirrels. Am J Physiol 275: R1232-1238.

Boyer, B.B., and Barnes, B.M. (1999) Molecular and metabolic aspects of mammalian hibernation. Expression of the hibernation phenotype results from the coordinated regulation of multiple physiological and molecular events during preparation for and entry into torpor. Bioscience 49: 713-724.

Brooks, S.P.J., and Storey, K.B. (1992) Mechanisms of glycolytic control during hibernation in the ground squirrel Spermophilus lateralis. J Comp Phys B 162: 23-28.

Brownell, J., Zhou, J., Ranalli, T., Kobayashi, R., Edmondson, D., Roth, S., and Allis, C. (1996) Tetrahymena Histone Acetyltransferase A: A Homolog to Yeast Gcn5p Linking Histone Acetylation to Gene Activation. Cell 84: 843-851.

Bruick, R.K., and McKnight, S.L.. (2001) A conserved family of prolyl 4-hydroxylases that modify HIF. Science 294: 1337-1340.

Buck, M.J., and Barnes B.M. (2000) Effects of ambient temperature on metabolic rate, respiratory quotient, and torpor in an arctic hibernator. Am J Physiol 279: R255262.

Buck, M.J., Squire, T.L., and Andrews, M.T. (2002) Coordinate expression of the PDK4 gene: a means of regulating fuel selection in a hibernating mammal. Physiol 


\section{Genomics 8: 5-13.}

Buratowski, S., and Sharp, P.A. (1990) Transcription initiation complexes and upstream activation with RNA polymerase II lacking the C-terminal domain of the largest subunit. Mol Cell Biol 10: 5562-5564.

Buzadzic, B., Spasic, M., Saicic, Z.S., Radojicic, R., Petrovic, V.M., and Halliwell, B. (1990) Antioxidant defenses in the ground squirrel Citellus citellus. 2. The effect of hibernation. Free Radic Biol Med 9: 407-413.

Carey, H.V., Frank, C.L., and Seifert, J.P. (2000) Hibernation induces oxidative stress and activation of NK-kappaB in ground squirrel intestine. J Comp Physiol B 170: $551-559$.

Casey, T.M., Pakay, J.L., Guppy, M., and Arthur, P.G. (2002) Hypoxia causes downregulation of protein and RNA synthesis in noncontracting mammalian cardiomyocytes. Circ Res 90: 777-783.

Chae, H.Z., Robison, K., Poole, L.B., Church, G., Storz, G., and Rhee, S.G. (1994) Cloning and sequencing of thiol-specific antioxidant from mammalian brain: alkyl hydroperoxide reductase and thiol-specific antioxidant define a large family of antioxidant enzymes. Proc Natl Acad Sci USA 91: 7017-7021.

Chae, H.Z., Kim, H.J., Kang, S.W., and Rhee, S.G. (1999) Characterization of three isoforms of mammalian peroxiredoxin that reduce peroxides in the presence of thioredoxin. Diabetes Res Clin Pract 45: 101-112.

Chan, K., and Kan, Y.W. (1999) Nrf2 is essential for protection against acute pulmonary injury in mice. Proc Natl Acad Sci USA 96: 12731-12736.

Chanas, S.A., Jiang, Q., McMahon, M., McWalter, G.K., McLellan, L.I., Elcombe, C.R., 
Henderson, C.J., Wolf, C.R., Moffat, G.J., Itoh, K., Yamamoto, M., and Hayes, J.D. (2002) Loss of the Nrf2 transcription factor causes a marked reduction in constitutive and inducible expression of the glutathione S-transferase Gsta1, Gsta2, Gstm1, Gstm2, Gstm3 and Gstm4 genes in the livers of male and female mice. Biochem J 365: 405-416.

Chauhan, V.P., Tsiouris, J.A., Chauhan, A, Sheikh, A.M., Brown, W.T., and Vaughan, M. (2002) Increased oxidative stress and decreased activities of $\mathrm{Ca}^{2+} / \mathrm{Mg}^{2+}$ ATPase and $\mathrm{Na}^{+} / \mathrm{K}^{+}$-ATPase in the red blood cells of the hibernating black bear. Life Sci 71: 153-161.

Chen, Y., Matsuhita, M., Nairn, A.C., Damuni, Z., Cai, D., Frerichs, K.U., and Hallenbeck, J.M. (2001) Mechanisms for increased levels of phosphorylation of elongation factor-2 during hibernation in ground squirrels. Biochemistry 40: 11565-11570.

Cheung, P., Allis, C.D., and Sassone-Corsi, P. (2000) Signaling to chromatin through histone modifications. Cell 103: 263-271.

Cho, H.Y., Jedlicka, A.E., Reddy, S.P., Kensler, T.W., Yamamoto, M., Zhang, L.Y., and Kleeberger, S.R. (2002) Role of NRF2 in protection against hyperoxic lung injury in mice. Am J Respir Cell Mol Biol 26: 175-182.

Choi, M.H., Lee, I.K., Kim, G.W., Kim, B.U., Han, Y.H., Yu, D.Y., Park, H.S., Kim, K.Y., Lee, J.S., Choi, C., Bae, Y.S., Lee, B.Y., Rhee, S.G., and Kang, S.W. (2005) Regulation of PDGF signalling and vascular remodelling by peroxiredoxin II. Nature 435: 347-353.

Ciechanover, A. (1998) The ubiquitin-proteasome pathway: on protein death and cell life. 
EMBO J., 17: 7151-7160.

Davie, J.R. (1998) Covalent modifications of histones: expression from chromatin templates. Curr Opin Genet Dev 8: 173-178.

DeGracia, D.J., Kumar, R., Owen, C.R., Krause, G.S., and White, B.C. (2002). Molecular pathways of protein synthesis inhibition during brain reperfusion: implications for neuronal survival or death. J Cereb Blood Flow Metab 22: 127-141.

Denko, N., Wernke-Dollries, K., Johnson, A.B., Hammond, E., Chiang, C.M., and Barton, M.C. (2003) Hypoxia actively represses transcription by inducing negative cofactor 2 (Dr1/DrAP1) and blocking preinitiation complex assembly. $J$ Biol Chem 278: 5744-5749.

Dery, M.A., Michaud, M.D., and Richard, D.E. (2005) Hypoxia-inducible factor 1: regulation by hypoxic and non-hypoxic activators. Int J Biochem Cell Biol 37: $535-540$.

Drew, K.L., Toien, O., Rivera, P.M., Smith, M.A., Perry, G., and Rice, M.E. (2002) Role of the antioxidant ascorbate in hibernation and warming from hibernation. Comp Biochem Physiol C 133: 483-492.

Eddy, S.F., McNally, J.D., and Storey KB (2005) Up-regulation of a thioredoxin peroxidase-like protein, proliferation-associated gene, in hibernating bats. Arch Biochem Biophys 435: 103-111.

Ellis, E.M., and Hayes, J.D. (1995) Substrate specificity of an aflatoxin-metabolizing aldehyde reductase. Biochem J 312: 535-541.

Ellis, E.M., Slattery, C.M, and Hayes, J.D. (2003) Characterization of the rat aflatoxin B1 aldehyde reductase gene, AKR7A1. Structure and chromosomal localization of 
AKR7A1 as well as identification of antioxidant response elements in the gene promoter. Carcinogenesis' 24: 727-737.

Fahlman, A., Storey, J.M., and Storey, K.B. (2000) Gene up-regulation in heart during mammalian hibernation. Cryobiology 40: 332-342.

Feldser, D., Agani, F., Iyer, N.V., Pak, B., Ferreira, G., and Semenza, G.L. (1999) Reciprocal positive regulation of hypoxia-inducible factor 1alpha and insulin-like growth factor 2. Cancer Res 59: 3915-3918.

Foster, D.O. (1984) Quantitative contribution of brown adipose tissue thermogenesis to overall metabolism. Can J Biochem Cell Biol 62: 618-622.

Frank, C.L. (1992) The influence of dietary fatty acids on hibernation by golden-mantled ground squirrels (Spermophilus lateralis). Physiol Zool 65: 906-920.

Frank, C.L., and Storey, K.B. (1995) Optimal depot fat composition for hibernation by golden-mantled ground squirrels (Spermophilus lateralis). J Comp Physiol B 164: $536-542$.

Frerichs, K.U., Kennedy, C., Sokoloff, L., and Hallenbeck, J.M. (1994) Local cerebral blood flow during hibernation, a model of natural tolerance to "cerebral ischemia". J Cereb Blood Flow Metab 14: 193-205.

Frerichs, K.U., Smith, C.B., Brenner, M., DeGracia, D.J., Krause, G.S., Marrone, L., Dever, T.E., and Hallenbeck, J.M. (1998) Suppression of protein synthesis in brain during hibernation involves inhibition of protein initiation and elongation. Proc Natl Acad Sci USA 95: 14511-14516.

Geiser, F. (1990) Influence of polyunsaturated and saturated dietary lipids on adipose tissue, brain and mitochondrial membrane fatty acid composition of a mammalian 
hibernator. Biochim Biophys Acta 1046: 159-166.

Geiser, F. (2004) Metabolic rate and body temperature reduction during hibernation and daily torpor. Annu Rev Physiol 66: 239-274.

Görlach, A., Diebold, I., Schini-Kerth, V.B., Berchner-Pfannschmidt, U., Roth, U., Brandes, R.P., Kietzmann, T., and Busse, R. (2001) Thrombin Activates the Hypoxia-Inducible Factor-1 Signaling Pathway in Vascular Smooth Muscle Cells. Circ Res 89: 47-54.

Grigg, G.C., Beard, L.A., and Augee, M.L. (2004) The evolution of endothermy and its diversity in mammals and birds. Physiol Biochem Zool 77: 982-997.

Gunstone, F.D. (1996) Fatty Acid and Lipid chemistry. Aspen Publishers, Maryland.

Guyton, K.Z., Liu, Y., Gorospe, M., Xu, Q., and Holbrook, N.J. (1996) Activation of mitogen-activated protein kinase by $\mathrm{H} 2 \mathrm{O} 2$. Role in cell survival following oxidant injury. $J$ Biol Chem 271: 4138-4142.

He, C.H., Gong, P., Hu, B., Stewart, D., Choi, M.E., Choi, A.M., and Alam, J. (2001) Identification of activating transcription factor 4 (ATF4) as an Nrf2-interacting protein. Implication for heme oxygenase-1 gene regulation. $J$ Biol Chem 276: 20858-20865.

Hebbes, T.R., Thorne, A.W., and Crane-Robinson, C. (1988) A direct link between core histone acetylation and transcriptionally active chromatin. EMBO J 7: 1395-1402.

Heller, H.C., and Ruby, N.F. (2004) Sleep and circadian rhythms in mammalian torpor. Annu Rev Physiol 66: 275-289.

Hellwig-Burgel, T., Rutkowski, K., Metzen, E., Fandrey, J., and Jelkmann, W. (1999) Interleukin-1beta and tumor necrosis factor-alpha stimulate DNA binding of 
hypoxia-inducible factor-1. Blood 94: 1561-1567.

Hendzel, M.J., Wei, Y., Mancini, M.A., Van Hooser, A., Ranalli, T., Brinkley, B.R., Bazett-Jones, D.P., and Allis, C.D. (1997) Mitosis-specific phosphorylation of histone $\mathrm{H} 3$ initiates primarily within pericentromeric heterochromatin during $\mathrm{G} 2$ and spreads in an ordered fashion coincident with mitotic chromosome condensation. Chromosoma 106: 348-360.

Hermes-Lima, M., Storey, J.M., and Storey, K.B. (2001) Antioxidant defenses and animal adaptation to oxygen availability during environmental stress. In Cell and Molecular Responses to Stress (Storey, K.B. and Storey, J.M. eds.), Elsevier Press, Amsterdam, Vol. 2, pp. 263-287.

Hewitson, K.S., McNeill, L.A., Riordan, M.V., Tian, Y.M., Bullock, A.N., Welford, R.W., Elkins, J.M., Oldham, N.J., Bhattacharya, S., Gleadle, J.M., Ratcliffe, P.J., Pugh, C.W., and Schofield, C.J. (2002) Hypoxia-inducible Factor (HIF) Asparagine Hydroxylase Is Identical to Factor Inhibiting HIF (FIH) and Is Related to the Cupin Structural Family. J Biol Chem 277: 26351-26355.

Hittel, D., and Storey, K.B. (2001) Differential expression of adipose- and heart-type fatty acid binding proteins in hibernating ground squirrels. Biochim Biophys Acta 1522: 238-243.

Hittel, D., and Storey, K.B. (2002a) Differential expression of mitochondria-encoded genes in a hibernating mammal. J Exp Biol 205: 1625-1631.

Hittel, D., and Storey, K.B. (2002b) The translation state of differentially expressed mRNAs in the hibernating 13-lined ground squirrel (Spermophilus tridecemlineatus). Arch Biochem Biophys 401: 244-254. 
Hofmann, B., Hecht, H.J., and Flohe, L. (2002) Peroxiredoxins. Biol Chem 383: 347-364.

Hopfl, G., Ogunshola, O., and Gassmann, M. (2003) Hypoxia and high altitude. The molecular response. Adv Exp Med Biol 543: 89-115.

Huang, H.C., Nguyen, T., and Pickett, C.B. (2000) Regulation of the antioxidant response element by protein kinase C-mediated phosphorylation of NF-E2-related factor 2. Proc Natl Acad Sci USA 97: 12475-12480.

Huang, H.C., Nguyen, T., and Pickett, C.B. (2002) Phosphorylation of Nrf2 at Ser-40 by protein kinase $\mathrm{C}$ regulates antioxidant response element-mediated transcription. $J$ Biol Chem 277: 42769-42774.

Huang, L.E., Gu, J., Schau, M., and Bunn, H.F. (1998) Regulation of hypoxia-inducible factor lalpha is mediated by an $\mathrm{O}_{2}$-dependent degradation domain via the ubiquitin-proteasome pathway. Proc Natl Acad Sci USA 95: 7987-7992.

Imai, S., Armstrong, C.M., Kaeberlein, M., and Guarente, L. (2000) Transcriptional silencing and longevity protein Sir2 is an NAD-dependent histone deacetylase. Nature 403: 795-800.

Itoh, K., Chiba, T., Takahashi, S., Ishii, T., Igarashi, K., Katoh, Y., Oyake, T., Hayashi, N., Satoh, K., Hatayama, I., Yamamoto, M., and Nabeshima, Y.I. (1997) An Nrf2/Small Maf Heterodimer Mediates the Induction of Phase II Detoxifying Enzyme Genes through Antioxidant Response Elements. Biochem Biophys Res Commun 236: 313-322.

Itoh, K., Wakabayashi, N., Katoh, Y., Ishii, T., Igarashi, K., Engel, J.D., and Yamamoto, M. (1999) Keap1 represses nuclear activation of antioxidant responsive elements by Nrf2 through binding to the amino-terminal Neh2 domain. Genes Dev 13: 76- 
86.

Ivan, M., Kondo, K., Yang, H., Kim, W., Valiando, J., Ohh, M., Salic, A., Asara, J.M., Lane, W.S., and Kaelin, W.G. Jr. (2001) HIFalpha targeted for VHL-mediated destruction by proline hydroxylation: implications for $\mathrm{O}_{2}$ sensing. Science 292: 464-468.

Iwai, K., Yamanaka, K., Kamura, T., Minato, N., Conaway, R.C., Conaway, J.W., Klausner, R.D., and Pause, A. (1999) Identification of the von Hippel-Lindau tumor-suppressor protein as part of an active E3 ubiquitin ligase complex. Proc. Natl Acad. Sci. USA, 96: 12436-12441.

Jaakkola, P., Mole, D.R., Tian, Y.M., Wilson, M.I., Gielbert, J., Gaskell, S.J., Kriegsheim, Av., Hebestreit, H.F., Mukherji, M., Schofield, C.J., Maxwell, P.H., Pugh, C.W., and Ratcliffe, P.J. (2001) Targeting of HIF-alpha to the von HippelLindau ubiquitylation complex by $\mathrm{O}_{2}$-regulated prolyl hydroxylation. Science 292: 468-472.

Jewell, U.R., Kvietikova, I., Scheid, A., Bauer, C., Wenger, R.H., and Gassmann, M. (2001) Induction of HIF-1alpha in response to hypoxia is instantaneous. FASER $J$ 15: $1312-1314$

Jiang, B.H., Rue, E., Wang, G.L., Roe, R., and Semenza, G.L. (1996) Dimerization, DNA binding, and transactivation properties of hypoxia-inducible factor 1. J Biol Chem 271: $17771-17778$.

Jiang, B.H., Zheng, J.Z., Leung, S.W., Roe, R., and Semenza, G.L. (1997) Transactivation and inhibitory domains of hypoxia-inducible factor 1 alpha. Modulation of transcriptional activity by oxygen tension. $J$ Biol Chem 272 : 
19253-19260.

Kaelin, W.G.Jr., and Maher, E.R. (1998) The VHL tumour-suppressor gene paradigm. Trends Genet., 14: 423-426.

Kang, S.W., Chae, H.Z., Seo, M.S., Kim, K., Baines, I.C., and Rhee, S.G. (1998) Mammalian peroxiredoxin isoforms can reduce hydrogen peroxide generated in response to growth factors and tumor necrosis factor-alpha. J Biol Chem 273: 6297-6302.

Kang, S.W., Rhee, S.G., Chang, T.S., Jeong W., and Choi, M.H. (2005) 2-Cys peroxiredoxin function in intracellular signal transduction: therapeutic implications. Trends Mol Med 11: 571-578.

Katoh, Y., Itoh, K., Yoshida, E., Miyagishi, M., Fukamizu, A., and Yamamoto, M. (2001) Two domains of Nrf2 cooperatively bind CBP, a CREB binding protein, and synergistically activate transcription. Genes Cells 6: 857-868.

Kim, E., Du, L., Bregman, D.B., and Warren, S.L. (1997) Splicing factors associate with hyperphosphorylated RNA polymerase II in the absence of pre-mRNA. J Cell Biol 136: 19-28.

Kim, H., Lee, T.H., Park, E.S., Suh, J.M., Park, S.J., Chung, H.K., Kwon, O.Y., Kim, Y.K., Ro, H.K., and Shong, M. (2000) Role of peroxiredoxins in regulating intracellular hydrogen peroxide and hydrogen peroxide-induced apoptosis in thyroid cells. $J$ Biol Chem 275: 18266-18270.

Kim, H.S., Kang, S.W., Rhee, S.G., and Clerch, L.B. (2001a) Rat lung peroxiredoxins I and II are differentially regulated during development and by hyperoxia. $\mathrm{Am} J$ Physiol 280: L1212-L1217. 
Kim, I.C., Masutani, H., Yamaguchi, Y., Itoh, K., Yamamoto, M., and Yodoi, J. (2001b) Hemin-induced activation of the thioredoxin gene by $\mathrm{Nrf} 2$. A differential regulation of the antioxidant responsive element by a switch of its binding factors. J Biol Chem 276: 18399-18406.

Kim, M.S., Kwon, H.J., Lee, Y.M., Baek, J.H., Jang, J.E., Lee, S.W., Moon, E.J., Kim, H.S., Lee, S.K., Chung, H.Y., Kim, C.W., and Kim, K.W. (2001c) Histone deacetylases induce angiogenesis by negative regulation of tumor suppressor genes. Nature Med 7: 437-443.

Kim, J.A., Park, S., Kim, K,. Rhee, S.G., and Kang, S.W. (2005) Activity assay of mammalian 2-cys peroxiredoxins using yeast thioredoxin reductase system. Anal Biochem 338: 216-223.

Knoepfler, P.S., and Eisenman, R.N. (1999) Sin meets NuRD and other tails of repression. Cell 99: 447-450.

Kranias, E.G., and Jungmann, R.A. (1978) Phosphorylation of calf thymus RNA polymerase II by nuclear cyclic 3',5'-AMP-independent protein kinase. Biochim Biophys Acta 517: 439-446.

Krishnamachary, B., Berg-Dixon, S., Kelly, B., Agani, F., Feldser, D., Ferreira, G., Iyer, N., LaRusch, J., Pak, B., Taghavi, P., and Semenza, G.L. (2003) Regulation of colon carcinoma cell invasion by hypoxia-inducible factor 1. Cancer Res 63 : 1138-1143.

Kuroshima, A. (1993) Brown adipose tissue thermogenesis as physiological strategy for adaptation. Jpn J Physiol 43: 117-139.

Lando, D., Peet, D.J., Gorman, J.J., Whelan, D.A., Whitelaw, M.L., and Bruick, R.K. 
(2002) FIH-1 is an asparaginyl hydroxylase enzyme that regulates the transcriptional activity of hypoxia-inducible factor. Genes Dev 16: 1466-1471.

Lee, D.Y., Hayes, J.J., Pruss, D., and Wolffe, A.P. (1993) A positive role for histone acetylation in transcription factor access to nucleosomal DNA. Cell 72: 73-84.

Lee, P.J., Jiang, B.H., Chin, B.Y., Iyer, N.V., Alam, J., Semenza, G.L., and Choi, A.M.K. (1997) Hypoxia-inducible factor-1 mediates transcriptional activation of the heme oxygenase-1 gene in response to hypoxia. $J$ Biol Chem 272: 5375-5381.

Ma, Y.L., Zhu, X., Rivera, P.M., Toien, O., Barnes, B.M., LaManna, J.C., Smith, M.A., and Drew, K.L. (2005) Absence of cellular stress in brain after hypoxia induced by arousal from hibernation in Arctic ground squirrels. Am J Physiol Regul Integr Comp Physiol 289: 1297-1306.

MacDonald, J.A., and Storey, K.B. (1999) Regulation of ground squirrel $\mathrm{Na}^{+} \mathrm{K}^{+}-\mathrm{ATPase}$ activity by reversible phosphorylation during hibernation. Biochem Biophys Res Commun 254: 424-429.

MacDonald, J.A., and Storey, K.B. (2005) Mitogen-activated protein kinases and selected downstream targets display organ-specific responses in the hibernating ground squirrel. Int J Biochem Cell Biol 37: 679-691.

Malysheva, I.N., Storey, K.B., Lopina, O.D., and Rubtsov, A.M. (2001) Ca-ATPase activity and protein composition of sarcoplasmic reticulum membranes isolated from skeletal muscles of typical hibernator, the ground squirrel Spermophilus undulatus. Biosci Rep 21: 831-838.

Marczin, N., El-Habashi, N., Hoare, G.S., Bundy, R.E., and Yacoub, M. (2003) Antioxidants in myocardial ischemia-reperfusion injury: therapeutic potential and 
basic mechanisms. Arch Biochem Biophys 420: 222-236.

Maxwell, P.H., Wiesener, M.S., Chang, G.W., Clifford, S.C., Vaux, E.C., Cockman, M.E., Wykoff, C.C., Pugh, C.W., Maher, E.R., and Ratclife, P.J. (1999) The tumour suppressor protein VHL targets hypoxia-inducible factors for oxygen-dependent proteolysis. Nature (London) 399: 271-275.

McArthur, M.D., and Milsom, W.K. (1991) Changes in ventilation and respiratory sensitivity associated with hibernation in Columbian (Spermophilus columbianus) and golden-mantled (Spermophilus lateralis) ground squirrels. Physiol Zool. 64: 940959.

Michel, G., Minet, E., Mottet, D., Remacle, J., and Michiels, C. (2002) Site-directed mutagenesis studies of the hypoxia-inducible factor-1alpha DNA-binding domain. Biochim Biophys Acta 1578: 73-83.

Mitsumoto, A., Takanezawa, Y., Okawa, K., Iwamatsu, A., and Nakagawa, Y. (2001) Variants of peroxiredoxins expression in response to hydroperoxide stress. Free Radic Biol Med 30: 625-635.

Mole, D.R., Maxwell, P.H., Pugh, C.W., and Ratcliffe, P.J. (2001) Regulation of HIF by the von Hippel-Lindau Tumour Suppressor: Implications for Cellular Oxygen Sensing. EMBO J 52: 43-47.

Morin, P. Jr., McMullen, D.C., and Storey, K.B. (2005) HIF-1alpha involvement in low temperature and anoxia survival by a freeze tolerant insect. Mol Cell Biochem 280: 99-106.

Ng, H.H., and Bird, A. (2000) Histone deacetylases: silencers for hire. Trends Biochem Sci 25: 121-126. 
$\mathrm{Ni}, \mathrm{Z}$. (2004) Antioxidant defense in the hibernating thirteen-lined ground squirrel Spermophilus tridecemlineatus. M.Sc. Thesis, Carleton University.

Norton, V.G., Imai, B.S., Yau, P., and Bradbury, E.M. (1989) Histone acetylation reduces nucleosome core particle linking number change. Cell 57: 449-457.

Odani, N., Negishi, M., Takahashi, S., and Ichikawa, A. (1996) Induction of protein disulfide isomerase mRNA by delta 12-prostaglandin J2. Biochem Biophys Res Commun 220: 264-268.

O'Neill, L.P., and Turner, B.M. (1995) Histone H4 acetylation distinguishes coding regions of the human genome from heterochromatin in a differentiationdependent but transcription-independent manner. EMBO J 14: 3946-3957.

Osborne, P.G., Gao, B., and Hashimoto, M. (2004) Determination in vivo of newly synthesized gene expression in hamsters during phases of the hibernation cycle. Japan J Physiol 54: 295-305.

Osborne, P.G., and Hashimoto, M. (2006) Brain antioxidant levels in hamsters during hibernation, arousal and cenothermia. Behav Brain Res 2005 Dec 9; [Epub ahead of print].

Papaiahgari, S., Kleeberger, S.R., Cho, H.Y., Kalvakolanu, D.V., and Reddy, S.P. (2004) NADPH oxidase and. ERK signaling regulates hyperoxia-induced Nrf2-ARE transcriptional response in pulmonary epithelial cells. J Biol Chem 279: 4230242312.

Park, E.Y., and Rho, H.M. (2002) The transcriptional activation of the human copper/zinc superoxide dismutase gene by 2,3,7,8-tetrachlorodibenzo-p-dioxin through two different regulator sites, the antioxidant responsive element and 
xenobiotic responsive element. Mol Cell Biochem 240: 47-55.

Pi, J., Qu, W., Reece, J.M, Kumagai, Y., and Waalkes, M.P. (2003) Transcription factor $\mathrm{Nrf} 2$ activation by inorganic arsenic in cultured keratinocytes: involvement of hydrogen peroxide. Exp Cell Res 290: 234-245.

Postnikova, G.B., Tselikova, S.V., Kolaeva, S.G., and Solomonov, N.G. (1999) Myoglobin content in skeletal muscles of hibernating ground squirrels rises in autumn and winter. Comp Biochem Pysiol A Mol Integr Physiol 124: 35-37.

Puerta, C., Hernandez, F., Lopez-Alarcon, L., and Palacian, E. (1995) Acetylation of histone H2A.H2B dimers facilitates transcription. Biochem Biophys Res Commun 210: $409-416$

Qiang, W., Cahill, J.M., Liu, J., Kuang, X., Liu, N., Scofield, V.L., Voorhees, J.R., Reid, A.J., Yan, M., Lynn, W.S., and Wong, P.K. (2004) Activation of transcription factor Nrf-2 and its downstream targets in response to moloney murine leukemia virus ts1-induced thiol depletion and oxidative stress in astrocytes. $J$ Virol $\mathbf{7 8 :}$ $11926-11938$.

Rabilloud, T., Heller, M., Gasnier, F., Luche, S., Rey, C., Aebersold, R., Benahmed, M., Louisot, P., and Lunardi, J. (2002) Proteomics analysis of cellular response to oxidative stress. Evidence for in vivo overoxidation of peroxiredoxins at their active site. J Biol Chem 277: 19396-19401.

Ratcliffe, P.J., O’Rourke, J.F., Maxwell, P.H., and Pugh, C.W. (1998) Oxygen sensing, hypoxia-inducible factor- 1 and the regulation of mammalian gene expression. $J$ Exp Biol 201: 1153-1162.

Rhee, S.G., Chang, T.S., Bae, Y.S., Lee, S.R., and Kang, S.W. (2003) Cellular regulation 
by hydrogen peroxide. J Am Soc Nephrol 14: S211-S215.

Rhee, S.G., Chae, H.Z., and Kim, K. (2005) Peroxiredoxins: a historical overview and speculative preview of novel mechanisms and emerging concepts in cell signaling. Free Radic Biol Med 38: 1543-1552.

Richard, D.E., Berra, E., Gothie, E., Roux, D., and Pouyssegur, J. (1999) p42/p44 mitogen-activated protein kinases phosphorylate hypoxia-inducible factor 1alpha (HIF-1alpha) and enhance the transcriptional activity of HIF-1. J Biol Chem 274: 32631-32637.

Rolfe, D.F., and Brown, G.C. (1997). Cellular energy utilization and molecular origin of standard metabolic rate in mammals. Physiol Rev 77: 731-758.

Sang, N., Stiehl, D.P., Bohensky, J., Leshchinsky, I., Srinivas, V., and Caro, J. (2003) MAPK signaling up-regulates the activity of hypoxia-inducible factors by its effects on p300. J Biol Chem 278: 14013-14019.

Semenza, G.L. (2000) HIF-1: mediator of physiological and pathophysiological responses to hypoxia. $J$ Appl Physiol 88: 1474-1480.

Serizawa, H., Conaway, J.W., and Conaway, R.C. (1993) Phosphorylation of C-terminal domain of RNA polymerase II is not required in basal transcription. Nature 363: 371-374.

Shen, G., Hebbar, V., Nair, S., Xu, C., Li, W., Lin, W., Keum, Y.S., Han, J., Gallo, M.A., and Kong, A.N. (2004) Regulation of Nrf2 transactivation domain activity. The differential effects of mitogen-activated protein kinase cascades and synergistic stimulatory effect of Raf and CREB-binding protein. J Biol Chem 279: 2305223060. 
Spasic, M.B., Saicic, Z.S., Buzadzic, B., Korac, B., Blagojevic, D., and Petrovic, V.M. (1993) Effect of long-term exposure to cold on the antioxidant defense system in the rat. Free Rad Biol Med 15: 291-299.

Stewart, D., Killeen, E., Naquin, R., Alam, S., and Alam, J. (2003) Degradation of transcription factor Nrf2 via the ubiquitin-proteasome pathway and stabilization by cadmium. J Biol Chem 278: 2396-2402.

Storey, K.B. (1987) Regulation of liver metabolism by enzyme phosphorylation during mammalian hibernation. $J$ Biol Chem 262: 1670-1673.

Storey, K.B. (2003) Mammalian hibernation. Transcriptional and translational controls. Adv Exp Med Biol 543: 21-38.

Storey, K.B., and Storey, J.M. (2004) Metabolic rate depression in animals: transcriptional and translational controls. Biol Rev Camb Phil Soc 79: 207-233.

Stroka, D.M., Burkhardt, T., Desbaillets, I., Wenger, R.H., Neil, D.A.H., Bauer, C., Gassmann, M., and Candinas, D. (2001) HIF-1 is expressed in normoxic tissue and displays an organ-specific regulation under systemic hypoxia. FASEB $J$ 15: $2445-2453$.

Tenhunen, R., Marver, H.S., and Schmid, R. (1968) The enzymatic conversion of heme to bilirubin by microsomal heme oxygenase. Proc Natl Acad Sci USA 61: 748755.

Thiagalingam, S., Cheng, K.H., Lee, H.J., Mineva, N, Thiagalingam, A., and Ponte, J.F. (2003) Histone deacetylases: unique players in shaping the epigenetic histone code. Ann NY Acad Sci 983: 84-100.

Van Breukelen, F., and Martin, S.L. (2002) Reversible depression of transcription during 
hibernation. J Comp Physiol B 172: 355-361.

Vander Heiden, M.G., Plas, D.R., Rathmell, J.C., Fox, C.J., Harris, M.H., and Thompson, C.B. (2001) Growth factors can influence cell growth and survival through effects on glucose metabolism. Mol Cell Biol 21: 5899-5912.

Venugopal, R., and Jaiswal, A.K. (1996) Nrf1 and Nrf2 positively and c-Fos and Fra1 negatively regulate the human antioxidant response element-mediated expression of NAD(P)H:quinone oxidoreductasel gene. Proc Natl Acad Sci USA 93: 1496014965.

Wade, P.A. (2001) Transcriptional control at regulatory checkpoints by histone deacetylases: molecular connections between cancer and chromatin. Hum Mol Genet 10: 693-698.

Wang, G.L., Jiang, B.H., and Semenza, G.L. (1995) Effect of protein kinase and phosphatase inhibitors on expression of hypoxia-inducible factor 1. Biochem Biophys Res Commun 216: 669-675.

Wang, L.C.H., and Lee, T.F (1996) Torpor and hibernation in mammals: metabolic, physiological and biochemical adaptations. In Handbook of Physiology: Environmental Physiology (Fregley, M.J., and Blatteis, C.M., eds.). Oxford University Press, New York, pp. 507-532.

Wang, G.L., and Semenza, G.L. (1993) Characterization of hypoxia-inducible factor 1 and regulation of DNA binding activity by hypoxia. $J$ Biol Chem 268: 21513 21518.

Wang, P., Chen, H., Qin, H., Sankarapandi, S., Becher, M.W., Wong, P.C., and Zweier, J.L. (1998) Overexpression of human copper,zinc-superoxide dismutase (SOD1) 
prevents postischemic injury. Proc Natl Acad Sci USA 95: 4556-4560.

Wenger, R.H., Kvietikova, I., Rolfs, A., Gassmann, M., and Marti, H.H. (1997) Hypoxiainducible factor-1 alpha is regulated at the post-mRNA level. Kidney Int 51: 560563.

Wickler, S.J., Hoyt, D.F., and van Breukelen, F. (1991) Disuse atrophy in the hibernating golden-mantled ground squirrel, Spermophilus lateralis. Am J Physiol 261: R1214-1217.

Wiese, A.G., Pacifici, R.E., and Davies, K.J. (1995) Transient adaptation of oxidative stress in mammalian cells...Arch Biochem Biophys 318: 231-240.

Woo, H.A., Chae, H.Z., Hwang, S.C., Yang, K.S., Kang, S.W., Kim, K., and Rhee, S.G. (2003) Reversing the inactivation of peroxiredoxins caused by cysteine sulfinic acid formation. Science 300: 653-656.

Wood, Z.A., Schroder, E., Robin Harris, J., and Poole, L.B. (2003) Structure, mechanism and regulation of peroxiredoxins. Trends Biochem Sci 28: 32-40.

Zatzman, M.L. (1984) Renal and cardiovascular effects of hibernation and hypothermia. Cryobiology 21: 593-614.

Zhu, X., Smith, M.A., Perry, G., Wang, Y., Ross, A.P., Zhao, H.W., LaManna, J.C., and Drew, K.L. (2005) MAPKs are differentially modulated in arctic ground squirrels during hibernation. J Neurosci Res 80: 862-868. 